\title{
SVERIGES GEOLOGISKA UNDERSÖKNING
}

SFr. C a.

\section{GEOKRONOLOGISKA STUDIER ÖFVER DET}

\section{FINIGLACIALA SKEDET}

I

ANGERMANLAND

PAGNAR LIDEN

MED 7 TAFLOR

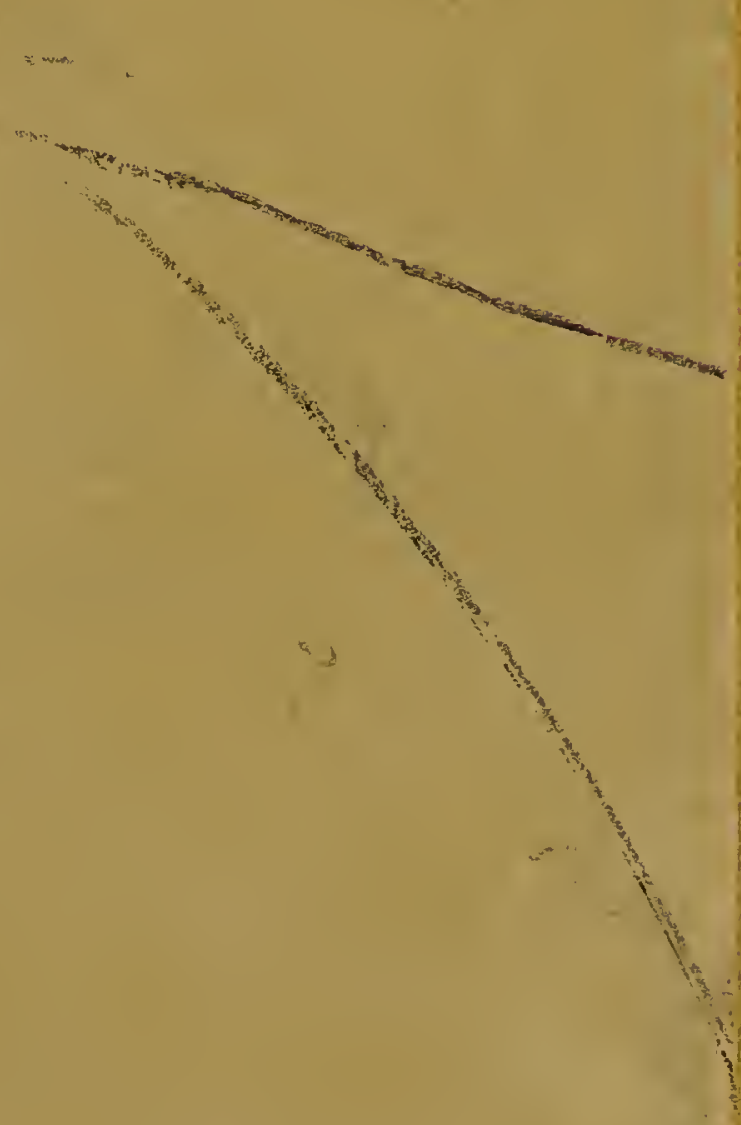


THE UNIVERSITY

OF ILLINOIS

\section{LIBRARY}

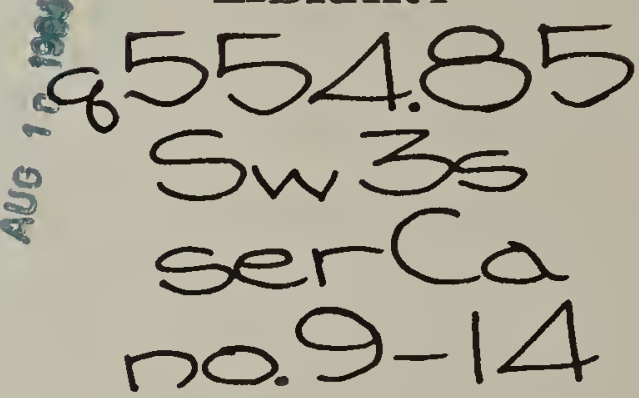

CEODGY LIERARY 
$\sqrt[3]{x+2}-2$

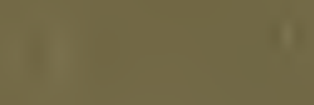

i 



\section{SVERIGES GEOLOGISKA UNDERSÖKNING}

\section{ÜBER}

\section{DIE KALKALGEN, SPONGIOSTROMEN UND EINIGE ANDERE FOSSILIEN}

DEM OBERSILUR GOTTLANDS

VON

Prof. AUG. ROTHPLETZ

MIT NEUN TAFELN UND EINER KARTE.
UMVERSTTY OF ILLWOUS Librain

MAY 71921 



\section{N H A I.TS V ERZEICH N I S.}

Einleitmg

I. Die Kalkalgen.

Vorgeschichte . . . . . . . . . . . . . . . . 6

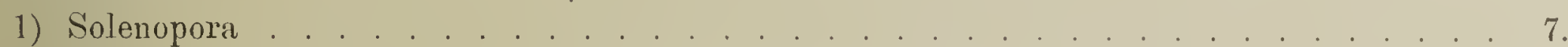

2) Hedströmia . . . . . . . . . . . . . . . . . . 16.

3) Sphaerocodium . . . . . . . . . . . . . . . . . . . . . . 19

4) Siphoneae verticillatae . . . . . . . . . . . . . . . . 27.

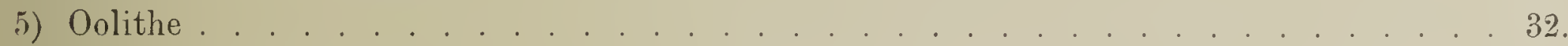

II. Die Spongiostromen. . . . . . . . . . . . . . . . . . . . . . . . . . 36.

III. Bohrende Organismen.

1) Bohrgänge von Tieren . . . . . . . . . . . . . . . . . . . . 40.

2) Bohrgänge von Pflanzen . . . . . . . . . . . . . . . . . 40.

IV. Einige tierische Fossilien.

1) Eine Foraminifere . . . . . . . . . . . . . . . . . . . 42.

2) Romingeria candelabrum . . . . . . . . . . . . . . 42.

3) Palechiniden-Stacheln . . . . . . . . . . . . . . . 44 . .

4) Ein Phyllocarid . . . . . . . . . . . . . . . . . . 45.

5) Crustaceen-Kot . . . . . . . . . . . . . . . . . . 45.

V. Stratigraphische Schlussfolgerungen _ . . . . . . . . . . . . . . . . . . . . . . 49.

Tafclerliärung . . . . . . . . . . . . . . . . . . . 55 . . 



\section{Einleitung.}

Über Algen und Hydrozoenknollen aus dem Obersilur von Gottland und Ösel habe ich 1908 in den Abhandlungen der Schwedischen Akademic der Wissenschaften einc Arbeit veröffentlicht ${ }^{1}$ und darin nachgewiesen, dass dic mir von Prof. G. Houm vor sieben Jahren zur Bcarbeitung übergebenen Girvanellaknollen tcils Kalkalgen aus den Gencra Sphaerncodium und Solenopora, teils Hydrozoen des Genus Spongiostroma sind. Dic verschiedenen Fundplätze dicser Girvanellen waren mir unbekannt, da ich weder die Inscl Gottland noch Ösel aus eigencr Anschauung kanntc, und ich war deshalb auch ganz im ungewissen, ob meine Bestimmungen gleichzeitig in stratigraphischer Beziehung von Bedeutung sein würden. Nach Veröffentlichung dicscr Arbeit bot mir der Dircktor der Schwedischen geologischen Landesanstalt J. G. Anderssos im Juni 1908 das im dortigen Muscum befindliche schr reichhaltige Material obersilurischer Kalkalgen Gottlands zur Bearbeitung an. So bckam ich alsbald 1908 von den Hcrren Munthe und Henström eine unerwartet grosse Anzahl von Kalkknollen und Dünnschliffen, deren Bcstimmung viel Zeit erforderte. Neue Scrien crhielt ich dann ferner von densclben Herren 1910 und 1911. Ihnen, welche beide mit der gcologischen Aufnahme Gottlands betraut sind, konnte ich in Fcbruar 1910 schon vorläufige Bestimmungen mitteilen, welche in den von ihnen vcrfassten Führern für den internationalen Geologenkongress in Stockholm bereits Verwendung gefunden haben. ${ }^{2}$ Unter Führung von Munthe und Prof. Wiman habe ich sodann im Herbst 1910 eincn Teil der Lagerstätten auf Gottland besucht und dabei selbst manchcs sammcln können. Eine weitere Kollektion von 108 Nummern brachtc mir Mustue im Frühjahre 1911 nach München, der bei dieser Gelegenheit sümtliche von mir untersuchten Schliffe durchmusterte und mir dabei über dic stratigraphische Stcllung der einzelnen Stücke wichtige Anhaltspunktc gab. Die Fülle des Materials vcrzögerte jedoch den endlichen Abschluss meincr Bestimmungen; denn es waren über 300 Dünnschliffe und ausscrdem vielerlei Vergleichsmaterial zu Rate zu ziehcn.

Als ich im Mai 1912 endlich das Manuskript druckfertig hergestellt hattc, schricb mir Dr. Munthe, dass er noch weitere 250 Schliffe gemacht habe und er ersuchte mich

1 AUG. RothPLetZ, Über Algen und Hydrozoen im Silur von Gotland und Ösel. K. Vet. Akad. Handl.

Bd. 34. Stockholm 1908 .

2 Henr. Munthe, On the Sequence of Strata within Southern Gotland. Geol. För. i Stockholm Förh. Bd 32. 1910. (Ebenso im Excursions-Guide N:o 19). Herman Hedström, The Stratigraphy of the Silurian Strata of the Visby district. Ebenda 1910 (Esc.-Guide N:0 20).

1-131049. S. G. U. Ser. Ca, N:o 10. Rothpletz, Obersilur. Kalkalgen etc. Gottlands. 
auch dieses Material in der Arbeit zu verwerten. Die Untersuchung desselben ergab in mancher Hinsicht besonders aber mit Bezug auf die Rhabdoporcllen, von denen dic älteren Schliffe nur ganz wenige enthielten, so viel neues, dass fast alle Kapitel ergänzt, inehrere ganz neu geschrieben werden mussten, und die Arbeit, wie sie jetzt vorliegt, erst im Januar dieses Jahres fertig wurde.

In der Hauptsache muss ich mich auf die systematische Beschreibung der mir vorliegenden Versteinerungen beschränken und es den schwedischen Kollegen überlassen, die stratigraphischen Schlussfolgerungen daraus zu ziehen. Wenn ich gleichwohl auch dicsem Gegenstand ein kleines Schluss-Kapitel gewidmet habe, so bin ich von dessen Unvollständigkeit vollkommen überzeugt. Aus eigener Anschauung sind mir nur einige der Fundorte, von denen das Material stammt, bekannt und mein Besuch Gottlands war zu kurz, um ein eigenes sicheres Urteil über die Stratigraphie des dortigen Silurs zu gewinnen, die infolge des häufigen Fazieswechsels überhaupt nur auf Grund eines sehr eingehenden Studiums klargelegt werden kann.

Das hier bearbeitete Material ist, abgesehen von meinen eigenen Aufsammlungen im Jahre 1910, von folgenden Herren zusammengebracht worden: In Nordgotrland, Blatt Visby (siehe die Karte Taf. 10), von H. Hedström und G. Liluevalis; in Südgottland, Blätter Roma und Hamra, von H. Munthe, J. C. Moberg, K. A. Grönwali, G. Holm, Hj. Lundbonn, A. Hj. Olsson, J. A. Bergquist und M. Dalborg. Allen diesen Hericn und insbesondere auch dem Direktor der Schwed. geol. Landesanstalt Prof. Anderisson bin ich für die Überlassung dieses herrlichen Materials und die Drucklegung meiner Arbeit zu grösstcm Danke verpflichtct.

Zur besseren Orientierung des Lesers ist auf Tafel 10 eine Übersichtskarte Gottlands beigegeben, auf der die Herren Henström und Munthe die in dieser Arbeit erwähnten Fundorte eingetragen haben. Für den Leser ist dies eine sehr nützliche Bcigabe, denn es ist sehr mühsam und z. T. auch unmöglich, auf den vorhandenen topographischen Karten der Insel diese Fundplätze ausfindig zu machen. - Die Karte ist eine Verkleinerung der topographischen Karte des schwedischen Generalstabcs im Massstabe von $1: 100000$.

\section{Petrographischer Erhaltungszustand.}

Von Wichtigkeit für die richtige Deutung der Versteinerungen ist es, Klarheit zu erlangen über die Art, in der die hier zu beschreibenden Versteinerungen erhalten sind. Es ist deswegen notwendig, einen Blick auf die Beschaffenheit der obersilurischen Gcsteine Gottlands zu wcrfen. Im allgemeinen ist der Erhaltungszustand der Versteinerungen ein vorzüglicher. Die Schichtgcsteine haben weder durch vulkanische noch durch tektonische Ereignisse bemerkenswerte Umwandlungen erfahren. Die alten Meeressedimente liegen auch heute noch beinahe horizontal, und wcmnauch Mustrie in Südgottland eine lange Verwerfung nachgewiesen hat, so ist deren Sprunghöhe doch zu unbedeutend, als dass sie grosse petrographische Umwandlungen in den Gesteinen hätte hervorrufen können. 
Nur geringfügige Differenzen sind zwisehen den orographisehen und stratigraphisehen Niveauflitchen naehzuweisen und sie beweisen, dass starke einseitige Hebungen und Senkungen oder Faltungen nicht eingetreten sind. Das geht auch aus der zum Teil geradezu roryïgliehen Erhaltung der Versteinerungen hervor, welche unter dem Mikroskop noch die feinsten Strukturverhältnisse erkennen lassen. Gleiehwohl maehen sich gewisse Veränderungen benerkbar, die die Tier- und Pflanzenreste betroffen haben. Sie sind es, die hier zunäehst besproehen werden sollen.

Die fossilführenden Sehiehtgesteine setzen sich aus zweierlei Material zusammen: aus den Überresten von Organismen und aus klastischem Material. Das klastische Material ist zweierlei ganz versehiedenen Ursprungs. Feine Quarzkörner und kleine Muskovit- und Biotitblättehen kommen massenhaft in den tieferen Lagen besonders im Süden Gottlands vor, bilden oft riehtige Sandsteinbänke, finden sieh aber auch in vielen Kalksteinen eingestreut. Doch entziehen sie sieh dort der Beobaehtung leichter als im Sandstein. Sie sind landesfremde Gäste, die, worauf auch ihr kleines Korn hinweist, von fernher dureh Neeresströmungen an ihre heutige Stelle getragen wurden. Die Tiefbohrung bei Visby bestatigt diese Auffassung. Das andere klastisehe Material hingegen stammt aus näehster Nähe. Es sind Trümmer von solehen Kalkalgen, Hydrozoen, Korallen, Bryozoen, Echinodermen, Brachiopoden, Mollusken und Arthropoden, welche an vielen Stellen aueh in vollständiger Gestalt erhalten geblieben sind. Diese Trümmer sind zum Teil eekig und scharfkantig, so dass sie als Zerfallsprodukte angesehen werden dürfen, die sieh als solche an Ort und Stelle gebildet haben. Andere hingegen zeigen eine bald mehr, bald weniger deutliehe Abrundung, die auf eine gewisse Verfrachtung im Meere hinweist. In manehen Gesteinslagen sind sogar alle Versteinerungen stark abgerundet und verkleinert und liegen in einem feinkörnigen Kalkbindemittel, das aus Kalkschlamm hervorgegangen zu sein seheint.

Neben diesen klastisehen Bestandteilen kommen ungezählte Versteinerungen vor, die so vorzüglieh erhalten sind, dass sie als dic Überreste von Organismen gedeutet werden müssen, die an Ort und Stelle gelebt haben und gestorben sind. Oft kommen sie in solchen Mengen vor, dass sie den Kalkstein fast aussehliesslieh aufbauen. Das gilt besonders für die Crinoideen- und Korallenkalke. Immer aber sind diese authigenen wie aueh die allothigenen Bestandteile dureh ein dichtes Bindemittel verbunden, das nur im Dünnsehliff sieh zu einem sehr feinkörnigen Caleitaggregat anflöst. Es hüllt nicht nur die Versteinerungen ein, sondern es füllt auch deren ursprüngliehe Hohliäume vollkommen aus. Diesem Umstande ist es zu verdanken, dass Gehäuse selbst mit dünnsten Schalen und alle Pflanzenzellen ihre ursprüngliehe Form erhalten haben, ohne dureh die Last der naehfolgenden und auflagernden Sedimentmassen zusammengedrüekt worden zu sein. Es muss dieses Bindemittel also reeht bald naeh dem Absterben der Organismen eingedrungen sein. Die Frage, wann und wie dies gesehah, ist sehr schwer zu beantworten und die Antwort wird aueh nieht leichter, wenn wir uns mit dem Wort »Diagenese» helfen. Man könnte wohl daran denken, dass die verwesenden, organisehen Substanzen in den Zellumina und in den Tiergehäusen das im Meereswasser gelöste Kalkkarbonat und -Sulphat zur Fällung brachten. Allein dieses Hilfsmittel versagt in vielen Fällen ganz, wo es sich nämlieh um solehe Hohlräume handelt, die schon zu Lebzeiten der Organismen von organiseher Substanz frei waren. Das gilt ganz besonders für die basalen Zellen der Kalkalgen, deren verkalkte 
Wände schon zu Lebzeiten nur noch als Stützorgane dienten, und für die Korallen, wo in den lange vorher schon leblosen tieferen Teilen genau so wie in den oberen zur Zeit der Einbettung noch mit organischer Substanz erfüllten Abteilungen das kalkige Füllnittel ausgezeichnet entwickelt ist. Auch die abgebrochenen und verschleppten, zum Teil sogar abgerollten Teile von Kalkalgen und Hydrozoen, die oben schon erwähnt wurden, zeigen ihre feinsten Hohlräume mit Calcitaggregat ausgefüllt. Es ist aber sehr unwahrscheinlich, dass diese Ausfüllung scholl eingetreten war, ehe diese Teile klastisch wurden. Wenigstens sprechen die Erfahrungen des gegenwärtigen Meeresstrandes dagegen, wo solche abgebrochene Reste gerade deshalb von dem bewegten Wasser weit fortgetragen werden, weil sie noch verhältnismässig leicht sind infolge ihrer vielen luftführenden Hohlräume. Auch wäre andernfalls zu erwarten, dass sich das Ausfüllungsmaterial solcher klastischer Bestandteile chemisch oder physikalisch und insbesondere durch seine Farbe von dem Bindemittel seiner Umgebung schärfer abheben würde, als dies tatsächlich der Fall ist. Im Dünnschliff fällt die fragmentäre Natur der betreffenden Körper zunächst gar nicht in die Augen und sie kann nur erst aus dem Widerspruche festgestellt werden, der zwischen deren äusseren Umrissen und der inneren organischen Struktur besteht. Wenn aber diese klastischen Körper erst infiltriert wurden, nachdem sie verfrachtet waren, dann ist der protoplasmatische Inhalt wohl in den meisten Fallen schon lange verschwunden gewesen. Man wird deshalb vielleicht eher daran zu denken haben, dass der feine Bodenschlamm bei diesen Ausfüllungen eine Rolle gespielt habe. Es darf angenommen werden, dass sich solcher in den wenig tiefen Meeresräumen in Menge gebildet hat und dass er nicht nur aus der mechanischen Wirkung der Brandung auf die festen Bestandteile der abgestorbenen Tiere und Pflanzen hervorgegangen ist, sondern dass auch die lebenden Organismen selbst teils während ihres Lebens, teils bei ihrem Absterben einen wesentlichen Bestandteil dazu lieferten. Dafür sprechen insbesondere die sehr verbreiteten und noch deutlich erkennbaren Exkremente, die, soweit sie von Crustaceen herrühren, in einem besonderen Kapitel besprochen werden sollen. Chemisch betrachtet wird der Bodenschlamm als eine Mischung von Kolloiden und Kristalloiden aufzufassen sein, und ehe er seine jetzige feste Gestalt erhielt, werden eine Menge von Wanderungen und Umsetzungen darin vor sich gegangen sein, über die wir aber zur Zeit nichts bestimmtes wissen. Wenn jedoch der Bodenschlamm, wie wir wohl annehmen dürfen, das Hauptmaterial für das kalkige Bindemittel der Silurkalke geliefert hat, dann ist es klar, dass die feinkristallinische Natur desselben, wie wir sie jetzt im Dünnschliff erkennen, erst allmählich erworben worden ist als eine Folge der Diagenese. Damit in Verbindung ist wohl auch der Fossilisationsprozess zu bringen.

Die erhalten gebliebenen Hartgebilde der Tiere und Pflanzen bestehen zumeist aus kohlensaurem Kalk. Chitin ist verhältnismässig sehr selten und erscheint als eine das licht nicht doppeltbrechende, gelbliche Substanz im Dünnschliff. Der kohlensaure Kalk war ursprünglich teils in Form von Calcit, teils von Aragonit auskristallisiert. Von den Echinodermenresten besteht auch heute noch jeder aus einem einzigen besonderen Calcitkristall, genau so wie dies zu Lebzeiten der Fall war, und man darf deshalb annehmen, dass hier eine Umkristallisation nicht eingetreten ist. Bei anderen Tiergruppen wissen wir nicht, ob sie ursprünglich Aragonit oder Calcit ausgeschieden haben und deshalb lässt 
es sich nicht mehr leicht feststellen, in wiefern hier eine Umwandlung des Aragonits in Calcit eingetreten ist. Mit einiger Sicherheit hingegen dürfen wir annehmen, dass die Hartgebilde der Oolithe, Sphaerocodien, Hedströmien und wahrseheinlich auch der Tetrakorallen aus Aragonit bestanden, weil dies aueh bei den lebenden Hexakorallen, den rezenten Oolithen und den niederen Grünalgen der Fall ist. Weniger sieher ist es, ob dies auch für Solenopora angenommen werden darf, da diese Gattung möglicherweise mit den lebenden Lithothamnien verwandt ist, welehe nicht Aragonit sondern Caleit in ihren Zellwandungen zur Ausscheidung bringen.

Diese naehträigliche Unwandlung des Aragonits in Calcit ist häufig erfolgt, ohne die Umrisse der Kalkwandungen gegen das Bindemittel zu verwisehen. Die Hartgebilde heben sich nieht nur durch eine schwache Trübung (durch organisehe Bestandteile bedingt?) von den helleren Bindemittel ab, sondern auch dadurch, dass ihre neugebildeten Caleitkristalle nicht randlieh in das Bindemittel hineinragen, sondern von diesem seharf getrennt sind. Diesem Umstand allein ist es zuzusehreiben, dass wir heute noch imstande sind, den feinsten Zellbau der fossilen Kalkalgen so genau zu erkennen. Freilieh kommen auch, und zwar gar nicht allzu selten, Kalkalgenknollen vor, in denen die Zellstruktur dadureh fast völlig verwiseht ist, dass die Ausfüllung der Zellen und deren Wandungen gleiehmässig in ein Calcitaggregat umgewandelt worden ist, wobei die ursprüngliehe Zellstruktur meist nur noeh aus der Trübung erkannt wird, welehe den Wandungen eigen ist. Hier ist also offenbar während der Diagenese aus lokalen Ursachen eine gleichzeitige Umkristallisation der Kalkwände und der Füllmasse eingetreten. Besonders deutlich kann dies bei Solenopora naehgewiesen werden. Aber aueh sonst sind so manche Reste im Dünnsehliff nur mit grosser Unsicherheit als Sphaerocodien oder Spongiostromen zu bestimmen und es wäre vergebliehe Mühe, in solehen Fällen die Art oft auch die Gattung mit Sieherheit feststellen zu wollen.

Aus all dem geht hervor, dass trotz der vorzüglichen Erhaltung der Versteinerungen doch die silurischen Gesteine Gottlands während ihres Entstehungsprozesses maneherlei Veränderungen durehgemacht haben. Doeh kommen aueh Veründerungen anderer Art als diese diagenetischen vor. In einem Sehliff dureh einen Kalkstein, der fast aussehliesslieh aus Stielgliedern von Crinoideen zusammengesetzt ist, konnte ieh Drueksuturen erkennen ron allerdings mikroskopisch kleinen Dimensionen. Sehr deutlieh war zu sehen, wie einzelne der Crinoideenglieder trot\% ihrer guten Erhaltung sich stylolithenartig in andere hineingebohrt haben und diese Verzahnungen setzen in Form echter Drueksuturen weiter dureh das Gestein fort, ein Beweis, dass der Druek der auflastenden Sedimentmassen hier genügte, um jene ehemischen Auflösungen an den Berührungsstellen versehiedener Kalkkörper herrorzurufen, welche sonst allerdings in viel höherem Masse da einzutreten pflegen wo tektonische Bewegungen die Kalkgesteine erfasst haben. 


\section{Die Kalkalgen.}

\section{Zur Vorgeschichte.}

Sehon Lindström hat das Vorkommen von Girvanella, die von Nicholson 1878 aus dem sehottisehen Untersilur besehrieben worden war, in der Stufe $c$ des Obersilurs von Gottland erwähnt, ${ }^{1}$ aber auf die grosse Verbreitung und Wiehtigkeit dieser Fossilien in Stufe $c, a$ und $e$ Lindströms hat doeh erst Stolley 1896 hingewiesen, ${ }^{2}$ der dieselben aueh in Sehonen und in den diluvialen Gesehieben Norddeutsehlands erkannt hat. Er schloss sieh dabei meiner 1891 veröffentliehten Auffassung an, dass die Girvanellen keine Foraminiferen sind, sondern zu den kalkabsondernden Algen aus der Gruppe der Siphoneen gehören. Vorher (sehon 1893) hatte er (1) aus dem baltischen Untersilur eine Anzahl neuer vertieillierter Siphoneen beschrieben und konnte nun feststellen, dass diese im sehwedisehen Obersilur fast ganz verschwinden, gleiehzeitig mit dem massenhaften Auftreten der Girvanellaknollen. Letztere fasste er (4) unter dem Namen Girvanella problematica zusammen in der Meinung allerdings, dass dieser Artname nur eine Kollektiv-Bezeiehnung sei. Aueh die sehwedisehen Geologen hatten ihre Aufmerksamkeit in erhöhtem Masse auf diese Dinge geriehtet, und schieden bei der stratigraphisehen Einteilung des Silurs besondere Girvanellakalke aus. Sehon im Sommer 1906 haben Munthe und Grönwall festgestellt, dass in Südgottland der Sandstein über dem unteren Girvanellamergel liegt. Doeh blieb diese Entdeckung in den Tagebüchern der S. G. U. begraben und wurde erst 1902 von Munthe in den Geol. Fören. in Stoekholm Förhandl. veröffentlieht. Naehdem ieh dann 1908 den Naehweis erbracht hatte, dass unter diesen Kalkknollen drei versehiedene Genera verborgen liegen, nämlieh Sphaerocodium, Solenopora and Spongiostroma, ist es den Herren Munthe und Hedström 1910 gelungen, einen oberen und unteren Sphaerocodium-Horizont zu unterseheiden, wobei der obere Horizont durch Spongiostroma eharakterisiert ist, welehes im unteren Horizont fehlt. Ein Ergebnis der

1 List of fossil faunas of Sweden. Stockholm 1888.

2 Ich nehme hier Bezug auf folgende Arbeiten STOLLEYs:

1) Über die Verbreitung algenführender Silurgeschiebe. Okt. $1893 \mathrm{im}$ N. Jahrbuch f. Min. etc. $1894, \mathrm{Bd} \mathrm{I}$.

2) Naturwissenschaftliche Wochenschrift, Berlin 1896, N:0 15.

3) Untersuchungen über Coelosphaeridien, Cyclocrinus, Mastopora und verwandte Genera des Silur. Archiv f. Anthropologie und Geologie Schleswig-Holsteins, Bd I. 1896.

4) Die silurische Algenfacies und jhre Verbreitung im skandinavisch-baltischen Silurgebiet. Schriften des naturwissenschaftlichen Vereins für Schleswig-Holstein, Bd. XI. 1897. 
rorliegenden Arbeit ist, dass wir zwei Arten von Sphaerocodium und drei Arten von Solenopora, ausserdem zwei Arten eines neuen Genus Hedströmia, neben den Spongiostromen zu unterscheiden haben, dass aber auch klcine verticillierte Siphoneen gar nicht selten vorkommen.

\section{Solenopora Dyвowsiri.}

Genusdiagnose. Vielzellige, knollenförmige Stöcke bildende Kalkalge. ${ }^{1}$ Die meist runden bis nierenförmigen Stöeke variieren in Form und Grösse erheblich. Ihre Oberfläche ist glatt. Die grössten beobachteten Knollen messen bis $5 \mathrm{~cm}$ im Durchmesser.

Das Gewebe besteht aus feinen im Querschnitt polygonalen Zellfäden, deren Breite je nach der Art zwischen 25 u. $130^{\mu}$ wechselt. Die Seitenwände der Fäden sind stets kräftig verkalkt und treten deshalb im Dünnschliff als dunklere Linien in dem helleren Gestein deutlich hervor. Die Querwände hingegen, welche die einzelnen Zellen innerhalb eines jeden Fadens von einander trennen, sind meistens weniger stark verkalkt und entziehen sich deshalb manehmal der Beobachtung. Durch Wandporen sind die Zellen miteinander in Vcrbindung gesetzt, die Zellen gleicher Reihe durch je einen Porus in der Mitte der Querwand, die benachbarten Zellenreihen durch Poren in ihren Seitenwänden. Die ganze Alge besteht aus zweierlei Gewebearten, dem Hypothallium und dem Perithallium.

Mit dern Hypothallium liegt die Pflanze auf dem fremden Substrat und breitet sich auf ihm aus. Die Zellfäden kriechen über dasselbe hin und vermehren sich bei dieser Flächenausdehnung sehr rasch durch Dichotomie. Ihr Verlauf ist durch die Gestalt der Unterlage beeinflusst und meist nicht sehr regelmässig. Doch tritt eine eigentliche Verfilzung der Fäden nicht ein. Sie laufen vielmehr horizontal auseinander und die Zwischenrïume werden von dichotom sich abzweigenden Fäden ausgefüllt. Es können sieh auch mehrere Lagen soleher Hypothallfäden übereinander bilden, aber schliesslich biegen sie sich in die Höhe und gehen dann in das Perithall über, in welchem sie geradlinig aufsteigen, regelmässig nebeneinander liegen und sich nur noch entsprechend der kugelförmigen Erweiterung des ganzen Stockes langsam durch Dichotomie vermehren. Die Breite der Fäden und die Länge der einzclnen Zellen ist im Perithall viel gleiehmässiger als im Hypothall.

Grössere Schlauchzellen, die als Sporangien gedeutet werden können, kommen nur im Perithall, aber niemals im Hypothall vor. Sie liegen stets vereinzelt in dem parenchymartigen Perithallgewebe eingeschaltet und sind erheblich breiter als die gewöhnlichen Zellfäden, im Querschnitt kreisrund, im Längssehnitt schlauchförmig.

Das Dickenwachstum der Alge beruht aut der Entwicklung des Perithalls; doch scheint dasselbe ein beschränktes gewesen zu sein. Meist sehr bald und stets nach Erreichung einer Dicke von einigen $\mathrm{mm}$, höchstens einem $\mathrm{cm}$ endet es. Fremde Organismen siedeln sich stellenweise darauf an. Aber an freien Stellen können die distalen

\footnotetext{
${ }^{1}$ Dybowski stellte 1877 dieses Genus zu den Chaetetiden, ALex. Brown 1894 zu den Nulliporen.
} 
Enden der Zellfäden weiterwachsen und es entsteht dann eine neue Hypothallschicht, welche sich horizontal über die Oberfläche des Fremdkörpers und auch des Algenkörpers selbst ausbreitet und darauf zu einer neuen Perithallzone auswächst. Auf diese Weise ist es gekommen, dass nicht allzu selten mehrere fremde Organismen in den Algenkörper ganz eingeschlossen worden sind.

Diese Diagnose gründet sich auf die Durchsicht zahlreicher Schliffe von Solenopora gotlandica, spongioides und compacta. Ausser diesen Arten ist mir nur noch eine bekannt, von der ich aber nur einen Schliff zu sehen bekommen habe. Es ist die Solenopora filiformis Nıch. Die übrigen aus dem Silur angeführten Arten halte ich teils für Varietäten, teils für besondere Erhaltungszustände der vier erwähnten Arten. Solange man die pflanzliche Natur von Solenopora nicht erkannt hatte (Dybowsixi, Billings, Nicuolson, EtueRIDGe, Dawson und Foori) und geneigt war, sie unter den Coelenteraten unterzubringen, konnte man über die Verschiedenartigkeit der zweierlei Gewebearten dieser Pflanze keine klare Vorstellung gewinnen. Da die Arten nur auf Grund von Dünnschliffen sich unterscheiden lassen, so wurde es für solche Unterscheidung verhängnisvoll, dass man vertikale und tangentiale Schliffe unmittelbar miteinander verglich und nach ihren Verschiedenheiten Arten aufstellte. So ist es gekommen, dass z. B. Schnitte durch das Hypothall und solche durch das Perithall ein und derselben Art als zu zwei verschiedenen Arten gehörig beschrieben wurden, weil natürlich Schnitte durch zwei verschiedene Gewebearten auch ganz verschiedene Bilder liefern. Ferner hat man aus Schnitten, die weder genau vertikal noch tangential orientiert waren, wiederum besondere Arten gemacht. Wenn man diese Irrtümer beseitigt, bleiben von den acht beschriebenen nur vier gute Arten übrig. Alex. Brown hat zwar, auf einer von Nicholson schon 1885 ausgesprochenen Vermutung weiterbauend, 1894 die pflanzliche Natur von Solenopora eingehend zu begründen versucht und sogar eine direkte Beziehung zu den Lithothamnien vermutet, aber seine Argumente sind nur teilweise zutreffend. Die Ungleichheit der Zellumrisse, die in Schliffen durch das Hypothall stets hervortreten müssen, weil die Zellen in solchen abwechselnd quer und längs geschnitten werden, hat er so aufgefasst, als ob die grösseren und länglich erscheinenden Zellen Sporangien, die kleineren und mehr regelmässig polygonalen die gewöhnlichen vegetativen Zellen seien. In Wirklichkeit hat Brown Sporangien gar nicht beobachtet und auch mir ist dies bis jetzt nur bei der Solenopora yotlandica gelungen, wo Sporangien allerdings ungemein häufig sind, aber nicht im Hypothall, sondern im Perithall liegen.

Die septenähnlichen Vorsprünge, welche bei Tangentialschnitten in den Zellumina auf den Zeichnungen von Nicholsos und Etrenidge zu sehen sind, und die für die Korallennatur dieser Organismen sprechen sollten, sind merkwürdiger Weise bei den Zeichnungen von Brown fast ganz verschwunden und nur bei dem Tangentialschnitt von Solenopora nigra noch vorhanden. Solche Vorsprünge sind in Querschnitten nur dann zu sehen, wenn dieselben nicht durch Perithall sondern durch Hypothall gelegt sind. In diesem Gewebe ist, wie schon erwähnt, die dichotome Teilung sehr häufig und die scheinbaren Septen erklären sich als die Anfünge der neu entstehenden Zwischenwände.

In vollkommen vertikalem Schnitt durch das Perithall erscheinen die Zellfäden wie langgezogene Röhren, die von Querwänden in einzelne Zellen gegliedert sind. Sobald aber 
der Schnitt nicht genau vertikal ist oder wenn, was bei dem globulösen Wachstum des Stockes oft eintreten muss, die Zellfidden nicht genau geradlinig aufsteigen, dann erscheinen sie nur auf eine kurze Erstreckung im Schliff, verschinäler'n sich an den Austrittstellen, wo sie einer anderen Serie von Fäden Platz nuchen. Dadurch erscheinen sie im Schliff mit spindelförmigen Umrissen und auf ein solches Bild hat Brown eine besondere Art aufgestellt (Sol. fusiformis), die aber in allen anderen Eigenschaften mit Sol. filiformis Nıch. übereinstimınt.

Merkwürdigerweise haben alle Autoren Zeichnungen der Röhren und, wo vorhanden, auch der Querwände ohne jede Andeutung der Poren gegeben, und doch sieht man solche, - vorausgesetzt, dass der Schliff dünn genug ist - stets. Die Wände erscheinen, wo nicht nachträglich Kristallisation eingetreten ist und dadurch das ganze Bild verwaschen wurde, stets als dunkle Linien. Sobald man sie aber bei starker Vergrösserung eine Strecke weit verfolgt, bemerkt man Unterbrechungen. Das ist so regelmässig der Fall, dass an Zufälligkeiten dabei nicht gedacht werden kann. Bei delı Querwänden ist das noch viel ausgeprägter der Fall, denn da ist die Unterbrechung oft so gross, dass von den Querwänden nur noch die randlichen Ansatzstellen an den Längswänden zu sehen sind. In einer sehr interessanten Arbeit „Über einige gesteinsbildende Kalkalgen von Japan und China», die Herr H. Yabe in den Science reports of the Tohoku imperial university, II. Ser. Bd. 1, 1912, veröffentlicht hat und die mir gerade noch rechtzeitig vom Verfasser zugesandt wurde, um sie beim Abschluss meines Manuskriptes benutzen zu können, hat sich Herr $\mathrm{Y} \Lambda \mathrm{BE}$ auch über diese Poren geäussert. Er hält die Unterbrechungen, welche die Quer- und Längswände so häufig zeigen, nicht für wirkliche Poren, sondern für sekundäre Bildungen. Er sagt »die Wände und besonders die Querböden bei Metasolenopora (ein oberjurassisches oder untercretacisches neues Algengenus, das er heschreibt und auf dessen Ähnlichkeit mit Solenopora er hinweist) sind eigentlich sehr dünn und deshalb werden sie sehr leicht bei Kristallisation von Calcitkörnern zerstört; nur sind die Nähte der Zellwände und Querböden verhältnismässig dick und widerstandsfähig und bleiben inchr oder weniger wohl erhalten. Bei schwächerer Vergrösserung aber finden wir auf solchen Sclıliffen die Längs- und Querböden ununterbrochen, doch bei stärkerer sind sie zu den Längs- und Querreihen von Knoten aufgelöst und bestehen nicht mehr aus selbstständigen Balken.» Gerade dieser letztere Umstand scheint mir jedoch dafür zu sprechen, dass es sich hierbei um wirkliche Poren handelt, die so im Schliff liegen, dass darunter oder darüber noch etwas von der Wand zu sehen ist bei schwacher Vergrösserung, bei stärkerer hingegen verschwindet sie bei scharfer Einstellung auf den Porus, sie erscheint aber wieder, wenn man den Tubus etwas senkt oder hebt. Dies ist wenigstens meine Erfahrung bei Solenopora. In anderen Fällen allerdings ist von der darunter oder darüber liegenden Wand im Schliff nichts mehr zu sehen und der Porus erscheint dann als eine vollkommene Unterbrechung der Wand. Bei Lithothamnium ist das Zellgewebe zu fein, so dass solche Fälle nicht leicht vorkommen können, selbst bei dünnsten Schliffen. Gleichwohl habe ich auch da die Poren bei stärksten Vergrösserungen nachweisen können bei langsamem Heben des Tubus, wobei die Wand an der betreffenden Stelle verschwindet und der Porus als solcher sichtbar wird. Recht hingegen muss ich Herrn YABE darin geben, dass häufig mangelhafte Erhaltung infolge ungenügenden Fossilisationsprozesses

2-131019. S. G.U. Ser. Ca, N:o 10. Rothpletz, Obersilur. Kalkalgen etc. Gottlands. 
die Zellwände verwischt hat. Oft zeigen ganze Knollen kaum mehr merkliche Spuren des Zellaufbaues, wennschon er in einzelnen kleinen Partien oder Zonen noch vorzüglich erhalten ist und ganz klar hervortritt. Lücken und Unterbrechungen dieser Art in der Gitterstruktur äussern sich aber ganz unregelmässig und haben mit den Porenlücken nichts zu tun. Jedenfalls sind die Poren bei Solenopora viel grösser als bei Lithothamnium, was iudessen nicht allzu verwunderlich ist, weil auch ihre Zellen grössere Dimensionen besitzen.

Die Breite der Zellen bei den ron mir untersuchten Lithothamnium-Arten schwankt zwischen 6 und 20" und beträgt durchschnittlich 11", bei Metasolenopora 30, bei Solenopora gotlandica 25-35, Sol. compacta 50-130". Metasolenopora Rotlipletzi hat YABE (S. 5) generisch von Solenopora abgetrennt, wegen der Entwicklung einer eigenartigen Zellengruppe, welche wohl mit Recht der Basalschicht (Hypothallium) von Lithothamnium verglichen werden kann. Ich habe aber schon 1908 darauf hingewiesen (S. 13 u. 16), dass auch bei Solenopora, wennschon nicht so ausgeprägt wie bei den Lithothamnien eine Differenzierung des Gewebes in Hypo- und Perithall rorkommt und das grosse Material, das ich inzwischen aus Gottland studieren konnte, hat die Tatsache dieser Differenzierung noch deutlicher erkennen lassen. Ich glaube deshalb, dass kein Grund inehr besteht, die japanische Art aus den Grenzschichten zwischen Jura und Kreide in ein besonderes Genus zu stellen, und ich bin überzeugt, dass es auch bald gelingen wird, aus den Schichten, welche zeitlich zwischen die Jura- und Silurperiode fallen, Solenopora-Arten nachzuweisen ${ }^{1}$. Dadurch wird dann vielleicht auch die phylogenetische Beziehung zu Lithothamnium deutlicher werden.

\section{Arten des Genus Solenopora.}

Nach dem gegenwärtigen Stand unserer Kenntnis lassen sich von den 8 Arten nur 4 aufrecht erhalten, nämlich Solenopora compacta, spongioides, filiformis und gotlandica. In Wegfall kommen: Solenopora dendriformis, jurassica, fusiformis und lithothamnioides. Von letzteren soll zunächst die Rede sein.

1) Sol. dendriformis BRown ${ }^{2}$ aus den Kegel'schen Schichten (D. 2) des unteren Silur's ron Sak in Estland. Der Tangentialschliff (Figur 7 bei Brown) zeigt stark und ganz unregelmässig verzweigte röhrenähnliche Gebilde, deren Breite zwischen 0,01 bis 0,05 $\mathrm{mm}$ schwankt und nach den Angaben im Text sogar bis 0,06 $\mathrm{mm}$ anschwellen kann. Zwischen den Röhren liegt eine ungefähr ebenso breiten Raum einnehmende Masse, in der deutliche Röhren nicht mehr erkannt werden können, so dass man den Eindruck gewinnt, es handle sich hier um ein dichtes, feinkristallinisches Zwischenmittel, welches die einzelnen Röhrchen voneinander trennt. Solche Bilder liefern die Solenoporaarten niemals, und auch dann nicht, wenn die Schliffe das Hypothall getroffen haben. Brown bemerkt dazu, dass die Zellen nach allen Richtungen (also wohl auch in Vertikalschliffen, von denen leider Abbildungen nicht gegeben worden sind) sich verziveigen und dass dies eine charakteristische Eigenschaft der Art sei. Unter diesen Umständen können diese

1 Dies ist während der Drucklegung für die Carbonformation durch HINDE bereits geschehen.

2 On Solenopora. Geol. Magaz. IV, 1, 1894. 
Formen nieht zu Solenopora gestellt werden und ich habe bereits 1908 die Vernutung ansgesprochen, dass es sich hierbei wahrscheinlieh um ein Spongiostroma handelt.

2) Solenopora jurassica Brown. Diese Art habe ieh 1908 in ein besonderes Genus Solenoprorella gestellt. Die Gründe dafür sind dort in einzelnen angegeben und sollen hier nicht wiederholt werden. Der Hauptgrund ist der, dass die Zellen keinerlei Poren zeigen und dass wir es deshalb mit einer Alge zu tun haben, die weder mit Solenopora noch mit Lithothammium eher vielleieht mit den Ralfsiaceen und Lithodermataeeen aus der Klasse der Fucoideen in nähere Verwandtsehaft gebracht werden kann.

3) Solenopora fusiformis Brown kommt zusammen mit Sol. filiformis in Ordovician-Kalkstein Ayrshires vor und hat dieselben Zelldimensionen wie diese Art. Der cinzige Unterschied soll in der spindelförmigen Gestalt der Zellröhren liegen, was, wie schon erwähnt, auf der ungenauen Orientierung des Sehliffes beruht. Die Art ist somit cinzuzichen.

4) Solenopora lithothamnioides BRown ist auf ein einziges Stück gegründet, das von Shalloch Mill bei Girvan in Ayrshire stammt, von porzellanartigem Aussehen und sowohl härter als auch von diehterer Besehaffenheit ist, wie irgendein Stück der anderen Arten. Taeh den Zelldimensionen stimmt es mit Sol. compacta vollständig überein und unterseheidet sich nur dureh die fast quadratischen Zellen. Wir wissen aber, dass die gleiehe Besehaffenheit bei Sol. compacta, wennauch oft weniger deutlieh, zu beobachten ist. Jenes Stück zeigt infolge seiner grösseren Härte und besseren Erhaltung das Perithall von Sol. compacta besonders gut und ist infolgedessen mit dieser Art zu vereinigen.

\section{Die silurischen Arten von Solenopora.}

1) Solenopora compacta Bilingas spec.

Tafel 1, Fig. 5-6 und 1908, Tafel 3, Fig. 1-6.

Diese Art ist bisher nur aus dern unteren Silur bekannt gewesen, in Amerika aus dem mittleren Untersilur oder Ordovician (Trenton u. Blaekriver limestone), in Sehottland aus dem Craighead limestone bei Girvan (Ayrshire, Schottland). Nicholson gibt sie auch aus den Kegel'schen Schichten Estlands an, aber wahrscheinlieh gehören diese Stiieke zu Sol. spongioides. Ob sieh die von Nicholson als var. Peachii besehriebene Abart in Sehottland aufrecht erhalten lässt, kann erst entschieden werden, wenn festgestellt sein wird, ob die Angabe breiterer Zellen sich auf das Peri- oder Hypothall bezicht; denn in letzterem treten grössere Breiten gewöhnlieh an den Stellen stärkerer Verzwcigung aueh bei der echten Sol. compacta hervor. Naeh Sehliffen von Stüeken aus dem Trentonkalk habe ieh 1908 eine Besehreibung dieser Art gegeben, der ieh \%. Z. neues nieht hinzuzufügen habe. Doch kommt diese Art auch im Obersilur Gottlands vor, ist dort aber verhältnisinässig selten. Ich kann sie von 13 Fundorten erwähnen: 
Blatt Visby:

Fundorte (siehe die Karte Taf. 10):

$2^{1}$ ) Der nördlichste Ort liegt bei Vialms a m Fårösund im Kirchspiel ${ }^{2}$ Fleringe, ein 1 cm grosser Stock (Perithall) ist von Spongiostroma überkrustet.

5) Bei Lickershamn an der NW-Küste ron Gottland, K. Stenkyrka, ein Schnitt durch das Hypothall eines $3 \mathrm{~mm}$ grossen Stockes im Schliff zusammen mit Spongiostroma.

14) Bei Vattenfallet, Visby, am kleincn obersten Fall östl. vom 7:ten Brunnen, cin 5 mm grosser Stock zusammen mit Sphaerocodium Munthei und Hedströmia halimedoidea.

17) Aus dem Steinbruch bei Visborgs slätt bei Visby, 2 klcine bis $3 \mathrm{~mm}$ grosse abgerollte Stücke im Kalkstein zusammen mit Sponyiostroma und Hedströmia halimedoidec.

19) Von Allehage, WSW vom Schloss, im K. Vesterkejde, im »oberen Girvanellakalk» ein $2 \mathrm{~cm}$ grosser Stock. (Taf. 1, Fig. 5-6.)

25) Vom Hörsne kanal im K. Hörsne ein $5 \mathrm{~mm}$ grosser Stock zusammen mit Spongiostroma, Sol. gotlandica und Hedströmia.

\section{Blatt Roma:}

53) Vom Kanal nordwestl. von Hallegårda im K. Sjonkem zusammen mit Spongiostroma und Hedströmia halimedoidea in bräunlichem, mergeligem Kalkstein.

54) Südwestlich von Sjonhemsbacke im K. Sjonhem zusammen mit Spongiostroma balticum in Kalkstein.

27) Von K. Tofta, S von Stafsklint, abgcrollt wie auch Spongiostroma und Sphaerocodium gotlandicum, in Kalksandstcin.

27) Südsüdwestlich von Stafsklint im K. Tofta zusanmen mit Solenopora gotlandica und abgerollten Stücken von Hedströmia und Spongiostroma.

30) Nördlich von Nasume im K. Toftı zusammen init Hedströmia halimedoidea und abgerollten Stücken von Sphaerocodium und Spongiostroma.

66) Östlich von Muntsarfve im K. Hejde im Pentamerus-Kalk, von Sphaerocodium gotlandicum und Spongiostroma überwachsen.

67) Östlich von Qvie im K. Hejde zusammen mit Sphaerocodium gotlandicum. und Spongiostroma in Kalkstein.

127) Südlich von Östcrby im K. Kräklingbo aus feinoolithischen Megalomuskalk.

109) Westlich von Jugennes im K. Burs aus Rhizophyllum-Riffkalk mit Sphaerocodium gotlandicum. Untere Stufe(?).

Ausser diesen fand ich in vier Dünnschliffen Überreste, welche in allen Einzelheiten mit Sol. compacta übcreinstimmen, so dass man sie unbedenklich zu diescr Art stellen könnte, wenn nicht der Durchmesscr der Zellen etwas kleiner wäre. Während dieser bei Sol. compacte 70-130" bcträgt und kleinere Zellen bis zu einer Breite von 40" nur an Teilungstellen vorkommen, schwankt der Durchmesser bci den zwei erwähnten Schliffen nur zwischen 50 u. $60^{\mu}$. Vielleicht sind die betreffenden Stöcke unter ungünstigen Be-

1 Die Nummern beziehen sich auf den Nummern der Karte, Taf. 10.

2 Kirchspiel wird weiterhin zu K. verkürzt. 
dingungen herangewachsen und es haben deshalb ihre Zellen die normale Grösse nieht crreichen können. Es könnte aber auch sein, dass es sich hierbei um eine konstante Varietit handelt. Da ich aber zu wenig und zu kleines Material davon besitze, so kann ich eine Entseheidung über diese zwei Möglichkeiten nieht treffen und ich begnüge mieh, die Reste als Sol. compacta minor hier aufzuführen. Zu Sol. filiformis kann ieh sie nicht stellen, obwohl die Breite der Zellreihen dagegen nieht allzusehr sprechen würde. Aber die Querwände sind in benaehbarten Zellfüden deutlich in gleiehen Höhen angeordnet. Solehe Stöeke habe ieh:

\section{Blatt Visby:}

12) Aus dem neuen Bruch von Galgberget bei Visby unter der" „Diskordanzlinie» zusammen mit Sol. gotlandica und Hedströmia.

19) Von Allehage im K. Vesterlejde, wo sie zusammen mit Spongiostroma im Leperditiasehiefer liegen.

\section{Blatt Romil:}

117) SO von Hallbjenne in K. När zusammen mit Sphaerocodium gotlandicum, mergeliger Riffkalk. Untere Stufe(?).

110) Nördlich von Hemmor im K. När mit Sphaerocodium gotlandicum. Untere Stufe(?).

Bemerkenswert ist es, dass Solenopora compacta bis jetat nur in Nord- und im nördlichen Mittelgottland gefunden worden ist und aueh da meist in der oberen Gottlandstufe, nämlich in dem Spongiostroma- (oberen Girvanella-) Kalk, in Leperditia-Schiefern, und in Kalken mit Pentamerus und mit Megralomus. Nur zwei oder dreimal habe ieh sie auch in der unteren Stufe angetroffen.

Ausserdem kenne ich sie auch aus dem Obersilur von Ösel, wo sie von Spongiostroma balticum überwaehsen ist und 1908 irrtümlich von mir als eine tabulate Koralle erwähnt wurde. (Siehe dort Tafel 6, Fig. 3.)

\section{2) Solenopora spongioides Dyb.}

Taf. 2, Fig. 1-3.

Von dieser Art hat Dybowski einen Tangential- und Vertikalschnitt abgebildet. Ersterer hat wahrscheinlich das Hypothall angetroffen, letzterer sicher das Perithall. Die Querwände fehlen in der Zeiehnung und wurden von DrBowski nicht beobaehtet. Nach seiner Beschreibung ist für diese Art eharakteristisch einmal der wellenförmige Verlauf der Seitenwände, zum anderen der Durehmesser der Röhren, weleher zwischen $30^{\mu}$ u. 80" im Querschnitt sehwankt, was mit dem Tangentialsehnitt übereinstimmt. Die Röhren des Vertikalsehnittes ergeben naeh der Zeichnung nur $30-50^{\prime \prime}$.

Bei Sak habe ieh 1897 einige kleine bis zu $3 \mathrm{~cm}$ grosse Exemplare gesammelt. Sie stammen zwar aus einem tieferen Horizont des Untersilur's, aber aus demselben, von welchem Nicholson sein Material hatte, das el zur Spezies compacta stellte. Ieh finde aber, dass ein wesentlieher Untersehied zwisehen den Saker-Stöeken und der echten Sol. com- 
pacta bcsteht. Im Perithall haben die Zellfüden durchweg einen etwas kleineren zwischen 30 und 70" schwankenden Durchmesser. Die Querwände stehen nicht auf gleicher Höhe in den benachbarten Fïden und auch in ziemlich weiten Abständen, so dass sie mit den Längswänden im Schliff nicht jenes regelmässige Gitterwerk bildcn wie bei Sol. compacta. Die Zellen sind mindestens doppelt so lang als breit und vielfach auch noch erheblich länger. Das war wohl der Grund, weshalb Driowsix die Querwände ganz übersehen hat. Eine weitere Eigentümlichkeit liegt in der Beschaffenheit der Längswände, die ziemlich regelmässig einen feinwelligen Verlauf zeigen. Das kommt zwar auch bei Sol. compacta vor, aber doch nur selten und niemals so stark ausgeprägt.

Noch schärfer ist diese Art durch die Entwicklung des Hypothalliums von Sol. compacta unterschieden. In diesem herrscht ein ganz regelloser Verlauf der Zellfäden, die rhizoidartig bald an-, bald abschwellen, auf ganz kurze Entfernung zu Breiten von $30-120^{\mu}$. Die dichotome Teilung ist cine sehr lebhafte und das Zellgewebe hat mehr den Charaktär eines Geflechtes. Sobald jedoch die Zellfäden in das parenchymatische Perithall überzugehen beginnen, nehmen sie einc grössere Regelmässigkeit an. Ihre Breite variiert nur noch zwischen 30 u. $70^{\prime \prime}$. Sie laufen genau parallel nebeneinander her und Vermehrung durch Teilung wird seltener.

In den Hypothallfäden habe ich mit Sicherheit Querwände nicht nachweisen können.

Diese Art ist bist jetzt nur aus Estland und zwar von Herküll aus den Borckholmer Schichten (F. 2) des obersten Untersilurs und von Sak aus der oberen Kegel'schen (Vassalem'schen) Schicht (D. 3) beschrieben worden. Ich habe sie ausserdem bei Kucker's in den Jewe'schen Schichten (D. 1) gefunden.

\section{3) Solenopora filiformis Nicr.}

Taf. 2, Fig. 4 .

Dicse Art wurde 1888 von Nicholson aufgestellt, der sie im Ordovician limestone von Craighead bei Girvan zusammen mit Sol. compacta fand. Sie ist dort sehr häufig, aber ihre Struktur nach den Angaben von NicHoLSON durch Kristallisation gewöhnlich verwischt. Sie teilt somit diese Eigentümlichkeit mit der jüngeren Sol. gotlandica. NicLolson hat die Zeichnung eines Tangential- u. Vertikalschnittes durch das Perithall gegeben. Danach sind die Querwände in wechselnden Abständen angeordnet, ähnlich wie bei Sol. spongioides. Der Durchmesser der Zellen soll durchschnittiich $40^{\mu}$ betragen. Nach den gegebenen Zeichnungen wäre dies jedoch eher das Maximum und würden die Zellen zwischen $20 \mathrm{u}$. 40 variieren. Die Abbildungen, welche BRown 1894 gegeben hat, sind wohl den gleichen Schliffen entnommen und sie stimmen mit den von Nicirolson gegebenen genau überein. Das Hypothall ist somit von dieser Art noch nicht bekannt.

Zu dieser Art scheint ein kleiner Stock zu gehören, dessen Zellen 35-40" breit sind und der mit Spongiostroma, Sphaerocodium und Hedströmia zusammen im Kalkstein mit Pentamerus conchidium $700 \mathrm{~m}$ südlich von Hejde Kirche (68), Bl. Roma, in der oberen Gottlandstufe gefunden worden ist. 
4) Solenopor’a gotlandical mihi.

Taf. 1, Fig. 1-4 und Taf. 7, Fig. 3, sowie 1908, Taf. 4, Fig. 1-5.

Diese Art habe ich 1908 von Gammelhamn auf Fårö (1) nach dem von G. Howı gesammelten Material beschrieben. Es hat sich inzwischen ergeben, dass sie auch auf Gottland eine weite Verbreitung besitzt und insbesondere in Nordgottland sehr häufig ist.

Die Knollen zeichnen sich durch ihre dichte Beschaffenheit und meist helle Farbe aus und erreichen Grössen bis über $3 \mathrm{~cm}$. Das Hypothall unterscheidet sich von dem Perithall dadurch, dass die Zellfäden wie bei Sphaerocodium über das Substrat hinkriechen, sich dabei vielfach durch Teilung vermehren und in ihrer Breite Schwankungen zwischen 25 und $35^{\prime \prime}$ zeigen (s. Fig. 4). Es erlangt keine Mächtigkeit und das Perithall hebt sich ziemlich scharf von ihm ab durch seine regelmässig angeordneten Zellfäden, bei denen die Querwände deutlich hervortreten, und auch viel dichter stehen als bei den Füden des Hypothalls. Die Zellen sind meist so lang als breit, manchmal auch kürzer, zuweilen aber auch länger. Ihre Breite beträgt 25-30", kann aber bei Teilungen und am freien Rande der Büschel bis auf $35^{\prime \prime}$ anschwellen. Es scheint, dass die regelmässige Anordnung im Inneren der Bündel eine grössere Verbreiterung nicht gestattet.

Das Dickenwachstum des Perithalls erfährt häufig Unterbrechung und die randlichen Zellen wachsen dann nicht mehr weiter mit Ausnahme einiger Stellen, wo durch gehäufte Zellteilung ein Büschel von Fäden herauswächst, der sich fächerförmig ausbreitet, so dass die randlichen Fäden eine Strecke weit horizontal, über die Zellen der abgestorbenen Flächen hypothallartig hinlaufen, bis sie sich wieder in mehr vertikale Stellung aufrichten. So enstehen auf alten Stöcken einzelne Äste, die gewöhnlich so lange nur in die Breite wachsen, bis sie mit den anderen Ästen seitlich zusammenstossen. (Siehe 1908, Taf. 4, Fig. 1-4.)

Im Perithall wachsen einzelne der vegetativen Zellfäden zu 60-80 chen aus, die eine Länge von bis $250^{\prime \prime}$ erreichen können. Diese als Sporangien zu deutenden Schläuche liegen stets vereinzelt in dem parenchymartigen Gewebe und zeigen keinerlei Art regelmässiger Anordnung etwa in bestimmten Zonen oder zu konzeptakelähnlichen Häufchen. Diese Art von Sporangienbildung ist sehr häufig und fehlt in grösseren Dünnschliffen nur selten. (Siche Fig. 1 u. 2 und Taf. 4, Fig. 3 u. 5.)

Manchmal ist eine starke Umkristallisation des ganzen Stockes nachträglich eingetreten. In diesem Falle sieht man nur noch stellenweise in dem feinkörnigen Calcitaggregat den Zellbau durch dunkle Linien angedeutet, die das Aggregat ohne Rücksicht auf die Kristallumrisse durchsetzen.

\section{Blatt Vis by:}

\section{Fundorte:}

1) Insel Fårö bei Gammelhamn.

25) Im K. Hörsne im Kanal zusammen nit Spongiostroma, Sol. compacta und Sphaerocodium gotlandicum.

21) Bei Korpklint, K. Vesterhejde, in unteren Teil des oberen Riffkalkes in konglomeratartigem Crinoideenkalk über Mergelschiefer. 
12) bei Visby, Galgberget, mit Spongiostroma und Sol. compacta unmittelbar unterhalb der bekannten Diskordanzfläche.

bei Visby, Vattenfallet, zwischen 18,7 u. $29 \mathrm{~m}$ zusammen mit Splacerocodium gotlandicum, Spongiostroma und Hedströmia hatimedoidea.

16) bei Cementfabrik-Kilinten, Visby, 2-3 m unter der Oberkante.

18 u. 22) im K. Vesterhejde bei Nygårdsbäcken und Suderbys mit Spongiostroma.

19) im K. Vesterhejde bei Hallbros im Megalomuskalk.

19) bei Allehage, K. Vesterhejde, im oberen Girvanellakalk und 12-15 in darunter mit Spongiostroma.

\section{Blatt Roma:}

32) S von Nasume im K. Tofta in konglomeratartigem Kalkstein mit Spongiostroma überzogen und zusammen mit Sphaerocodium gotlandicum.

32) $500 \mathrm{~m}$ nördlich von Nisume im K. Tofta aus »Lefverkalk» mit Eatonia.

70) circa $1 \mathrm{~km}$ südlich von Stenstugu im K. Hejde aus an Coenites reichem Kalkstein zusammen mit Fragmenten von Sphaerocodium gotlandicum.

65) südlich von Tippsarfve im K. Hejde aus Coenites-Kalk.

69) von Sigsarfve im K. Hejde aus dichtem Kalkstein mit Herlströmia(?).

56) südwestlich von Anhalten im K. Viklau aus dichtem Kalkstein mit Spongiostroma und Sphaerocodium gotlandicum.

57) südlich von Olleifs im K. Viklau aus dichtem Kalk mit Spongiostroma und Sphaerocodium gotlandicum.

63) von Klinteberget im K. Klinte aus Kalk mit Pentamerus conchidium und Sphaerocodium Munthei.

Diese Art hat somit auf Gottland eine ähnliche horizontale Verbreitung wie Sol. compacta, denn auch sie ist im südlichsten Gottland noch nicht nachgewiesen. Um so auffülliger mag es erscheinen, dass Reste beider Arten in demselben Handstück nur selten aufzufinden waren, als ob sie getrennte Bezirke bewohnt hätten, in denen sie sich gegenseitig ausschlossen. Am häufigsten sind beide Arten in der oberen Stufe, aber während Solenopora compacta der unteren Stufe nicht fehlt und in anderen Ländern selbst im Untersilur häufig ist, hat sich Solenopora gotlandica bis jetat nur im Profil von Vattenfallet, Visby, schon in der unteren Stufe, aber ziemlich hoch oben bei 18,7 m nachweisen lassen, sonst liegt sie ausschliesslich in der oberen Stufe.

\section{Hedströmia nov. gen.}

Genusdiagnose. Der Thallus besteht aus kettenförmig gegliederten dicho- bis polychotom verzweigten Ästen. Die Glieder sind rundlich und bestehen aus dicho- bis polychotom sich verzweigenden Zellfäden, von denen einige jeweils in die zunächst höheren Glieder übergehen, um sich da von neuem zu verzweigen. Querwände in diesen Zellfüden sind nicht nachweisbar, Fortpflanzungsorgane unbekannt. Dieses in der äusseren 
Erscheinung an Halimeda erinnernde Genus ist auch nach seinem Zellenaufbau am ehesten mit diesen lebenden Codiaceen in Verbindung zu bringen.

\section{1) Hedströmia halimedoidea nov. spec.}

Taf. 3, Fig. $1-6$.

Speziesdiagnose. Die einzelnen Thallusglieder erreichen eine Grösse von bis zu $6 \mathrm{~mm}$ und bestehen aus einem Büschel von Zellfüden, die an der Basis der Glieder entspringen, durch Teilung sich vermehren und radial nach oben ausstrahlen. Mit der Teilung nimmt im allgemeinen der Durchmesser der Fäden ab. Er beträgt an der Basis bis zu 180" und verringert sich nach oben bis auf $50^{\mu}$. Im Tangentialschliff erscheinen die einzelnen Fäden des proximalen Teiles der Glieder deutlich polygonal und liegen dicht nebeneinander. In den distalen Teilen tritt mit zunehmender Verschmälerung zugleich eine etwas regellosere Anordnung der Fäden ein. Ihre dicho-bis polychotomen Verzweigungen laufen mehr geflechtartig durcheinander und es treten auch durch Fusionen benachbarter Füden stellenweise Anastomosen ein. Einige der breiteren Fäden laufen von dem proximalen bis zu dem distalen Ende in axialer Richtung durch das ganze Glied und diese sind es, die in das nächstfolgende oder bei Dichotomie in die zwei nächstfolgenden Glieder übertreten.

Nicht selten sind vereinzelte Glieder in Spongiostroma-oder Sphaerocodium-Knollen eingeschlossen. Es scheint, dass sie sich auf deren früherer Oberfläche angesiedelt hatten und dann von der Seite her überwuchert wurden, bevor sie Zeit fanden, weitere Glieder zu entwickeln. Auch sonst finden sich in den Kalksteinen häufig einzelne isolierte Glieder von Hedströmia, die aber nicht an Ort und Stelle gewachsen, sondern als Detritusmaterial dorthin verschleppt worden sind. Anscheinend haben diese Algen stellenweise den Boden des Silurmeeres in grossen Mengen rasenartig besiedelt und so zur Bildung von Hedströmiakalken geführt. Sie bedurften reines Wasser und kommen deshalb in Sandsteinen und Mergeln nicht vor. Sie bekleideten die Korallenriffe, wobei die jungen Pflänzchen häufig von den mit ihnen konkurrierenden Sphaerocodien und Spongiostromen vor der Zeit durch Überwucherungen getötet wurden. Die ausgewachsenen Pflanzen wrirden nach ihrem Tode von der Brandung oftmals zerbrochen und einzelne Glieder verschleppt, die so zum Aufbau des Detrituskalkes ihren Beitrag geliefert haben.

\section{Blatt Visby:}

\section{Fundorte:}

6) K. Lummelunda, bei Storbrut mit Spongiostroma.

Visby, am häufigsten ist diese Pflanze bis jetzt in der Umgebung von Visby gefunden worden, wo sie zusammen mit Spongiostroma vorkommt. Im Profil von Vattenfallet (14) tritt sie erst von $28 \mathrm{~m}$ Höhe an auf, also mit Beginn der oberen Gottlandstufe. Andere Fundorte von dort sind Järnvägsklinten (15), Galgberget (12), Bingerskvarn (11), Visborgs slätt (17), Allehage (19), Allehagebysen (23), Hästnäs (8).

25) K. Hörsne, am Hörsne kanal mit Spongiostroma, Sol. gotlandica und Sol. compacta. 3-131048. S. G.U. Ser. Ca, N:o 10. Rothpletz, Obersilur. Kalkalyen etc. Gottlands. 
Blatt Roma:

29) K. Tofta, bei Norrgåda mit Spongiostroma und Sphaerocodium gotlandicum.

30) 》 nördlich von Nasume. Zahlreiche Hedströmia-Äste, dazwischen Sphaerocodium-Fetzen. Ist ein schon mit der Lupe erkennbarer Hedströmiakalk.

33) 》 $400 \mathrm{~m}$ südwestlich von Rangvalds, abgerollte Ast-Bruchstücke.

34) 》 südsüdwestlich von Kroks (südwestlich von Rangvalds) in Kalksand abgelollte Hedströmia-Äste.

54) K. Sjonhem, südwestlich von Sjonhems backe mit Spongiostroma und Solenopora compacta.

51) 》 nördlich von Hellinge in Leperditiaschiefer über dem Spongiostromahorizont, zusammen mit Stromatoporiden und Spongiostroma.

55) K. Viklau, bei Vikarfve in mergeligem Ilioniakalk in Symbiose mit Sphaerocodium und Spongiostroma.

68) K. Hejde, $700 \mathrm{~m}$ südlich von Hejde Kirche in Kalkstein mit Pentamerus conchidium. In Symbiose mit Spongiostroma und Sphaerocodium.

64) K. Klinte, $350 \mathrm{~m}$ südlich von Klinte Kirche Bruchstücke von Hedströmia zusammen mit Spongiostroma-Knollen und Dentalina.

112) K. När, N von Folka in Mergelkalkstein mit Spongiostroma.

\section{Blatt Hamra:}

141) K. Öja, bei Barkarfve im Ostrakodenkalk mit Spongiostroma.

142) K. Vamlingbo, nördlich von Sibbjens im Ostrakodenkalk mit Spongiostroma.

Diese Art ist somit über den grössten Teil der Insel Gotland ausgebreitet. Soweit deren stratigraphische Stellung bekannt ist, gehören alle Fundstellen der oberen Gottlandstufe an.

2) Hedströmia bililosa nov. spec.

Taf. 2, Fig. 56-68.

Diese Art unterscheidet sich von der vorhergehenden sehr deutlich. Der Thallus besteht zwar auch aus einzelnen gegliederten Ästen, aber die Glieder sitzen mehr rasenartig übereinander, und bilden so kuchenartige Stöcke. Die einzelnen Glieder erreichen etwas grössere Dimensionen wie bei H. halimedoidea. Doch ist es schwer, eine richtige Vorstellung von dem Äusseren der Pflanze zu gewinnen, da mir Überreste nur in vier Dünnschliffen vorliegen, die alle von einem einzigen Gesteinshandstück stammen. Die Struktur der Glieder ist dadurch charakterisiert, dass an ihrem Aufbau zwei Arten von Zellfäden teilnehmen. Im Tangentialschliff gewahrt man infolgedessen zwischen den grösseren rundlich-polygonalen Zellquerschnitten, deren Durchmesser zwischen 85 u. 180" schwankt, feinere Zellen, die nur $18-36^{\prime \prime}$ messen. Die grösseren Fäden teilen sich wicderholt und nehmen dabei an Breite ab. Aber diese Abnahme ist weder regelmässig noch so bedeutend wie bei $/ /$. halimedoidea. Die Seitenwände haben ausserdem keinen so regelmässigen Verlauf, dass die Fäden im Längsschnitt wellig an- und abschwellen. Die feineren Fïden laufen zwischen den anderen dahin. Es war mir nicht möglich festzustellen, ob sie unabhängig von den grösseren sind oder ob sie, was mir wahrschein- 
licher ist, aus diesen hervorgehen. An manchen Stellen sieht man nämlich, dass von den grossen Fïden durch Teilung schmälere sich abzweigen, ausserdem aber sieht man häufig auch Anastomosen, wodurch sowohl die grossen als auch die kleinen Fäden netzförmig miteinander in Verbindung treten. Besonders auffällig ist, dass bei Vertikalschliffen die distale Randzone eines jeden Büschels durch das Torherrschen des feineren Fadengeflechtes ausgezeichnet ist, und dass in dieser Zone ein vollstandig regelloser Verlauf der Fïden zu herrschen scheint. Polychotome Teilung scheint stärker als bei H. lualimedoidea rorzuherrschen. Doch macht sich wie bei dieser Art auch hier im axialen Teil jeden Gliedes ein Strang dickerer Fäden deutlich bemerkbar. Der in Fig. 6 abgebildete Ast ist doppel so breit als die in Fig. 5 dargestellten. Ich vermute jedoch, da alle aus demselben Handstück stammen und auch den gleichen Zellaufbau haben, dass auch dieses Stïck derselben Art angehört, die vielleicht die Eigentümlichkeit besass, an den oberen Teilen ihrer Zweige grössere Glieder zu bilden. Weiteren Funden muss die Entscheidung vorbehalten bleiben.

Fundort: Acker NW von Dibjers backe im K. Hörsne (26). Der Gesteinsblock enthält neben der Hedströmia noch viele Knollen von Sphaerocodium gotlandicum, welches die beschriebenen Hedströmia-Stöcke zum Teil ganz umwachsen hat. Spongiostroma hingegen fehlt völlig. Ich vermute deshalb, das es sich um einen Block aus dem unteren Girvanellakalk handelt und dass Hedströmia bifilosa der unteren Gottlandstufe angehört, also älter wie $H$. latimedoidea ist.

\section{Sphaerocodium Rothpletz.}

\section{1) Sphaerocodium gotlandicum Ro'HP.}

Taf. 4, Fig. 1-2, Taf. 7, Fig. 3 und 1908, Taf. 1, Fig. 5-6 und Taf. 2, Fig. 1-4.

Diese Art habe ich 1908 auf Stücke gegründet, die G. Horm von Ronehamn und von Tidemans bei Hörsne gesammelt hat. Ich besass im ganzen nur 5 Dünnschliffe; denn die meisten der mir von Houm übergebenen Stücke und Schliffe von »Girvanella» erwiesen sich als zu Spongiostroma gehörig. Inzwischen hat mir das neue Material der schwedischen geologischen Landesanstalt inindestens 15 mal soviel Schliffe von Sphaerocodium gebracht und so bin ich jetzt imstande, eine genauere Artbeschreibung zu geben, die ineine früheren Angaben in einigen Punkten berichtigt, die ich übrigens schon in der Beschreibung des oberdevonischen Sphaerocodium Zimmermanni erwähnt habe. (Jahrb. Preuss. Geol. Landesanstalt 1911, Bd. XXXII, S. 112.)

Speziesdiagnose. Die Alge wächst stets auf fremden Körpern, die sie inkrustiert und schiesslich allseitig umschliesst. So entstehen Knollen von verschiedenster Form und Grösse, je nach der Natur des eingeschlossenen Fremdkörpers. Im allgemeinen sind die Algenknollen rundlich und können bis $5 \mathrm{~cm}$ dick werden. Ist aber der Fremdkörper' ausgesprochen länglich, z. B. ein Stock von Ptilodictya lanceolata, dän erhalten auch die Knollen eine längliche, mehr walzenförmige Gestalt. (Siehe Abbildung bei Muntue, l. c. 1910, fig. 2.) Der inkrustierende Algenkürper erreicht keine sehr grosse Dicke. Als Maxi- 
mum habe ich $1^{1 / 2} \mathrm{~cm}$ gemessen; die Oberfläche der Knollen ist nierenförınig gewellt, oder wächst sich zu kurzen, gedrängt stchenden Ästchen aus. In der äusseren Form erinnern die Knollen sehr an gewisse Lithothamnium-Knollen. Im Querbruch gewahrt man schon mit blossem Auge eine unregelmässig konzentrische Struktur, welche die Art des Wachstums dieser Pflanze erkennen lïsst.

Innere Struktur. Der Algenkörper besteht aus einem dichten Geflecht verkalkter Zellfäden, die so dünn sind, dass sie erst in feinen Dünnschliffen erkannt werden können. Es lassen sich drei Arten von Fäden unterscheiden. Die feinsten derselben messen nur 6-8" in der Breite (Taf. 4, Fig. 1). Ich habe sie früher zwar nicht übersehen, aber ich war so unsicher über ihre Natur, dass ich sie nicht erwähnt habe. Die gröberen Fäden sind $14-18^{\mu}$ breit, also ungefähr doppelt so breit wie die feineren. Aus Versehen habe ich 1908 angegeben, sie hätten die gleichen Dimensionen wie bei Sphaerocodium Bornemanni. Bei dieser triasischen Art haben die Fäden aber nur einen Durchmesser von 4$8^{\prime \prime}$ und im Durchschnitt $6^{\prime \prime}$, sind also ungeführ so fein wie die feinsten bei $S$. gotlandicum. Jene zwei Arten von Faden, die sich beide dichotom verzweigen, liegen in dünnen miteinander abwechselnden Lagen übereinander. Aber häufig sieht man vereinzelte dickere Fäden auch inmitten der feineren liegen. Ob jene aus diesen hervorgehen, oder ob beide Formen selbständig neben einander fortwachsen, darüber konnte ich keine Klarheit gewinnen. Aber sicher bleibt, dass das Grundgewebe dimorph ist.

Die Endzellen sind 25-40" breit, verbreitern sich durch Dichotomie, die oft in Polychotomie übergeht, zu fingerförmigen Gebilden, die man als solche in Tangentialschliffen gut beobachten kann, während sie in vertikalen Schnitten als perlschnurartige Zellfäden erscheinen, weil sie ganz allgemein nur auf der jeweiligen Oberfläche der Algenknolle flach fächerförmig ausgebreitet liegen. Nur in ganz wenigen Fällen, von denen Fig. 2 eine Abbildung gibt, konnte ich bis 500" lange und bis 50" dicke Schlauchzellen innerhalb des Endzellengewebes erkennen, die vielleicht als Fortpflanzungsorgane anzusehen sind, während die gewöhnlichen Endzellen der Assimilation dienten.

Die Verkalkung hat diese drei Formen von Fäden nicht immer gleich stark betroffen, oder sie hat sich nach dem Tode der Pflanzen nicht gleich gut erhalten. Häufig ist es, dass in Dünnschliffen die gröberen Fäden des Grundgewebes sehr gut zu sehen sind, nicht aber die feineren und auch nicht die Endzellen. Man kann daraus vielleicht den Schluss ziehen, dass die gröberen Fäden die Funktion von Stützorganen (Verfestigungsgewebe) hatten und deshalb stärker verkalkten als die anderen Fäden.

Weitere Unterschiede machen sich nach der Richtung geltend, dass bei manchen Stöcken die Endzellen in überreicher Menge entwickelt sind, in anderen aber nur sehr wenig, ferner, dass das Grundgewebe über dem Substrat oft sehr mächtig wird, ehe Endzellen sich einstellen, während anderwärts diese fast auf dem fremden Substrat aufliegen, so dass kaum Platz für das Grundgewebe bleibt.

Häufiger noch als bei Solenopora haben sich auf den Knollen fremde Organismen angesiedelt und damit deren weiteres Wachstum gehemmt. Aber auch da ist es der Alge oft genug gelungen, von der Seite her den fremden Gast zu überwältigen und in sein Gewebe ganz einzuschliessen. Am merkwürdigsten aber ist das Verhältnis, in dem Sphaerocodium zu Spongiostroma stand. Diese beiden Organismen haben in vielen Fallen zu- 
sammen am Aufbau von Knollen gearbeitet. Lagen von Spongiostroma und von Sphaerocodium wechselten mitcinander ab und umschlossen sich infolge dessen so innig, dass man an eine Symbiose denken kann. Doch lässt sich eine derartige intime Beziehung beider Organismen nicht beweisen, da sie viel häufiger vereinzelt als zusammen vorkommen, und die Sphaerocodien sogar auf Gottland schon lange Zeit gelebt hatten, ehe die Spongiostromen einwanderten (Tafl. 7, Fig. 3). Wenn ich also bei den Fundortsangaben kurzweg von Symbiose spreche, will ich damit nur die 'Tatsache dieser innigen Verwachsung: andeuten.

Mit Bezug auf ihr Substrat waren die Sphaerocodien nicht wählerisch. Es gibt kaum eine fossile Art, um die sie sich nicht gelegentlich angesiedelt hätten. Aber am merkwürdigsten ist es, dass sie sich gar nicht selten um ein Haufwerk von Oolithen herungesponnen und dasselbe sackförmig eingeschlossen haben.

\section{Blatt Visby:}

\section{Fundorte:}

3) K. Hall, bei Hallshuk. „Unt. Girvanellabank.» Untere Stufe.

16) Visby, Cementfabrik 2-3 rn unter der Klintkante.

19) K. Vesterhejde, Allehage, »ob. Girvanellakalk» mit Spongiostroma und aus Leperditiaschiefer mit Spongiostroma. Obere Stufe.

21) bei Korpklint aus konglomeratartigen Crinoideenkalk $10 \mathrm{~m}$ über Mergelschiefer.

20) \ $\quad$ von Ygne mit Spongiostroma. Obere Stufe.

26) K. Hörsne, bei Dibjers backe nit Hedströmia bifilosa bei Tidemans.

25) 》 Kanal mit Spongiostroma. Obere Stufe.

\section{Blatt Roma:}

48) K. Dalhem, bei Dunegårda im Kalk mit Pterinea. Obere Stufe.

50) K. Ganthem, W von d. Kirche Kalkstein mit Spongiostroma. Obere Stufe.

28) K. Tofta, oberhalb Blåhäll. Mergeliger Kalkstein, c:a 24 in ob. d. Meeresspiegels. Untere Stufe(?).

31) 》 von Nasume mit Spongiostroma. Obere Stufe.

30) 》 nördlich von Nasume mit Hedströmic. Obere Stufe.

29) 》 $400 \mathrm{~m}$ nördlich von Norrgårda mit Spongiostroma. Obere Stufe.

27) 》 Stafsklint mit Spongiostroma von den oberen Klinten. Obere Stufe.

33) 》 SSW von Rangvalds feinoolith. Kalkstein mit Spongiostroma und Solenopora gotlandice. Obere Stufe.

38) 》 bei Östergårda. Dichter bis feinkristallin. Kalkstein. Obere Stufe.

73) K. Fröjel, südlich von Däpps. Dichter Kalkstein mit Solenopora. Obere Stufe.

64) K. Klinte, bei Klinteberget südsüdöstl. von der Kirche mergel. Kalkstein. Untere Stufe.

64) $\gg 500 \mathrm{~m}$ südl. von der Kirche mergel. Kalkstein c:a $26 \mathrm{~m} \mathrm{ob.} \mathrm{d.} \mathrm{Meeressp.}$ mit Siphoneen. Untere Stufe.

62) $》$ Klintebys, aus Oolith über Kalksandstein. Untere Stufe. 
70) K. Hejde, am Weg $1 \mathrm{~km}$ südlich von Stenstugu aus Kalkstein reich an Coenites und mit Solenopora gotlandica. Obere Stufe.

66) $\gg \quad$ östl. von Muntsarfve aus Pentameruskalk mit Solenopora compacta und Spongiostroma. Obere Stufe.

68) 》 $700 \mathrm{~m}$ südl. von Hejde Kirche Kalkstein mit Pentamerus conchidium. Obere Stufe.

67) » östlich von Qvie in Symbiose mit Spongiostroma und mit Solenopora compacta. Kalkstein. Obere Stufe.

47) K. Roma südöstl. von Larsarfve mergeliger Kalkstein mit Leperditia baltica (pectinata). Untere Stufe.

55) K. Viklau, von Vikarfve mit Hedströmia und in Symbiose mit Spongiostroma. Kalkstein. Obere Stufe.

55) 》 von Vikarfve im »Ostrakodenkalk». Obere Stufe.

56) » südwestl. von Anhalten dichter Spongiostromenkalk mit Solenopora gotlandica. Obere Stufe.

58) K. Guldrupe, Kalkstein vom Kanal N von d. Kirche. Obere Stufe.

57) K. Vänge, südlich von Olleifs im K. Viklau Kalkstein mit Spongiostroma und Solenopora gotlandica. Obere Stufe.

101) K. Hafdhem, südöstl. von Korsby. Mergel. Kalkstein. Untere Stufe.

100) K. Alfva, 1,2 km südsüdwestl. von Binge aus d. unter. Sphærocodiumlager. Untere Stufe.

99) $\quad 700 \mathrm{~m}$ nordwestl. von Kruse aus Mergelschiefer. Untere Stufe.

104) K. Rone, Kanal nördl. von Halor. Aus Mergelschiefer mit Kalkbändern. Unterste Stufe.

106) K. Burs, Luxe, Kalkstein über dem Dayialager. Untere Stufe.

108) 》 von Bondarfve Riffkalk mit Spirifera Schmidtii nahe über der Dayiabank. Untere Stufe.

107) 》 Rippsården im Mergelkalk. Untere Stufe.

109) » Jugennes im Rhizophyllumkalk. Untere Stufe.

102) K. Eke, NO von Djupkroks fiskeläge. Untere Stufe.

110) K. När, N von Hemmor in mergeligem oolithischem Kalk.

114) 》 bei Frigges Kalkstein mit Oolithen (über den Dayiamergeln?). Untere Stufe.

111) 》 Kapelludden. Oolithischer Kalkstein. Untere Stufe.

116) 》 SO von Mickels. Mergeliger Riffkalkstein. Untere Stufe.

117) 》 $\mathrm{O}$ von Hallbjenne. Mergeliger Riffkalkstein. Untere Stufe.

\section{Blatt Hamra:}

130) K. Hafuhem, Hejdslunds im Mergelkalk. Untere Stufe.

131) K. Grötlingbo, bei Dals. Oberer Sphoerocodiumkalkstein. Obere Stufe.

133) " Kattlunds. Oberer Sphaerocodiumkalkstein mit Spongiostroma. Obere Stufe.

135) 》 S von Lotsstation, Grötlingboudd. Obere Stufe.

137) 》 Grötlingboudd. 
136) K. Grötlingbo, Kråkskärr, Grötlingboudd, O von Lotsstation. Oberer Sphaerocodiumkalkstein mit Spongiostroma. Obere Stufe. Roms kvarn in feinoolithischem Kalkstein.

134) 》 am Südstrand des Grötlingboudd im Beyrichienkalk. Obere Stufe. 138) K. Näs, bei Sigleifs im unteren Sphaerocodiummergel. Untere Stufe.

144) K. Sundre, Hoburgen SW in oolithischem Konglomerat oberhalb d. Oolithe und Krinoidenkalkstein. ${ }^{1}$

Man sieht aus diesem Verzeichnis, dass diese Art äberall in Gottland anzutreffen ist, ron der nördlichsten Spitze dieser Insel bis zur südlichsten und dass sie, ohne Rücksicht auf die Gesteinsbeschaffenheit durch beide Stufen hindurchgeht. In den oberen Horizonten der oberen Stufe wird sie allerdings seltener und in den Cephalopoden-Schichten habe ich sie überhaupt gar nicht nachweisen können. In der unteren Stufe tritt sie häufig in einem bestimmten Lager in ungeheuren Mengen grosser Knollen auf. Dieses Lager wurde früher von Muntie als unterer Girvanellahorizont bezeichnet. Der sog. obere Girvanellahorizont führt zwar hauptsächlich Spongiostromenknollen. Doch fehlen auch da die Sphaerocodien keineswegs und stehen mit den ersteren sogar in einer Art ron symbiotischem Zusammenhang. Gleichwohl sind sie hier seltener und nehmen weiter nach oben so lange an Zahl ab, bis sie endlich ganz verschwinden.

Auch in den oberen Wenlockschichten Englands kommt diese Art vor. WeTineren hat 1893 (Journ. Geol. Soc. London, Vol. 49, S. 236, auf Tafel 6, Fig. 4 b) eine Abbildung gegeben, die vollkommen die fächerförmigen Endzellen unserer Art wiedergibt. In Figur 1 u. 5 sind solche Endzellen im Vertikalschnitt getroffen, während Figur 4 a und 3 die gröberen Zellfüden des Grundgewebes zur Darstellung bringt. Ich stimme Wetheren darin bei, dass die grösseren $0,1-0,14 \mathrm{~mm}$ dicken Röhren, die in Figur 1 u. 2 die Sphaerocodiumfäden umhüllen, nicht zu diesen gehören und ich vermute, dass sie ïberhaupt nicht pflanzlicher Natur sind. Diese von WeTheren als Girvanella problematica. beschriebenen Formen stammen aus der Umgebung von May Hill in Gloucestershire und von Purley in der Nühe von West Malvern und sie sind somit mit denjenigen der unteren Stufe Gottlands ungefähr gleichalterig. Ob diese Art auch im Obersilur von Schonen vorkommt, weiss ich nicht, da ich die von SToLley 1894 von dort erwähnten Girvanellaknollen nicht untersucht habe.

\section{2) Sphaerocodium Munthei nov. spec.}

Taf. 4, Fig. $3-6$.

Speziesdiagnose. Diese neue Art unterscheidet sich vom S. gotlandicum dadurch, dass das Grundgewebe nicht dimorph ist. Die Zellfäden haben eine Breite von 12-25" und im Durchschnitt von $18^{\prime \prime}$. Sie sind also etwas breiter als bei $S$. gotlandicum, aber zugleich unterscheiden sie sich noch dadurch, dass die dichotome Teilung in kürzeren Intervallen als bei $S$. gotlandicum eintritt, was zu einer fächerförmigen Ausbreitung führt, die grosse Ähnlichkeit mit derjenigen bei den Endzellen der S. gotlandicum hat. Die

1 Siehe Abbildung bei Munthe, 1. c. Fig. 19. 
wirklichen Endzellen der neuen Art sind 30-80" breit und übertreffen darin diejenigen von S. gotlandicum ganz erheblich. Ausserdem ist die fücherförmige Teilung unregelmässiger und die letzten 'Teilungsglieder schwellen zu grossen bis $120^{\prime \prime}$ breiten schlauchförmigen Säcken, den wahrscheinlichen Fortpflanzungsorganen, an.

Es ist somit nicht schwer, die beiden Arten im Dünnschliff auseinander zu halten. Aber in der äusseren Form der Knollen habe ich einen Unterschied nicht finden können.

Blatt Visby:

\section{Fundorte:}

12) Visby, von Galgberget, südlich vom Galgen, $11 \mathrm{~m}$ unter dem Platean (also wahrscheinlich aus der unteren Gottlandstufe).

20) K. T'esterhejde, S von Ygne zusammen mit Spongiostroma in Symbiose. Obere Stufe.

19) $\gg$ von Allehage, westlich vom Schloss, zusamnien mit Sphaerocodium gotlandicum.

25) K. Hörsne, in Kanal westlich von der Brücke gerade vor der Windmühle aus dem unteren Teil des Riffkalkes mit Stromatopora.

\section{Blatt Roma:}

49) K. Hörsne, westlich von Bunna aus oolithischen Kalkstein, der grosse Knollen von Sphaerocodium Munthei einschliesst.

27) K. Tofta, südlich von Stafsklint aus kristallin. Kalkstein mit Atrypa Angelini, c:a $20 \mathrm{~m}$ oberhalb d. Meeresspiegels. (Cfr Muntue, l. c. 1910, p. 1439.)

46) K. Mästerby, vorn Kanal nordöstl. von Bander aus mergeligem Kalk mit Leperditia baltica (pectinata) der unteren Gottlandstufe.

118) K. Lau, vom Lauhügel in Ilioniakalk, zusammen mit Spongiostroma. Obere Gotlandstufe.

118) 》 von ebenda mit Spongiostroma.

Daraus ergibt sich, dass diese Art auf Gottland zeitlich ungefähr dieselbe Verbreitung wie Sphaerocodium gotlandicum hat, dass sie aber erheblich seltener ist.

3) Sphaerocodium-Fetzen unbestimmbarer Art.

In etwa 70 Dünnschliffen aus dem gottländischen Silur ist es mir bisher gelungen, die Sphaerocodienreste der Art nach entweder als S. gotlandicum oder als S. Munthei zu bestimmen. Aber ausserdem kommen sehr häufig in den Kalksteinen kleine Fragmente dieses Algengeschlechtes vor, die eine Artbestimmung nicht zulassen, wennschon ïber deren Zugehörigkeit zu dem Genus kein Zweifel besteht. Ich fand solche ausser in den schon erwähnten 70 in weiteren 54 Schliffen, die ich ebenfalls aufzählen will. Denn sie beweisen, dass die Sphaerocodienknollen des gottländer Silurmeeres schon zu Lebzeiten oder mindestens kaum nach ihrem Tode vielfach zerstückelt worden sind, und dass kleine Fetzen derselben von den Strömungen des Meeres weithin verfrachtet wurden, bis sie irgendwo eine Ruhestätte in Sedimenten fanden, an deren Autbau jene Kalkalgen direkt gar nicht beteiligt waren. 
Es ist dabei beachtenswert, dass diese kleinen Fetzen, die oft nicht einmal den Durchmesser von $1 \mathrm{~mm}$ erreichen und bald wie abgerollte Sandkörner, bald als ganz unregelmässige Körner erscheinen, stets gegen ihre Ungebung scharf abgegrenzt sind. Ihre Struktur ist genau dieselbe wie in den grossen Sphaerocodienknollen, doch enthalten sie wegen ihrer Kleinheit gewöhnlich nur eine der verschiedenartigen Gewebearten und sind deshalb spezifisch nicht bestimmbar. Bald zeigen sie nur ganz feine oder gröbere Röhrchen, wie sie dem Grundgewebe entsprechen, bald nur perlschnurartige oder fächerförmige Endzellen. Sie erweisen sich somit als Fragınente und als Fremdkörper innerhalb des Haufwerkes anderer Organismen, welche den Kalkstein aufbauen. Am Rande der Körner enden die Zellfäden dieser Fragmente ganz unvermittelt, und niemals hat die Pflanzenstruktur eine ursächliche Beziehung zu der äusseren Form der Fetzen, wie dies auch bei gevaltsam abgerissenen und bei ihrem Transport noch weiter verstümmelten Bruchstücken nicht anders zu erwarten ist. Diese Zertrümmerung der festen Algenknollen ist voraussichtlich in derselben Weise erfolgt, wie wir dies in den Meeren der Gegenwart erleben. Bohrende Organismen, deren Spuren sich ja auch im Silur Gottlands haben nachweisen lassen, oder Tiere, welche die noch lebende Oberfläche der Algenkugeln abweideten, die Wogen der Meeresströmungen, der Ebbe und Flut und der Stürme konnten zur Silurzeit ebenso gut wie heute ihre zerstörenden Wirkungen ausüben, denn der Boden des Gottländer Meeres lag nicht tief, wie der Reichtum an Algen zur Genüge beweist.

\section{Blitt Roma:}

\section{Fundorte:}

48) K. Dalhem, von Dunegårda aus grossoolithischem Kalkstein über dem Pterinea-Kalk. 30) K. Tofta, nördlich von Nasume in Hedströmia-Kalk. Obere Stufe.

33) 》 $400 \mathrm{~m}$ südwestlich von Rangvalds mit Hedströmia. Obere Stufe.

30) : 500 in nördlich von Nasume mit Solenopora gotlandica und Eatonia. Obere Stufe.

36) 》 ron Sallmunds. Obere Stufe.

27) „ südl. von Stafsklint, aus Kalkstein in Mergelschiefer, 15 bis $16 \mathrm{~m}$ oberh. des Meeres, mit Spirifera exporrecta. Untere Stufe.

42) K. Träkumla, Kanal bei Anglarfve. Mergeliger Kalkstein. Untere Stufe.

41) K. Stenkumla, nördlich von Sojvide.

44) K. Eskelhem, südlich von Rovalds aus Mergelschiefer mit Pentamerus tenuistriatus. Untere Stufe.

45) " südlich von Valfva aus Mergelschiefer mit Siphoneen und Leptaena transversalis. Untere Stufe.

43) 》 Kanal von Blötmyr, SW von d. Kirche, Mergelschiefer. Untere Stufe.

59) K. Väte, Gullarfve. Oolithischer Kalkstein über dem Sandstein. Untere Stufe.

61) K. Klinte, nördlich von Verldsände. Mergel. Kalkstein zwischen flintführendem Kalkstein. Untere Stufe.

61) Verlds ände aus mergeligem Kalk. Untere Stufe.

63) Klinteberget.

63) 》 Klinteberget NW, in Pentamerus-Kalkstein.

4-131094. S. G.U. Ser. Ca, N:o 10. Rothpletz, Obersilur. Kalkalgen etc. Gottlands. 
72) K. Kröjel, von Stenstugu aus mergeligem Kalk mit Whitfeldia tumida. Unitere Stufe.

74) » östlich ron Iulde aus mergeligem Kalkstein über dern Kalksandstein. Untere Stufe.

78) 》 nördlich von Göstafs aus mergeligem Kalkstein.

76) 》 Prestklint aus feinkristall. Kalkstein. Obere Stufe.

76) 》 $800 \mathrm{~m}$ nördlich von d. Kirche, Prestklint, aus feinkristall. Kalkstein. Obere Stufe.

77) \Von d. Terrasse nördlich von d. Kirche aus mergeligern Kalkstein.

77) $》$ Ebenda W von d. Terrasse aus mergeligem Kalkstein.

82) 》 1,3 km südlich von Puser aus mergel. Kalkstein. Untere Stufe.

81) " WSW von Bosarfve aus mergel. Kalkstein. Untere Stufe.

79) 》 IV von Kusarfve aus mergel. Kalkstein. Untere Stufe.

$75) »$ bei Mulde. Kalkiges Band in d. Muldemergel. Untere Stufe.

80) 》 bei Rovide in mergel. Kalkstein. Untere Stufe.

121) K. Etelhem, Klinten südwestl. von Hageby Sumpf. Schwach mergeliger Kalkstein über dem Ascoceraskalk. Obere Stufe, höchster Horizont.

124) " $500 \mathrm{~m}$ nördlich der Kirche. Mergel. Kalkstein. Untere Stufe.

122) 》 von Tänglings aus Ilioniakalk. Obere Stufe.

123) 》 》 $\gg$ Pentameruskalk. Obere Stufe.

95) K. Gerum, von Båtels aus Mergelkalk. Untere Stufe.

94) K. Levede, Kanal ostnordöstlich von Sallmunds aus Kalkstein mit Whitfieldia tumida und Siphoneen. Untere Stufe.

86) K. Eksta, von Långstiteviken aus mergeligem Kalkstein. Untere Stufe.

85) 》 ostsüdöstlich von Kronvalls fiskeläge aus mergeligem Kalkstein. Untere Stufe.

84) 》 nördlich von Hejstäde; der Kalkstein schliesst Fragmente von Siphoneenkalk ein. Untere Stufe.

83) 》 $0,4 \mathrm{~km}$ östlich von Uggårds im Siphoneenkalk. Untere Stufe.

87) 》 Grenze gegen K. Sproge. Untere Stufe.

90) K. Sproge, südwestl. von Bosarfve. Mergelschiefer. Untere Stufe.

91) 》 $500 \mathrm{~m}$ nordwestlich von Bosarfve mit Siphoneen. Mergeliger Kalkstein. Untere Stufe.

97) K. Fardhem, südsüdwestl. von Sandarfvekulle aus mergeligem Kalkstein. Untere Stufe.

98) " Kanal von Visnemyr, kalkige Bänder in Mergelschiefer. Untere Stufe.

120) K. Stånga, Liffride in mergeligem, feinkristallinischem Kalkstein. Untere Stufe.

119) 》 $\mathrm{O}$ von Stångkie Klint.

126) K. Ala, 1 km ostsüdöstlich von Gurfiles aus grossoolithischen Megalomuskalk init Pentamerus. Obere Stufe.

129) K. Östergarn, von Gutenviks aus mergeligem, bräunl. Kalk mit Pleurotomaria planorbis und Ilionia. Obere Stufe.

128) 》 südwestlich von Ganne aus Ostrakodenkalk unter Stromatoporenkalk. Obere Stufe. 
125) K. Ardre, südlich von Torsburgen »Fragmentkalk» über dem unteren Megalomuskalk. Obere Stufe.

111) K. När, südlich von Kulla aus mergeligem Kalkstein.

Beachtenswert ist in dem Verreichnis, dass No. 121 (Etelhem, SW von Hageby Sumpf) aus dem obersten Horizont des Gottländer Silurs stanmt, in welchem spezifisch bestimmbare Sphaerocodien und ïberhaupt irgendwelche Algen bisher nicht nachzuweisen waren.

\section{Gruppe der Siphoneae verticillatae.}

Kialkalgen aus dieser Gruppe hat im baltischen Silur zuerst STOLLEY entdeckt und beschrieben. Er fand sie häufig im unteren, selten nur im oberen Silur. Sie sind so klein, dass sie inakroskopisch sehr schwer bemerkbar werden und auch dann nur, wenn sie in grösseren Mengen beieinander liegen, was aber nicht häufig der Fall ist.

\section{Vermiporella StoL.}

Tafel 7, Fig. 1-2.

Von dieser Gattung habe ich nur ein $3 / 5 \mathrm{~mm}$ langes und $1 / 5 \mathrm{~mm}$ breites gekrümmtes Röhrchen mit deutlichen Perforationen gefunden. Es liegt in einem Kalkblock von No. 21 (Korpklint im K. Vesterhejde) zusarnmen mit Sphaerocodium gotlandicum (Fig. 1). Die Wände sind $1 / 50 \mathrm{~mm}$ dick, die Kanale sind im Querschnitt rund und haben einen Durchmesser von etwa $1 / 100 \mathrm{~mm}$. Die $\mathrm{W}$ and selbst besteht aus einem unregelmässig körnigen Aggregat von Calcit und unterscheidet sich dadurch wesentlich von den Crinoideenskelettresten, die so massenhaft in den Kalksteinen vorkommen (T'af. 9, Fig. 5) und eine oft sehr ähnliche Perforierung zeigen, wobei aber die Wände selbst stets aus einem einzigen Calcitkristalle bestehen.

Die Art ist natürlich unbestimmbar und ich habe dieses Stück nur abgebildet, damit die Aufmerksamkeit bei späteren mikroskopischen Untersuchungen der Gottländer Kalksteine darauf gelenkt werde.

Ein anderes Stück habe ich in Fig. 2 abgebildet. Es stammt $S$ von Klintehamn (60), K. Klinte, aus der unteren Silurstufe. Die perforierte Wand ist dünner als bei dem vorigen Stück, aber ebenfalls unregelmässig geformt. Drei Röhrchen liegen in einer Weise nebeneinander, dass man an ihre Zusammengehörigkeit glauben kann. In diesem Falle würde es sich um eine gegliederte Vermiporella handeln.

\section{Rhabdoporella SToLL.}

Taf. 5, Fig. 1-6.

Sehr kleine gerade im Querschnitt runde Röhrchen kommen in manchen Gesteinen so häufig vor, dass man diese geradezu als Siphoneenkalke bezeichnen kann, in anderen treten sie gegenüber den sonstigen Gesteinskomponenten stark zurück und werden zu- 
weilen sogar ganz selten. In den meisten von mir untersuchten Dünnschliffen fehlen sie aber gänzlich.

Dass diese Röhrchen Kalkhüllen von Siphoneen sind, erkennt man daran, dass sie stets perforiert sind und der Kalk selbst nicht wie bei den Echinodermenresten jeweils ein Calcitkristall (Taf. 9, Fig. 5) ist, sondern aus Fasern besteht, die senkrecht zur Oberfläche der Röhrchen gestellt sind. In Querschnitten erscheint deshalb zwischen gekreuzten Nicols das bekannte dunkle Kreuz. Die Poren sind sehr feine gerade Kanälchen, die von der Innen- nach der Aussenwand gehen. Auf Oberflächenbildern erscheinen sie als kreisrunde, dunklere Flecken, die deutlich im Quincunx stehen. Sie entsprechen also alternierenden Wirteln von Seitenästchen, die aus der breiteren zentralen Zellröhre entspringen. Die längsten dieser Kalkröhrchen, die ich im Dünnschliff messen konnte, überschritten 1,5 mm nicht, meist blieben sie darunter. Ob die Röhrchen nur auscinandergefallene Glieder grösserer Stöcke, oder ob diese Alge ungegliedert war, liess sich durch Beobachtung nicht unmittelbar entscheiden.

Die Tatsache, dass morphologisch ganz gleichartige Querschnitte bedeutende Grössenunterschiede zeigen und dass meist entsprechend der Grösse auch die Breite der Kalkwand variiert, lässt darauf schliessen, dass entweder die oberen und damit jüngeren Glieder der Rhabdoporellenstöcke kleiner waren als die tieferen und älteren, oder dass die Individuen ein und derselben Art in ihrem Breitenwachstum stark variiert haben. Es ist mir nicht gelungen solche Röhrchen zu finden, welche an einem ihrer Enden auf eine Teilung des Zentralkanals nach Art von Cymopolia oder Ovulites schliessen lassen. In vielen Längsschnitten werden die Röhrchen nach beiden Enden zu schı̈̈ler und zugleich schliesst sich die Wand zusammen. Das ist natürlich eine Folge davon, dass der Schnitt die Röhre in einem spitzen Winkel zur Axe getroffen hat. Es bleibt somit ganz unsicher, welche Länge die Röhrchen hatten. Da sie anscheinend zusammengeschwemmt in einem schlammigen Kalk liegen, der ausserden stets noch eine Menge anderer und meist grösserer kalkiger Hartgebilde enthält, so muss man wohl annehmen, dass diese dünnen und sehr fragilen Kalkiöhrchen alle mehr oder minder stark zerłrochen sind, und es ist ganz gut möglich, dass die Pflanze gar nicht gegliedert war, sondern nur aus einzelnen oben geschlossenen feinen Röhrchen bestand.

Für beide Möglichkeiten liegen aus der Gegenwart genügende Analoga vor und wir müssen somit die Entscheidung darüber glücklicheren Fundereren überlassen.

Es lissen sich unter den untersuchten Resten zwei Arten ganz deutlich unterscheiden, die aber beide von der untersilurischen von STOLLEY beschriebenen Art verschieden sind.

\section{1) Rhabdoporella pachyderma nov. spec.}

Fig. $3-6$.

Diese Art unterscheidet sich ron der anderen sowohl als auch von Rhabdoporella baccillum STOLLEY durch die grössere Dicke der Kalkwand. Die längste Röhre dieser Art misst $3 \mathrm{~mm}$, ihre Breite betrügt nur $0,18 \mathrm{~mm}$, aber es gibt auch solche, die bis über $0,4 \mathrm{~mm}$ breit werden. Als Durchschnittsbreite fand ich $0,18 \mathrm{~mm}$, obwohl die Messungen im einzelnen zwischen 0,12 und 0,42 schwanken. 
Auch die Dicke der Wände unterliegt bedeutenden Variationen, die zwischen 0,03 und $0,10 \mathrm{~mm}$ schwanken. Einige Messungen mögen das Verhältnis der Wandstärke zum Röhrchenquerschnitt erläutern.

$\begin{array}{cc}\text { Breite des Querschnittes } & \text { der Wand } \\ 336 & 96 \\ 324 & 100 \\ 240 & 72 \\ 240 & 60 \\ 180 & 36 \\ 132 & 50 \\ 132 & 42 \\ 120 & 36 \\ 120 & 30\end{array}$

Es gibt auch Querschnitte, bei denen der Hohlraum zwischen den dicken Wänden sehr gering und zuweilen fast ganz verschwunden ist. In diesen Fällen gewahrt man gleichzeitig, dass die Porengänge nur z. T. die Wand ganz durchsetzen, während einige von aussen her nur bis in die Hälfte oder ein Drittel der Wand hereindringen und andere, von innen kommend, die Aussenwand nicht erreichen. Im Verhälnis zu dem normalen Querschnitt sind solche selten, aber sie beweisen, dass die Rhabdoporellen sich nach oben wie bei Neomeris geschlossen haben und dass die betreffenden Querschnitte durch dieses distale Ende quer hindurchgehen, wo natürlich der innere Hohlraum immer enger wird und schliesslich ganz verschwinden muss. Ich halte es deshalb für das wahrscheinlichste, dass unsere Rhabdoporella-Art nicht gegliederte, sondern nur einfache, sehr zierliche stäbchenartige Stöcke bildete. Die Perforierung der Schale durch enge Kanäle ist immer deutlich ausgeprïgt. Die Kanäle verlaufen geradlinig und sind sehr eng. Sie scheinen sich aber an der Aussenwand rasch zu erweitern bis zu einen Durchmesser von $12^{\prime}$, während sie in der Röhre selbst meist nur 5-6" weit sind. Gegen innen erweitern sie sich ebenfalls. Ihr Verlauf durch die Seitenwände ist gerade und rechtwinkelig zur Oberfläche der Wand, so dass sie im Längsschnitt alle zueinander parallel liegen, in Abständen von ca. 30". Im Querschnitt und am distalen Ende ändert sich das natürlich, sie haben eine von innen nach aussen divergierende Richtung, Verzweigungen innerhalb der Wand habe ich nie beobachten können und nur einmal sah ich einen Kanal, der in der Mitte der Wandung sich nach beiden Seiten verzweigte. Diese rechtwinkeligen Ábzweigungen erweiterten sich alsbald zu kleinen blind endenden Säckchen, die man als Sporangienräume deuten könnte, wenn sie sich noch öfters beobachten liessen. Dies ist mir aber bis jetzt nicht gelungen.

Eine weitere Eigentümlichkeit ist die, dass nicht allzu selten die Wandungen im Querschnitt auf der einen erheblich dicker als auf der anderen Seite sind. Zwei solcher Querschnitte ergaben folgende Ausmasse:

Querschnittbreite
0,145
0,4

Wanddicke

0,048 und 0,030

$0,1 \quad \gg \quad 0,06$ 
Diese Einseitigkeit entspricht durchaus den Wachstumserscheinungen, wie wir sie von Pflanzen kennen.

Da diese Art stets mit der anderen noch zu beschreibenden zusammen vorkommt, so will ich die Fundorte beider zusammen besprechen.

2) Rhabdoporella Stolleyi nov. spec.

Fig. 1-2.

Diese Art hat mit der von STOLLEY beschriebenen Art aus dem Untersilur eine grössere Ähnlichkeit als R. pachyderma. Sie unterscheidet sich aber doch ganz sicher von jener durch ihre grosse Zierlichkeit.

Rhabdoporella baccillum bildete Röhrchen von über $2 \mathrm{~mm}$ Länge und 0,5 $\mathrm{mm}$ Breite, die Wände sind $0,08 \mathrm{~mm}$ dick und die Poren stehen in Abständen von 0,08 $1 \mathrm{~nm}$. Die Masse für Rhabdoporella Stolleyi sind folgende: Länge bis zu $1^{1 / 2} \mathrm{~mm}$.

Breite der Röhrchen

80

120

130

175

230
Dicke der Wandungen in $\mu$

15

20

18

36

36 .

Daraus ergeben sich zugleich die Unterschiede zu $R$. pachyderma sehr deutlich. Auch die Porenkanäle sind nicht nur viel kürzer, sondern auch etwas breiter wie bei $R$. pachyderma und stehen etwas weiter voneinander ab, aber immer doch nur ungefähr $1 / 2$ so weit als bei $R$. baccillum.

Fundorte (beider Arten):

\section{Blatt Visly:}

14) Vishy, Vattenfallet in 21,95-22,75 m Höhe. Untere Stufe.

12 a) 》 am Strand gefundene Bruchstücke mit Romingeria (siehe unten).

\section{Blatt Roma:}

27) K. Tofta, südlich von Stafsklint in mergeligem Kalkstein mit Spirifera exporrecta und kleinen Sphaerocodium-Fetzen. 15-16 m oberh. des Meeres. Untere Stufe.

35) 》 am Strand von Gnisvärds fiskeläge, Kalkbank im Mergelschiefer mit Holophragma calceoloides. Untere Stufe.

45) K. Eskelhem, südwestlich von Valfva mit Sphaerocodium-Fetzen und Kot. Kalkbank im Mergelschiefer mit Leptaena transversalis. Untere Stufe.

52) K. Sjonkem, S von Petsarfve in kristallinem Kalkstein. Obere Stufe. Siphoneen nicht häufig. 
64) K. Klinte, eirea $500 \mathrm{~m}$ südwestlich von der Kirehe in mergeligem Kalk mit Gesteinsbruehstüeken, die von Spherocodium gotlandicum inkrustiert sind. Siphoneen nieht allzu häufig. Untere Stufe(?).

91) K. Sproge, $500 \mathrm{~m}$ nordwestlieh von Bosarfve in mergeligem Kalkstein mit Sphaerocodium-Fetzen. 》Siphoneenkalk.» Untere Stufe.

88) 》 Alfvegårds in mergeligem Kalkstein. Untere Stufe.

89) 》 südwestlich von Snoder in mergeligem Kalkstein. Untere Stufe.

96) K. Gerum, NO von der Kirehe in kalkigem Platten- u. Mergelschiefer. Untere Stufe.

84) K. Eksta, nordwestlieh von Hejstade in bituminösem Kalkstein mit Sphaerocodium-

Fetzen. Die Siphoneen liegen nur in von dem Kalkstein eingeschlossenen grösseren Gesteinsfragmenten oder Geröllen. Untere Stufe.

83) 》 $0,4 \mathrm{~km}$ östlieh von Uggårds in mergeligem Kalkstein mit SphaerocodiumFetzen. Untere Stufe.

93) K. Levede, Skinnarfve in mergeligem Kalkstein mit Pentamerus cfr Knightii. »Siphoneenkalk.» Untere Stufe.

94) "Kanal ostnordöstlieh von Sallmunds im Kalkstein mit Whitfeldia tumida und Spaerocodium-Fetzen. siphoneenkalk.» Untere Stufe. .

$92) 》 1,6 \mathrm{~km}$ südwestlieh von der Kirehe in mergeligem Kalkstein mit Kot. »Siphoneenkalk.» Untere Stufe.

82) K. Fröjel, 1,3 km südlieh von Puser in mergeligem Kalkstein mit SphaerocodiumFetzen. Untere Stufe(?).

81) 》 südwestlieh von Bosarfve in mergeligem Kalkstein mit SphaerocodiumFetzen. Untere Stufe.

80) 》 bei Rovide in mergeligem Kalkstein mit Sphaerocodium-Fetzen. Untere Stufe.

Die Nummern 91, 93, 94 und 92 können geradezu als Siphoneenkalke bezeichnet werden wegen des Überwiegens dieser gegenüber den anderen Versteinerungen.

In No. 14 und 12 a habe ieh nur Rhabdoporella Stolleyi gefunden, in No. 84 konnte ich nur Rhabdoporella pachyderma nachweisen, sonst aber seheinen überall beide Aiten, wenn aueh in weehselnden Mengen vertreten zu sein. Für No. 12 a ist es bezeichnend, dass die ziemlich häufigen Siphoneen-Röhren alle klein sind und das Grössenmaximum der Art nieht erreichen. Es schliesst dies um so mehr eine Identifizierung mit der untersilurisehen Art Rhabdoporella baccillum aus und sprieht dafür, dass das Gesteinsstüek dem Obersilur Gottlands angehört. Aus der geologisehen Kartenskizze von Muntue (1910) ergibt sieh, dass No. 27, 35, 91, 88, 89, 96, 84, 83, 93, 94, 92, 81 und 80 aus den unteren Mergelsehiehten stammen, die unter den eigentliehen Sphaeroeodiumsehiehten und dem Sandstein Südgottlands liegen. No. 45 mit Leptaena transversalis ist jedenfalls iiter als die Spongiostromasehiehten und nur No. 52 entstammt einem höheren Horizont und möglieherweise auch No. 82, obwohl der mikroskopisehe Befund in dieser Richtung keinen Anhaltspunkt gewährt.

No. 14 endlieh (Vattenfallet bei Visby) stammt sieher aus den Sehiehten, die unter dem Spongiostromalager liegen und nach Henström entspricht die Höhe von 21,95 
-22,75 $\mathrm{m}$ der mittleren Abteilung von Schicht III und wäre somit ebenfalls älter als der Spongiostroma-Horizont IV. Da auch für No. 12 a eine tiefere Lage im Gottländer Silur wahrscheinlich ist, so ergibt sich als Hauptverbreitung für diese Siphoncen (sc. Rhabdoporella) die untere Stufe des gottländischen Silurs. Auffällig könnte es erscheinen, dass die eigentlichen Sphaerocodienbänke bisher keine sicheren Siphoneen geliefert haben. Aber es ist zu beachten, dass bei Klinte (64) ein Zusammenvorkonmen mit SphaerocodiumKnollen konstatiert werden konnte und dass ausserdem in den meisten Siphoneengesteinen kleine Fetzen von Sphaerocodien vorkommen und dass weiter bei Visby die Siphoneen so hoch liegen, dass dieser Horizont mit dem Sphaerocodium-Bed Muntues wohl ungefahr identisch sein dürfte. Bei Visby sind aber noch keine Sphaerocodium-Knollen gefunden worden und daraus darf der Schluss gezogen werden, dass die Sphaerocodienvegetation nicht überall gleichnässig entwickelt war, dass im Silurmeer neben Plätzen, auf denen diese Kalkalge üppig gedieh, weit ausgedehnte Strecken lagen, die ihrer Entwicklung ungünstig waren, und dass in die Sedimente solcher Gebicte von den Sphacrocodienbänken aus nur einzelne Stücke, Bruchstücke oder Fetzen eingeschwemmt wurden.

Den zierlichen Siphoneen hingegen waren gerade diese Strecken günstiger als die eigentlichen Sphaerocodium-Bünke. Indessen darf nicht ausser Acht gelassen werden, dass ihre Überreste, auch wo sie geradezu gesteinsbildend sind (in No. 93, 94, 92), doch alle in zerbrochenem Zustande durcheinander gewürfelt liegen, so dass man nicht von eigentlichen fossilen Siphoneen-Rasen reden kann.

\section{Oolithe.}

Taf. 6, Fig. $1-7$.

Die Oolithe sind im gottländischen Silur sehr häufig, und es gibt Kalkbänke, die fast ganz aus ihnen zusammengesetzt sind. In anderen Kalksteinen treten sie zwar so augenfällig nicht auf, aber in Dünnschliffen gewahrt man sie in Menge zwischen den anderen Versteinerungen eingestreut. Andererseits gibt es auch Kalksteine, in denen sie ganz fehlen. Ein Teil dessen, was man früher ebenfalls zu den Oolithen gerechnet hat, darf heute nicht mehr dazu gestellt werden. Es sind dies die Sphaerocodien- und Spongiostromaknollen, die zwar durch ihre Grösse sofort als etwas besonderes auffallen, deren konzentrische Struktur aber mit blossem Auge von der Oolithstruktur nur schwer zu unterscheiden ist, und wo diese Gebilde zerbrochen und deren Bruchstücke abgerollt worden sind, ehe sie in Kalkstein eingebettet wurden, da ist eine Verwechslung mit echten Oolithen um so unvermeidlicher, da sie gewöhnlich mit diesen zusammen vorkommen.

Über die Entstehung der Oolithe sind die Meinungen geteilt. Die einen halten sic für anorganische, die anderen für organische Bildungen. Will man sie, wie dies in neuerer Zeit besonders Lrnck zu beweisen versucht hat, als chemische Niederschläge des im Wasser gelösten Kalkes auffassen, dann muss man, da eine genügende Menge von Natriumkarbonat dem gottlündischen Silurmeere nicht zugeführt worden sein kann, Ammoniumkarbonat als Fallungsmittel zu Hilfe nehmen, das sich bei der Zersetzung tierischer 
Leichen gebildet haben könnte. Für eine solehe Annahme scheint die ungreheure Menge ron tierischen Hartgebilden zu spreehen, welche in den gottländisehen Kalken vorkommen und die beweisen, dass sich ein reiches Leben in diesem Teile des silurischen Meeres entfaltet hat. Aber dieser Schein ist trïgeriseh, denn unter den fossilen Resten findet man eine Menge von fleiseh- und aasfressenden Tieren, die grösseren Mengren von Tierleichen eine langsame und ungestörte Verwesung nieht gestattet haben können. Um die ungezählten Milliarden von Oolithen zu erzeugen, wäre aber eine sehr grosse Menge von Ammoniumkarbonat, also cin grossartiger Verwesungsprozess erforderlich gewesen. Die Crustaceen aus der Gruppe der Ostraeoden und Trilobiten, deren Schalen in ungeheuren Mengen im Kalkstein erhalten geblicben sind, haben sicherlich das seichte Meereswasser vor einem die reiche Algenvegetation schädigenden Faulnisprozesse bewahrt.

Schwer vereinbar mit einer solchen Fallung des Kalkes ist auch die Gestalt der Oolithe. Sie zeigen die verschiedenartigsten Formen, sind häufig schr klein und rundlich mit konzentrischer und radialer Struktur, oder bilden rosettenartige Kugeln oder »Zwillinge» und »Viellinge», die durch einen gemeinsamen oolithischen Überzug verbunden sind. Ebenso häufig aber auch sind sie länglich oder ganz unregelmässig geformt und ziemlich gross. Sie umschliessen teils ganz kleine Fremdkürper, teils sehr grosse Bruchstücke von Schalen, Echinodermenresten, Korallen, Bryozoen u.s.w. und erscheinen dann trotz ihrer konzentrisehen und radialen Struktur mehr als Inkrustationen denn als Oolithe. lst der umsponnene Fremdkörper im Verhältnis zur Dicke der Inkrustation sehr gross und liat er eine von der Kugel stark abweichende Gestalt, dann tritt seine eharakteristische Form trotz der Uinhüllung noch erkennbar hervor, und man hat es dann mit sogenannten Munien zul tun.

Von den echten mehr oder minder rundlichen, eiförmigen oder auch stäbchenförmigen Oolithen unterseheiden sich diese Mumien sehon äusserlich so auffallend, dass man geneigt sein könnte, sie für eine Bildung cigener Art anzusehen. In Wirklichkeit jedoch sind beide dureh Übergïnge so innig miteinander verknüpft, dass es unmöglich erscheint, eine Grenzlinie zwisehen ihnen aufzuriehten; denn die Struktur ist immer dieselbe. Dünne Lagen liegen übercinander und bedingen die äussere Form dieser Gebilde. Rein konzentrisch kreisförmig sind sie, wenn der Fremdkörper sehr klein ist und dann bilden sic die echten Oolithe (oder Ooide). Manehmal seheint diesen ein zentraler Fremdkörper ganz zu fehlen. Doch ist dies nicht sicher zu erweisen und im Dünnschliff erseheint es nur so, wenn nämlich der Sehnitt das Zentrum nieht getroffen hat. Ist der Fremdkörper grösser und hat er eine etwas unregelmässige Gestalt, dann haben aueh die innersten Schichten des Oolithes eine entsprechend unregelmässige Form. Aber diese wird dureh die nachfolgenden Sehiehten immer mehr ausgeglichen und zuletzt nähert sie sich der Kugelfläche. So erklärt es sieh, dass wir in vielen äusserlich rund erseheinenden Oolithen dennoch im Innern einen ganz anders gestalteten Kern finden. Bei noch grösscren Kernen gelingt aber den Oolithen diese Ausgleichung nieht mehr recht. Bei länglichen geraden Kernen entstehen stäbchenförmige Oolithe, die schon eigentlieh den Namen Ooid nicht mehr verdienen. Bei zunehmender Vielgestaltigkeit und Grösse des Kernes ist es endlich den Oolithen ganz versagt, eine auch nur annahernd rundliche Gestalt anzunehmen, weil die Dieke der Inkrustation zu gering ist. Der Untersehied zwisehen den 5-131049. S. G.U. Ser. Ca, N:o 10. Rothpletz, Obersilur. Kallalgen elc. Gotilands. 
rundlichen echten und den mumienartigen Oolithen ist somit bedingt durch Form und Grösse des eingeschlossenen Fremdkörpers. Es gibt aber auch Oolithe mit mehreren fremden Körpern, von denen einer die erste Veranlassung zur Oolithbildung gegeben hat. Dann haben sich ein zweiter oder auch mehrere Fremdkörper an der Aussenseite angesetzt und sind bei weiterem Wachstum des Oolithes ebenfalls mit eingeschlossen worden, wodurch die äussere Form des ganzen Gebildes wiederum beeinflusst wurde. Dazu kommt noch, dass die einzelnen Schichten des Oolithes sich nicht immer gleichmässig übereinander legen. So entstehen entweder Diskordanzen oder wellige Krümmungen, welche letztere dem oolithischen Querschnitt ein rosettenartiges Aussehen verleihen.

Neben der Schichtstruktur macht sich durch die Anordnung der Kalkspatkristalle eine radiale Struktur bemerkbar, die jedoch im allgemeinen gegenüber der Schichtstruktur zurücktritt, häufig sogar nur ganz schwach angedeutet ist, aber sie kommt nicht nur in den regelmässigen Ooiden, sondern ebenso auch in den extremsten Mumienformen vor. Es ist somit auch in dieser Richtung nicht möglich, ein Unterscheidungsmerkmal zwischen diesen zwei Ausbildungsweisen zu finden und jedenfalls haben beide die gleiche Entstehungsursache.

Ausgehend von der anorganischen Bildungsweise hat man die Annahme gemacht, dass die kleinen Sandkörner inmitten der Oolithe, während der Bildung der oolithischen Umhïllung, im Meere in tanzender Bewegung schwebten. Man will damit rerständlich machen, weshalb diese Kalkniederschläge sich lings un die Fremdkörper in ganz gleicher Teise angesetzt lıaben. Für die grösseren Fremdkörper der Mumien ist die Unwahrscheinlichkeit eines solchen Tanzes so gross, dass man im Ernst davon nicht reden darf, und wie endlich wollte man sich diesen Vorgang für jene Oolithe vorstellen, welche während ihrer Bildung mehrere Fremdkörper eingeschlossen haben? Weder in der Natur noch im Laboratorium hat man Oolithe, sich auf diese Weise bildend, beobachten können und die anorganische Erklärung muss somit als eine rein hypothetische bezeichnet werden. Wenn wir statt dessen nach analogen Vorgängen in der Natur suchen, dann fallen uns im gottländischen Silur sofort die Sphaerocodien auf, die man früher ja auch zu den Oolithen gestellt hat. Sie sind unzweifelhaft pflanzlicher Entstehung, und doch haben diese Inkiustationen, die sich ebenfalls um Fremdkörper herum bilden, mit denen der Oolithe sehr grosse Ähnlichkeit. Wie diese haben die Sphaerocodien einen konzentrischen Schichtaufbau und die Tendenz, um Fremdkörper herum rundliche Inkrustationen zu bilden; aber auch ihnen gelingt das nicht immer. Die Form ihrer Knollen ist deshalb ebenfalls durch die Grösse und Gestalt des fremden Körpers wesentlich beeinflusst. Viele der mumienartigen Gebilde in den silurischen Kalksteinen sehen aus wie oolithische Mumien und es bedarf guter Dünnschliffe, um zu erkennen, dass sie in Wirklichkeit doch Sphaerocodienmumien sind. Hätten sie keine so unverkennbare Pfanzenstruktur oder wäre dieselbe durch Umkristallisation verloren gegangen, so würde man sich vielleicht ebenfalls darüber herumstreiten, ob sie organischer oder rein anorganischer Natur sind.

Diese Formähnlichkeit in Verbindung mit dem Studium der rezenten Oolithe ist für mich entscheidend dafür, die Oolithe des gottländischen Silurs für organische Gebilde zu halten, und dabei können nach meiner Meinung nur einzellige, kalkabsondernde Algen vom Typus der Spaltalgen in Betracht kommen. Alle die geschilderten Formeigentüm- 
lichkeiten der Oolithe und Oolithoide werden mit dieser Annahme nicht nur erklärlich, sonderu eigentlich selbstverstiindlich.

Besonders interessant sind die Sphaerocodium-Beutel (s. auch Muntele's Fïhrer für den internat. Geol. Congress 1910, Fig. 10), welche hunderte von Oolithen einschliessen. Hier (siehe Taf. 6, Fig. 5-6) ist es klar, dass letztere schon fertig gebildet sein mussten, che die Sphaerocodiumfaden sie zu umspinnen begannen. Andererseits aber liegen die Sphaerocodienknollen sclbst in einem Kalkstein, der ganz erfüllt ist von ebensolchen Oolithen wie die, welche in den Beuteln eingeschlossen sind. Die Oolithbildung muss somit gleichzeitig mit der der Sphareocodienknollen vor sich gegangen sein. Und tatsächlich lieferten diese beiden ja auch die hauptsächlichsten Bestandteile für den Kalkstein. Es wuchsen hier Spaltalgen und Siphoneen neben einander und schieden Kalk aus. Das ist jedenfalls leichter verständlich als die Annahme, dass in demselben Gewässer, in dem unter dem Einfluss verwesender 'Tierleichen soviel Ammoniumkarbonat erzeugt wurde, dass der Kalk aller der ungezählten Oolithe niedergeschlagen werden konnte, gleichzeitig eine reiche Siphoneenflora gedieh, welche ebenfalls den Kalk des Meereswassers ausfällte.

Soweit bekannt, scheiden die niederen Algen den Kalk stets in Form von Aragonit, dic höheren Rotalgen dagegen als Calcit aus. Auch die rezenten Oolithe bestehen aus Aragonit, einerlei, ob sie wie die im Golf von Suëz nur konzentrische, oder wie die im Great Saltlake auch radiale Struktur haben. Die fossilen Oolithe hingegen bestehen aus Calcit, und das muss wohl so aufgefasst werden, dass bei ihnen nachträglich eine Umkristallisation eingetreten ist. Darin mag auch der Grund liegen, weshalb die Deutlichkeit der mikroskopischen Struktur bei den fossilen Oolithen, oft sogar bei solchen desselben Dünnschliffes, so erheblichem Wechsel unterworfen ist. Es ist darum sehr schwer zu sagen, wie viel von den Eigentümlichkeiten der fossilen Oolithe ihrer ursprünglichen Beschaffenheit und wie viel ihrer späteren Umwandlung zuzuschreiben ist. Andererseits muss man auch im Auge behalten, dass wahrscheinlich nicht immer Spaltalgen derselben Gattung Oolithe erzeugt liaben und dass dicselben infolgedessen kleine Verschiedenheiten zeigen künnen, die primärer Natur sind. Aber zur Zeit ist es unın̈̈glich, nach dieser Richtung lin verschiedene Oolitharten zu unterscheiden. 


\section{Die Spongiostromen.}

\section{Spongiostroma GÜRICH. ${ }^{1}$}

Taf. 7, Fig. 3.

Ich habe 1908 zwei Arten dieses Genus beschrieben und abgebildet ${ }^{2}$, die sich zwar nicht durch ihre iussere Form, wohl aber durch die verschiedenen Breiten der Coenosarkröhren unterscheiden. Ihre Verschiedenheit ist also nur im Dünnschliff zu erkennen. Beide Arten kommen zusammen im selben Lager vor. Spongiostroma balticum lag mir vor von Limmanda auf der Insel Ösel und von Ronehamn in Südgottland; Spongiostroma Holmi von Lettenholm auf Ösel, von Bingerskvarn bei Visby, von Tidemans im K. Hörsne, sowie vom Kanal unterhalb Lunds in K. Hangvar in Nordgottland.

In dem neuen schwedischen Material habe ich merkwürdigerweise, soweit überhaupt eine spezifische Bestimmung der zahlreichen Knollen und der noch häufigeren Bruchstücke solcher möglich war, fast nur Spongiostroma Holmi nachweisen können. Von S. balticum fand ich bloss bei Sjonhem (Blatt Roma) eine sehr gut erhaltene Knolle zusammen mit Solenopora compacta.

Spongiostroma Holmi ist somit auf Gottland weitaus die vorherrschende Art.

\section{Blatt Visby:}

\section{Fundorte:}

2) K. Fleringe, Vialms mit Solenopora compacta im Girvanellakalk über dem unt. Riffniveau.

3) K. Hall, Houk im Girvanellakalk.

6) K. Lummelunda, Kanal von Lummelunda südl. v. Storbrut mit Hedströmia halimedoidea.

4) K. Hangvar, Kanal unterhalb Lunds.

10) Visby, Galgberget, neuer Bruch, unter der Diskordanz mit Hedströmia halimedoidea und Sol. gotlandica.

9) * Klintkanten mit Hedströmia halimedoidea u. Sol. gotlandica.

11) 》 Bingerskvarn mit Hedströmia halimedoidea.

1 Mémoires du Musée royal d’hist. nat. de Belgique 1906. Les Spongiostromides du Visécn de la pror. de Namur.

2 L. c. 1908 , Taf. 5, Fig. 3-6, Taf. 6, Fig. 1-6. 
14) Visbly, Vattenfallet 29,9-30 m, Konglomerat über Pterygotus.

$31,10 \mathrm{~m}$, mit Hedströmia hatimedoidea u. Sphaerocodium.

31,5 m, mit Hedströmia.

P'rofillager 9, Pterygotuslager mit IIedströmia halimedoidea 11. Solenopora gotlandica.

Kleiner oberster Fall üstl. v. 7:ten Brumnen, mit Hedströnia halimedoidea.

17) 》Visborgs slätt Steinbruch vestl. nit Hedströmia, Solenopora compacta und Vermiporella.

13) 》 Nahe NO von Norderport.

24) K. Follingbo. (Dic Lokalität ist nicht näher bekannt) Megalonuskalk mit Stromatopora.

7) K. Vestlinde, Idholmen.

19) K. Vesterhejde, Hallbros in grauem mergeligem Kalkstein.

19) 》 Allehage in Leperditiaschiefer mit Sphaerocodium gotlandicum, in Girvanellakalk u. in Leperditiaschiefer mit Solenopora gotlandica. Allehage mit Sol. compacta in ob. Girvanellakalk mit Sphaerocodium gotlandicum.

23) 》 Allehagebysen in bituminösem Girvanellakalk.

19)》 $\gg$ Allehage $4 \mathrm{~m}$ unter Klinten SW v. Bassis, mit Sol. gotlandica mehrere Meter unter dem Girvanellakalk mit Hedströmia halimedoidea.

Allehage 3, Niveau mit Hedströmia halimedoidea.

20)》 》 Ygne mit Sphaerocodium gotlandicum u. S. Munthei.

$22) \gg \quad$ Suderbys mit Sphaerocodium gotlandicum.

25) K. Hörsne, Hörsne kanal mit Sphaerocodium Munthei, Solenopora gotlandica u. Hedströmia halimedoidea.

25)» 》 Tidemans, Kanal bei der Kirche mit Hedströmia halimedoidea.

\section{Blatt Roma:}

50) K. Ganthem, WSW von d. Kirche mit Solenopora und Sphaerocodium gotlandicum.

31) K. Tofta, Nasume im Kalkstein mit Sphaerocodium.

29) "Norrgårda mit Sphaerocodium gotlandicum u. Hedströmia halimedoidea.

27) 》Stafsklint mit Sphaerocodium gotlandicum.

30) 》 nördlich von Nasume zusammen mit Hedströmia und Solenopora compacta.

33) 》 südlich von Rangvalds mit Sphaerocodium gotlandicum und Solenopora gotlandica, Kalkschiefer.

39) K. Stenkumla, westnordwestlich von Homa in Kalkstein.

5.3) K. Sjonhem, Kanal nordwestlich von Hallegårda, mergeliger, bituminöser Kalkstein mit Solenopora compacta, Hedströmia halimedoidea. Der Schliff enthält Fragmente von Spongiostroma.

$51) \searrow$ nördlich von Hellinge, Leperditiaschiefer über dem Spongiostromalager mit einzelnen Hedströmia-Büscheln und Stromatoporiden. 
55) K. Viklau, Vikarfve; mergeliger Spongiostromakalk mit Hedströmia und Sphaerocodium in Symbiose.

57) K. Vünge südlich von Olleifs in Viklau mit Sphaerocodium gotlandicum und Solenopora gotlandica.

71) K. Hejde, westsüdwestlich von Väntinge, kristallinischer Kalkstein. Obere Stufe.

66) 》 $\gg$ ötlich von Muntsarfve. Pentameruskalk mit Sphaerocodium-Knollen und Solenopora compacta.

68) 》 $\gg 700 \mathrm{~m}$ südlich von Hejde Kirche, Kalkstein mit Pentamerus conchidium, mit Sphaerocodium in Symbiose, abgebrochene Äste von Hedströmia halimedoidea.

67) » östlich von Kvie mit Sphaerocodium in Symbiose, Knollen bildend um Solenopora compacta.

64) K. Klinte, $350 \mathrm{~m}$ südlich von Klinte Kirche mit Dentalina.

118) K. Lau, Lau backar mit Sphaerocodium gotlandicum.

108) K. Burs, Bondarfve im Konglomeratsandstein.

112) K. När, nördlich von Folka im Ilioniakalk mit Hedströmiı.

110)» 》 N von Hemmor, Burgen, Kalkstein mit Oolithen u. Splacrocodium.

111) 》 Kulla, im Konglomeratkalkstein mit Sphaerocodium.

115) 》 Närsholm, Glasskär mit Oolithen.

\section{Blatt Hamra:}

139) K. Öja, SW von Sjöboudd jm Ilioniakalk.

141) 》 " Barkarfve im Ilioniakalk mit Hedströmia halimedoidea.

140) 》 „SO von Bergvide im Ilioniakalk mit Sphaerocodium.

143) K. Vamlingbo, bei Storms, S vom Kanal, im Ilioniakalk mit Heclströmia.

Daraus ergibt sich, dass die Spongiostromen auf die oberen Schichten des Gottländer Silur's beschrankt sind und in der unteren Stufe noch nicht vorkommen. Der sogenannte untere Girvanellakalk hat ebenso wie die Dayiaschichten bisher nicht eine Spur von ihnen gezeigt. Sehr häufig hingegen sind die Spongiostromen im sogenannten oberen Girvanellakalk, auch in dem Ostrakodenkalk und gehen sogar herauf bis in den Megalomuskalk. Sie kommen zusammen vor mit Sphaerocodium gotlandicum und S. Munthei, Solenopor a gotlandica und Sol. compacta, Hedströmia und Oolithen. An manchen Orten liegen sie in solchen Mengen beieinander, dass man die betreffenden Gesteinslagen früher als Konglomerate bezeichnet hat, weil man die Knollen für Kalkgerölle hielt. Später hat man sie dann irrtümlicherweise mit den Girvanellen zusammengeworfen.

Mit Bezug auf das Wachstum dieser Spongiostromaknollen, hat das erweiterte Untersuchungsmaterial einiges neue gebracht. Früher wusste ich nur, dass Fremdkörper von abgestorbenen Organismen von dem Spongiostroma-Coenosark überwuchert worden sind und nun wie Einschlüsse in den Knollen liegen; ferner, dass auloporaartige tabulate Korallen in symbiotischer Weise innerhalb des Coenosarkes der Hydrozoe init diesem in die Höhe wuchsen. Aus dem neueren Material ergibt sich jedoch mit Sicherkeit, dass auch Lagen und Büschel von Sphaerocorlium, Solenopora und Hedströmia in den Spon- 
giostromaknollen eingeschlossen vorkommen und zwar in einer Weise, die keinen Zweifel darüber lässt, dass diese Pflanzen sich zeitweilig an der Oberfläche des Hydrozoenstockes angesiedelt und ausgebreitet haben, dann aber von der Seite her durch das Coenosark überwuchert wurden. Dieser Prozess bat sich in ein und demselben Stock viele Male wiederholt. Als eine Symbiose im eigentlichen Sinne kann dieses Zusammenvorkommen nicht mit Sicherheit aufgefasst werden, da es sich hierbei vielleicht mehr um Zufalligkeiten handelt, insbesondere bei Solenopora und Hedströmia. Eher könnte man an eine wirkliche Symbiose bei Sphaerocodium denken, dessen in dern Hydrozoenkörper eingeschlossene Lagen so wenig scharf von diesem abgegrenzt sind, dass die Unterscheidung derselben von dem Coenost nur in recht dünnen Schliffen möglich ist und es manchmal schon den Anschein hat, als ob das Perithall der Alge mit dem Coenost der Hydrozoe gleichzeitig sich fortentwickelt habe.

Für die Entwicklung der Sphaerocodien, die ja schon in der unteren Gottlïnder Stufe vorhanden sind, war diese Art von Symbiose jedenfalls keine Notwendigkeit und eher kann man daran denken, dass die Spongiostromen die bei ihrer Einwanderung schon vorhandene ältere Algenflora sich dienstbar machten. Bei den einzelnen Fundorten habe ich das symbiotische Zusammenvorkommen mit Sphaerocodium nur da angegeben, wo es sehr auffallig im Schliffe hervortritt, aber es sind in anderen Schliffen oft ebenfalls Andeutungen eingewachsenen Sphaerocodiengeflechtes von mir beobachtet worden, nur waren sie nicht deutlich genug, um völlige Sicherheit zu erlangen. Und selbst wo solche Andeutungen ganz in einem Dünnschliffe fehlen, ist es doch möglich, dass der betreffende Knollen aus ciner Symbiose hervorgegangen ist, nur dass der Schliff zufällig ausschliesslich Spongiostroma-Coenost getroffen hat.

Zu der 1908 von mir veröffentlichten Figur 5 auf Tafel 6 habe ich zu bemerken, dass darin hauptsächlich Zellbüschel von Hedströmia halimedoidea zur Darstellung gekommen sind, die in einem Knollen von Spongiostroma Holmi eingeschlossen liegen neben einigen Röhren einer tabulaten Koralle.

Spongiostromiden sind bis jetzt nur aus dem unteren Carbon und dem oberen Silur beschrieben. Aber ich vermute, dass ähnliche Körper aus anderen Formationen, die schon längst bekannt und benannt sind, in dieselbe Abteilung der Ifydrozoen gehören. Dies gilt besonders für Haguia sphaerica WALc. ${ }^{1}$ aus dem mittleren Cabrium des Yellowstone Park und vielleicht auch für das praecambrische Cryptozoon WaLcotT's, von dem gute Abbildungen der mikroskopischen Struktur leider noch fehlen.

1 Cambrian Fossils of the Yellowstone national park by Cuarles Doolitsur Walcott, 1899, in Monograph XXXII, U. S. Geol. Survey, 'Taf. LXIII, Fig. 6 und 6 a. 


\section{Bohrende Organismen.}

\section{Bohrgiinge ron Tieren.}

Taf. 1, Fig. 3, Taf. 7, Fig. 5 .

Bei dem reichen Leben, das sich in dem Gottländer Silur entwickelt hat, dürfen wir erwarten, dass auch bohrende Organismen vorhanden waren und ihre Bohrgänge in den fossilen Hartgebilden zurückgelassen haben. In der Tat scheinen sie nicht selten gewesen zu sein, aber es wird nicht immer leicht, eine sichere Diagnose aufzustellen. Ich will deshalb zwei solcher Fälle abbilden, wo einige Sicherheit besteht.

Ein Schliff durch einen Kalkstein von Vattenfallet bei Visby $(20,3-20,4 \mathrm{~m})$ trifft die Oberfläche einer Knolle von Solenopora gotlandica. Man erkennt das Zellgewebe sehr deutlich und in demselben ganz am Rande grössere, längliche Schläuche, die man leicht wie in Fig. 2 für Sporangien nehmen könnte. Bei genauerem Zusehen gewahrt man aber, dass diese Schläuche nicht regelmässig zwischen die Zellfäden eingeschaltet sind, wie dies bei den Sporangien der Fall ist, und dass sie, umgekehrt wie bei diesen, nach unten an Dicke zunehmen. Ihr Durchmesser schwillt bis $0,1 \mathrm{~mm}$ an und sie verschmälern sich nach oben, wo sie mit einer engen Öffnung an der Oberflache des Kalkalgenknollens ausmünden. Es sind sicher Wohnräume von kleinen Bohrtieren gewesen.

Ein Schliff von När, Blatt Roma, zeigt einen Schnitt durch einen SphaerucodiumKnollen, der eine Muschelschale umkrustet hat. Der Bohrgang tritt von der Oberseite in den Schliff ein und setzt durch das Sphaerocodium hindurch bis in die Muschelschale hinein. Es ist klar, dass der bohrende Organismus seine Tätigkeit erst begonnen haben kann, nachdem der Sphaerocodiumknollen schon eine erhebliche Dicke erreicht hatte. Der Gang selbst hat cine Breite von über ${ }^{1 / 3} \mathrm{~mm}$.

\section{Bohrgänge von Pflanzen.}

Taf. 7, Fig. 4 u. 6.

In einem Schliffe vom Lau Kanal (118 a) im K. Lau (Bl. Roma) liegt ein Schalenfragment, das ganz von winzigsten Röhrchen kreuz und quer durchsetzt ist, die genau das Aussehen haben wie die rezenten Mycelfüden oder Algenfïden, die sich in Kalkfelsen oder Kalkschalen einbohren. Ich halte deshalb diese silurischen Röhrchen für pflanzlichen Ursprungs und glaube, dass sie die Existenz bohrender Pflanzen zur Silurzeit beweisen. Dahin ge- 
hören aueh die feinen dunkel erseheinenden Röhrehen in einer Brachiopodenschale von Vattenfallet bei Visby. Zufällig wurde ein Sehliff durch einen feinkörnigen kotreiehen Kalkstein von Levede, Bl. Roma, so angefertigt, dass der von rezenten Flechten besetzte Aussenrand des Gesteinshandstückes ebenfalls iın Schliff liegt. Die rezenten Mycelfäden sind zweierlei Art. Die einen, 10 $u$ breit, laufen ziemlich geradlinig in den Stein hinein, und treten als $1 / 2 \mathrm{~m}$ in breite dunkle Linien auf dem Bilde deutlich hervor. Auf der Photographie wurden sie zu dunkel, weil ihre Lumina von einer zwar durehsiehtigen aber rötliehen Substanz erfüllt sind. Die anderen Fäden sind äusser'st fein, nur etwa $2 \mu$ dick, und bilden auf Fig. 4 die stellenweise auftretenden besonders aber ain Gesteinsrand häufigen regellosen Strich-Netze. Diese Abbildung soll zur Erläuterung der Fig. 6 dienen.

\section{Blatt Vis by :}

\section{Fundorte:}

14) Vattenfallet bei Visby, in einer Brachiopodensehale.

\section{Blatt Roma:}

27) K. Tofta, in einem mergeligen Kalkstein SW von Stafsklint, der zugleich Reste von Siphoneen und Sphaeroeodien einsehliesst und der unteren Gottlandstufe angehört. Kalkstein mit Spirifera exporrecta.

37) 》 $\gg$ in einem Kalkstein $1 \mathrm{~km}$ nordwestlich von Dyple.

72) K. Fröjel in einem mergeligen Kalkstein mit Whitfieldia von Stenstugu. 118 a) K. Lau, in einem Sehalenfragment aus einem Kalkstein von Lau kanal. 


\title{
IV. Einige tierische Fossilien.
}

\section{Eine Foraminifere.}

\author{
Taf. 9, Fig, 6.
}

Es ist eine der merkwiurdigsten Eigentümlichkeiten des gottländischen Obersilurs, dass es bisher nur einige spärliche Überreste ron Foraminiferen geliefert hat. ${ }^{1}$ Die Querschnitte von Rhabdosphrera allerdings könnten auf den ersten Blick an perforierte Orbulinen erinnern, und ich habe diese Frage lange in Erwägung gezogen, bis die sich mehrenden Funde aufs klarste zeigten, dass diese Körper nicht kugelrund, sondern cylinderförmig sind.

Nur in einem Schliff von K. Klinte, $350 \mathrm{~m}$ südlich von Klinte Kirche (64), habe ich eine Form gefunden, die mit grosser Wahrscheinlichkeit zu den perforierten Foraminiferen gestellt werden darf, wennschon der fragmentäre Erhaltungszustand eine sichere generische Bestimmung unmöglich macht. Man erkennt aber doch ganz gut drei Kammern, die reihenförnnig angeordnet sind urd die in dieser Aufeinanderfolge an Grösse zunehmen. Die Aussenwand ist 60-70 $\mu$ dick, die 12 "dicken Poren stehen in Abständen von $25-30 \mu$, die Innenwände sind nur $25 \mu$ dick und ebenfalls perforiert. Die Aussenwände sind an zwei Stellen von aussen her etwas eingedrückt. Die letzte Kammer ist $1 / 2 \mathrm{~mm}$ breit, alle drei zusammen haben eine Länge von $1,2 \mathrm{~mm}$.

Unter den bekannten palaeozoischen Foraminiferenfamilien kann offenbar nur die der Lageniden zum Vergleich herangezogen werden und innerhalb dieser das Genus Nodosaria, wenn man demselben den weiten Umfang im Sinne BRADY's geben will. Andernfalls wäre unser Stück zu Dentalina zu bringen wegen der Krümmung seiner Schale.

\section{Romingeria candelabrum nov. spec. ${ }^{2}$}

Taf. 9, Fig. 3-4.

Von dieser neuen Art besitze ich nur das eine Stück, das in Fig. 4 in natürlicher Grösse abgebildet ist. Es wurde in diesem angewitterten Zustande am Meeresstrand bei

1 Cfr. Chapuan, F. On some Fossils of Wenlock Ago from Mulde, near Kilintehamn, Gotland. Ann. \& Mag. Nat. Hist. Ser. 7, Vol. 7, p. 142. London 1901. Dort angegeben werden Hyperammina ramusissima Chapm., Stacheia amplera (VINE) und St. stomatifera ChapM.

2 Rominger, C. Geol. Surv, of Michigan, Vol. III, Part II. Fossil Corals 1876, Seite 71. Nicholson, ALleyne, On the Structure of the Tabulate Corals, Scite 114 u. 219. 1879. 
Visby (12 a) von dem Herrn Photographen J. A. LAGERGres in Visby gefunden und mir ron Ilerrn Dr. Mustue zur Untersuchung geschenkt. Das seltsane Fossil erinnerte mich zuerst an Galaxaura, aber in Dünnschliff überzeugt man sich leicht, dass es keine Kalkalge, sonder'n ein tabulater Korallenstock ist. Gleichwohl erwies es sich für das Studium der Kalkalgen dadurch von Wichtigkeit, dass im Schutze seines Geästes eine Menge feiner Siphoneen-Bruchstïcke aufbewahrt geblieben sind, die ich als Rhabdoporellen beschrieben habe. Es wäre sehr wünschenswert zu wissen, aus welchem Horizonte des Gottländer Silurs diese Rhabdoporellen stammen, und das ist der Grund, weshalb ich die sie umbüllende Koralle hier beschreibe. Der Stock war ursprünglich viel grösser gewesen und es kann nicht zweifelhaft sein, dass ausser diesem noch viele andere solcher Stöcke auf Gottland zu finden sein müssen. Bei ihrer auffälligen Gestalt wird es nicht schwer sein, nachdem cinmal die Aufmerksamkeit darauf gelenkt ist, das Lager, in dem sie vorkommen, festzustellen. Das kinderfaustgrosse Gesteinsstück könnte allerdings auch als ein glaziales untersiluriches Geschiebe aufgefasst werden, aber dann müsste man annehmen, dass es durch spätere Verwitterung erst die Geröllform verloren habe, was nicht sehr wahrscheinlich ist.

Diagnose. Der ganze Stock besteht aus sich verzweigenden ${ }^{1 / 2}$ mm dicken Kalkiöhren, die durch Querböden abgeteilt sind. Diese Röhren steigen vertikal eine kurze Strecke weit in die Höhe, ohne sich dabei seitlich zu berühren, damn biegen einige von ihnen rechtwinkelig um, vermehren sich durch Teilung und bilden ein 1-2 cm breites, horizontales, schirmfürmiges Dach über den anderen frei endenden vertikalen Röhren. In diesen horizontalen Dïchern liegen die Röhren dicht nebeneinander und vermehren sich durch Teilung. Dann steigen sie von neuem rechtwinkelig in die Höhe und einige derselben breiten sich in einer Entfernung von ungefähr $5 \mathrm{~mm}$ von dem unteren Dache zu einem neuen aus, und dieser Vorgang wiederholt sich fortgesetzt, so dass der ganze Stock ein kandelaberähnliches Aussehen erhält. Es zerfallen demnach die aufsteigenden Röhren in zwei Gruppen, von denen die einen sich immerfort in die höheren Etagen fortsetzen, während die anderen jeweils in einer Zwischenetage frei enden. Querböden finden sich nur in der ersten Gruppe, während die freien vertikalen Enden der anderen ohne Querböden sind und infolgedessen jetzt von feinstem Kalkschlamm erfüllt, der nur in die mit Böden versehenen Röhrenteile nicht eindringen konnte.

Auf der Innenseite der dünnen und scharfbegrenzten Wände ist innerhalb der Röhren stets ein mehr oder minder kräftiges Verstärkungs-Sklerenchym abgesetzt, das nach innen verschieden weit rorspringt und im Dünnschliff bald mehr in dornen-, bald mehr in septenähnlichen Leisten endet, die aber nicht als wirkliche Septen gedeutet werden dürfen. In den frei endenden Röhrenteilen, wo keine Querböden mehr vorkornmen, ist dieses V'erdickungs-Sklerenchym nur ganz schwach entwickelt.

Die Querböden stehen in unregelmässigen Abständen und treten in Dünnschliff nicht inmer so scharf hervor, wie die Längswände. Wandporen konnte ich mit Sicherheit nicht nachweisen. Zwar kommen öfters in den seharf begrenzten eigentlichen Wänden kleine Unterbrechungen vor, die als Poren gedeutet werden könnten, aber sie sind so unregelmässig in ihrer Form und Lage, dass man sie wohl eher als Zufälligkeiten auffassen muss. Auch zeigt das Verdickungs-Sklerenchym an solchen Stellen keine entsprechenden Unterbrechungen und es schliesst somit die fraglichen Poren völlig zu. In den Wänden der 
freiaufragenden Röhrenteilchen fehlen aber selbst diese fraglichen Poren. Wenn man also für das Genus Romingeria die Anwesenheit von Wandporen als charakteristisch ansehen will, wie dies im Sinne Nicholson's liegt, dann darf man diese neue Art eigentlich nicht dazu stellen. lis ist aber beachtenswert, dass auch Nicholson diese Poren nicht hat nachweisen können und er beruft sich nur darauf, dass Rominger dieselben als vorhanden ausdrücklich erwähnt hat. Gleichwohl stelle ich unsere Art zu Romingeria und zwar aus dem Grunde, weil sie im Aufbau und Wachstuın der Röhren eine sehr grosse Ähnlichkeit mit den von Rominger beschriebenen Arten besitzt und hierin von allen anderen Genera der Tabulaten abweicht. Höchstens könnte man noch an Aulopora denken; denn bei dieser Art sind die Wandporen auch noch nicht sichergestellt, wenn schon Rominger und Nicholson sich in dieser Hinsicht mit grosser Reserve ausdrücken und die Möglichkeit des Vorhandenseins von Wandporen nicht verneinen. Aber bei Aulopora sind die Röhren anfangs wenigstens mit der Längsseite auf Fremdkörpern angewachsen, während für Romingeria das freie Wachstum und die seitliche Verzweigung in horizontaler Richtung charakteristisch ist. Ich ziche es deswegen vor, unsere Art diesem Genus einzureihen und nicht etwa ein neues Genus dafür aufzustellen. Besonders grosse Ähnlichkeit besteht init Romingeria umbellifera. Nur sind bei dieser die Röhren nocheinmal so dick und ihre horizontal ausgebreiteten Äste bilden keine geschlossenen Dächer, sondern stehen in einzelnen Wirteln.

\section{Palechiniden-Stacheln.}

Taf. 5, Fig. 4, Taf. 9, Fig. 1-2.

Kleine Sternchen von z. T. nur $80 \mu$ Grösse habe ich in den Schliffen öfters beobachtet. Obwohl die optische Prüfung erwies, dass sie nach Art des Echinodermenskelettes nur aus einem Calcitkristall aufgebaut sind, so bereitete mir ihre sichere Deutung doch Schwierigkeiten, bis ich endlich auch solche fand, die noch ein axiales feineres Gerüst nach Art der Echinoideenstacheln zeigen, und z. T. infolge schrägen Anschnittes auch in einer Richtung verlängert waren. Reine Längsschnitte hingegen habe ich noch keine auffinden können.

Die kleinen Stacheln haben eine Dicke von $88 \mu$ (Taf. 9, Fig. 1) bis $120 \mu$ (Fig. 2) und der schräge Längsschnitt (Fig. 2) hat eine Länge von 300.

Auf Tafel 5, Fig. 4 ist ein Stachel inmitten von Rhabdoporellen sichtbar, der $120 "$ " dick ist und sich von den sternchenartigen Stacheln dadurch unterscheidet, dass er eine hohle Axe hat, um die sich ein Kranz von Kalkmaschen legt (Axialscheide Hesse's), an dessen äusserem Rande 20 kurze Radialsepten angefügt und durch Interseptalleisten zusammengehalten sind. Sie sind in Sinne Hesse's zum Diadematypus zu stellen. Ob der Unterschied dieser Form von den vorher beschriebenen zu gross ist, um die Annahme $z u$ gestatten, dass beide Formen ein und demselben Echinocystisgehäuse angehörten, will ich dahingestellt sein lassen. 


\section{Ein Phyllocarid.}

Taf. 8, Fig. 1-2.

Das nur 1,4 mm lange Tier ist im Schliff der Länge nach geschnitten. Man sieht die Schale und das 10-gliederige Abdomen. Ob die Schale ein- oder zweiklappig war, ist im Längsschnitt nicht zu entscheiden. Da aber in demselben Schliff (Fig. 2) eine in Grösse und Struktur ganz ahnliche Schale im Querschnitt vorliegt, die deutlich aus zwei Hälften besteht, so erscheint es wahrscheinlich, dass auch das im Längsschnitt getroffene Tier ein zweiklappiges Rückenschild hatte. Ein Rostrum ist nicht sichtbar; doch geht daraus nicht hervor, dass es gefehlt hat.

Das Abdomen ist durch die grosse Zahl seiner Glieder ausgezeichnet. Man unterscheidet im Schliff deutlich 10 solcher und als letztes noch eines, das sich stachelförmig nach hinten zu verlängern scheint. $\mathrm{Ob}$ es einem Telson entspricht, bleibt ungewiss. Die 6 ersten Glieder erscheinen höher als die letzten und ein schärferer Absatz trennt diese beiden Serien. Ob dies eine in der Organisation begründete Eigentümlichkeit oder nur ein Erhaltungszustand ist, bleibt ungewiss. Am 5:ten Glied sitzt ein ${ }^{1 / 5} \mathrm{~mm}$ langer Gliederfuss an. Er lüsst 5 Glieder erkennen und endet mit zwei Borsten oder Dornen.

Von Nebalia unterscheidet sich diese Form durch die grössere Anzahl von Abdominalgliedern und die Vielgliederigkeit des Spaltfusses. Mit Ceratiocaris würde unter der Annahme, dass die Schale zweiklappig und ein Rostrum vorhanden war, die Verwandtschaft eine grössere sein. Doch ist bei diesem Genus die Zahl der Abdominalglieder keine so grosse. Dies würde eher für Hymenocaris sprechen, die aber nur eine einklappige Schale besitzt. Bei alldem ist es ganz ungewiss, ob unsere silurische Form von Gottland ein Telson oder nur stachelige Fortsätze hatte. Unter diesen Umständen ist deren generische Bestimmung unmöglich und ihre vorläufige Einreihung in die Familie der Phyllocariden bloss deshalb zulässig, weil zur Zeit in dieser Abteilung bereits recht verschiedenartige Formen untergebracht sind, deren gemeinschaftliche Eigentümlichkeit hauptsächlich darin besteht, dass sie weder zu den Ostrakoden, noch zu den Phyllopoden, noch auch zu den Copepoden gestellt werden können.

Das interessante dieser neuen Form liegt darin, dass sie abdominale Gliederfüsse hatte, die ganz an diejenigen der Copepoden und mancher Trilobiten erinnern. Von den Pleopoden der Nebalien unterscheiden sie sich durch die grössere Zahl ihrer Glieder.

Die beschriebenen zwei Reste fand ich in einem Dünnschliff durch einen Sandstein, der kleine Quarzkörner und Biotitplättchen, sowie grössere zum Teil abgerollte Bruchstücke voll Korallen und Sphaerocodien führte. Er stammt von Nürsholı (115) im Kirchspiel När, Blatt Roma, und gehört sehr wahrscheinlich zur unteren Gottlandstufe.

\section{Crustaceen.Kot nebst Bemerkungen über Bactryllium, die karbonischen Stercome (GÜRICH) und den Artemien-Kot (Stäbchen-0olithe) des Great Salt Lake.}

Tafel 8, Fig. 3-6.

Die als Crustaceen-Kot abgebildeten kleinen Butzen zeigen keinerlei organische Struktur. Sie können auch nicht als Kalksandkörner gedeutet werden, da sie just in 
den echten Sandsteinen vollständig fehlen. Sie liegen entweder nesterweise zwischen grösseren Fossilien eingelagert oder sind ziemlich gleichmässig ausgestreut in dem feinkörnigen und an Crustaceenresten reichen dichten Kalksteinen, als welche inbesondere die sogenannten Leperditiaschiefer hier in Betracht kommen. In letzteren können sie wegen ihrer Häufigkeit geradezu als gesteinsbildend bezeichnet werden. Sie überschreiten die Grösse von $1 \mathrm{~mm}$ gewöhnlich nicht, sind entweder länglich elliptisch oder etwas unregelmässig abgerundet bis eckig. Die wohl abgerundeten Fornen erinnern sowohl durch ihre Grösse wie durch ihre äussere Erscheinung lebhaft an die »Stäbchen-Oolithe», die ich $1892 \mathrm{im}$ Grossen Salzsee der U. S. gefunden habe ${ }^{1}$. Denn auch diese zeigen unter dem Mikroskop keine besondere organische Struktur, sind aus feinstem und etwas trübem Kalkmehl zusammengesetzt und zeigen im Längsschnitt elliptische, im Querschnitt rundliche Umrisse (Fig. 3). Ich hatte damals diese Körperchen zwischen echten Oolithen am Strande jenes Sees gefunden und sie deshalb mit diesen in eine genetische Verbindung gebracht, obwohl jenen die konzentrische wie die radiale Struktur fehlt und sie niemals einen grösseren Fremdkörper umschliessen. Ich habe dann 1906 diesen See nochmals besucht, und für die Untersuchung einen Dredge-Apparat mitgenommen. Unter freundlicher Mithilfe der Herren Prof. Talmage und Cardiff und des Herrn Anderson aus Great Salt Lake City konnte ich feststellen, dass die echten, eiförmigen Oolithe nahe am Ufer viel häufiger sind, als in grösseren Tiefen des Sees, dass hingegen die stäbchenförmigen Körper mit der Tiefe zunchmen und dort einen mächtigen Bodenbelag bilden, der stellenweise fast nur aus diesen winzigen Gebilden besteht, zwischen denen man ausserdem fast nur Überreste von Artemiagliedern findet. Für meine frühere Vermutung, dass auch diese Stäbchen pflanzlichen Ursprungs seien, fand ich hingegen nicht den geringsten Anhaltspunkt. Doch hoffte ich durch mikroskopische Untersuchung zu hause über deren Entstehung Aufschluss zu bekommen. Bei dem Versuche, mich über die Lebensweise der Artemien zu informieren, fand ich bei SIEBOLD, der seinerzeit Tierchen der Artemia salinaria lebend beobachtet hatte, eine kurze Notiz, in der er sein Erstaunen zum Ausdruck bringt über dic Massenhaftigkeit der Exkremente, welche diese Tierchen dadurch erzeugen, dass sie den Schlamm des Bodens auffressen und durch ihren Darm passieren lassen. Dies liess es mir ratsam erscheinen, die Form jener Exkremente kennen zu lernen. Prof. Cori in Rovigno hatte die Freundlichkeit, mir eine Anzahl lebender Artemien und gleichzeitig eine Portion des Schlammes zu schicken aus den Tümpeln, in denen diese Ticrchen lebten. Sic überstanden die Reise sehr gut, und als ich sie mit jenem Schlamm in ein grüsseres Glas mit Salzwasser brachte, tummelten sich dieselben sehr lebhaft darin herum und nach einiger Zeit legten sie auch eifrig Eicr ab. Es waren nur Weibchen. Ich konnte sie so über ein Jahr lang beobachten. Zwar nahmen sie nach einiger Zeit an Zahl ab. Ihre Leichen lagen auf dem Boden, soweit sie nicht von den gefrässigen Tierchen aufgezehrt wurden. Die überlebenden erlahmten allmählich in ihren Bewegungen, und zuletzt starben sie alle. Kleine Ḱolonien grüner Spaltalgen hatten sich während dieser Zeit an den Glaswänden angesetzt und es hatte den Anschein, dass die Artemien dieselben abweideten; denn die Pflänzchen nahmen zeitweilig ab und erreichten eine grössere Aus-

1 Botan. Centralblatt N:0 35, 1892. 
breitung, erst nachdem die Tiere alle tot waren. Nach einer kurzen Ruhepause schlüpfte aber aus den Eiern eine neue Generation kleinster Artemien aus, die sich allmählich entwickelten und grösser wurden, später auch Eier legten und schliesslich ebenfalls abstarben. Dieser Vorgang wiederholte sich, trotzdem durch Eintrocknen des Wassers während meiner zweimonatlichen Abwesenheit von München die Existenz der Tiere schwer bedroht erschien. Jedoch nahm bei jeder neuen Generation die Anzahl der Individuen etwas ab, und schliesslich konnten sie auch ihre volle Entwicklung nicht mehr erreichen, legten keine Eier mehr und init deren Tode hatten meine Beobachtungen ihr Ende erreicht. Während dieser Zeit hatten diese Tierchen den wenigen Schlamm immer wieder und wieder durch ihren Leib hindurchgetrieben und bei dem Austritt Stercome erzeugt, die den Stäbchen des Grossen Salzsees in der äusseren Form vollständig glichen und sich nur durch ihre Farbe und dadurch unterschieden, dass sie eine andere Zusammensetzung hatten. So war es mir klar geworden, dass auch die Stäbchen des Salzsees nichts anderes sein können als die Kotballen der Artemia fertilis VerriL und dass die Massenhaftigkeit dieser Gebilde am Boden des Sees gar nichts befremdendes haben kann. Sie bestehen alle aus Aragonit, was leicht erklärlich ist, wenn man bedenkt, dass die Artemien des Salzsees die Aragonit absondernden Kalkalgen abweiden und dabei auch deren Aragonit durch ihren Darm passieren lassen. Die Breite der Stäbchen entspricht ausserdem der Darmweite der Artemien so genau, dass dies nicht bloss als eine Zufälligkeit angesehen werden kann.

Die obenerwähnten rundlich länglichen, stercomähnlichen Körperchen im Silurkalk dürften deshalb ebenfalls Exkremente von Krebsen sein, deren Überreste (Trilobiten, Ostrakoden, Phyllocariden) ja auch in Menge mit ihnen zusammen vorkommen.

Ähnliche Gebilde hat Gürıch $1906^{1}$ aus dem Kohlenkalk von Visé beschrieben und als Stercome oder Kotballen gedeutet. Aber er führte sie nicht auf Crustaceen sondern auf Spongiostromiclen zurück, die er für Foraminiferen hielt. Dieser Deutung: kann ich natürlich nicht beipflichten, weil die Spongiostromen solche Exkremente wohl nicht erzeugen konnten und insbesondere, weil diese Stercome im Silur Gottlands gewöhnlich gar nicht in Verbindung mit den Spongiostromen auftreten. Die von GürICH abgebildeten Stercome haben Längsdurchmesser von 0,15-0,75 $\mathrm{mm}$ und Querdurchmesser von $0,07-0,25 \mathrm{~mm}$.

Ebenfalls als fossile Stercome müssen wohl die Bactryllien gelten, die O. Heer seinerzeit zu den Diatomeen zu stellen geneigt war. Ihre äussere Form hat mit den hier beschriebenen Stercomen eine unverkennbare Ähnlichkeit, aber sie haben eine nie fehlende, wenn auch oft nur schwach markierte Längsskulptur und ausserdem sind sie sehr gross. Ihre Länge beträgt $3-8 \mathrm{~mm}$, so dass sie leicht mit dem blossen Auge wahrgenommen werden könmen. Wir kennen sie bis jetzt nur aus der Trias, wo sie in bestimmten tonreichen Gesteinen und dann meist in grossen Mengen gefunden werden. Unter die Crustacecn-Stercome kann man sie wohl nicht einreihen schon aus dem Grunde, weil die Überreste solcher Tiere in den Bactryllien-führenden Schichten bis jetzt nicht gefunden worden sind. Nach ihrer Skulptur dürften sie eher als Gastropoden-Stercome anzuspre-

1 L. c. Scite 27, Taf. $7-9$. 
chen sein; doch bedarf dies noch besonderer Nachforschungen. Ich habe sie hier nur erwähnt um zu zeigen, dass so winzige Koprolithen in den Gesteinen viel häufiger erhalten worden sind, als man bisher anzunehmen berechtigt zu sein schien.

Grössenverhältnisse der fossilen Stercome:

\begin{tabular}{|c|c|c|}
\hline & Länge in $\mathrm{mm}$ & Breite in $\mathrm{mm}$ \\
\hline Oolithstäbchen vom Grossen Salzsee...... & bis 0,8 & $0,08-0,15$ \\
\hline $\begin{array}{l}\text { Silurische Stercome von Gerete in Rone (105), Gott- } \\
\text { land }\end{array}$ & $\triangleright 0.6$ & bis 0,3 \\
\hline Allehage (19), K. Vesterhejde, Gottland . . . . & $0,28-1,1$ & $0,15-0,3$ \\
\hline Katthammarsvik (129), Kirchsp. Östergarn, Gottland & 0,22 & $0,065-0,087$ \\
\hline Kohlenkalk Belgiens . . . . . . . . . . & $0,15-0,75$ & $0,07-0,25$ \\
\hline Bactryllien . . . . . & $3-8$ & $0,75-3$ \\
\hline
\end{tabular}

Die einzelnen Fundorte, von denen mir solcher fossiler Crustaceenkot auf Gottland bekannt worden ist, aufzuzählen, ist wohl nicht nötig, da sie ebenso häufig sind wie die Reste von Crustaceenschalen und sowohl in der unteren wie in der oberen Gottlandstufe vorkommen. Oft findet man sie gruppenweise zwischen anderen grösseren Versteinerungen versteckt, aber von besonderer Bedeutung ist es, dass sie in manchen Dünnschliffen geradezu als gesteinsbildendes Element auftreten, so dass man von einem Kotschlamm sprechen kann, der lebhaft an die »Stäbchen»-Anhäufungen im Great Salt Lake erinnert. 


\section{Stratigraphische Schlussfolgerungen.}

Wennschon es unmöglich ist, auf der Basis der fossilen Algen und der wenigen tierischen Organismen, welche in dieser Abhandlung beschrieben sind, eine stratigraphische Gliederung des Gottländer Silurs durchzuführen, oder die vorhandenen Gliederungen auf ihre Richtigkeit zu prüfen, möchte ich doch dasjenige hier kurz zusammenstellen, was mir in stratigraphischer Beziehung aus meiner Untersuchung hervorzugehen scheint.

Fast jeder Forscher, der bisher das Gottländer Silur eingehend studiert hat, ist dabei zu einer besonderen Gliederung gekommen, und wennauch einige davon leidlich untereinander übereinstimmten, so blieben doch auch in diesen Fällen immer noch zahlreiche Meinungsverschiedenheiten übrig. LAPPARENT hat das Gottländer Silur als eine vollständige Serie des Obersilurs angesehen und danach denı Obersilur überhaupt den Namen Gotlandien gegeben, doch steht es keineswegs fest, dass das Obersilur auf Gottland ganz vertreten ist. HeDström und Munthe haben in ihren zwei für den internationalen Geologen-Kongress angefertigten Führern durch Gottland zwar eine vorzügliche Darstellung, der eine von Nord-, der andere von Südgottland gegeben, aber beide bemerkten dazu, dass sie ihre stratigraphischen Untersuchungen noch nicht als abgeschlossen betrachten. Vergleicht man ihre geologischen Übersichtskarten, so gewahrt man sofort, dass da, wo beide zusammenstossen, die Grenzen der von beiden Autoren unterschiedenen stratigraphischen Glieder nicht ineinander übergehen. Der Grund dieser Inkongruenz ist aber nicht auf Unrichtigkeiten der Kartierung, sondern auf die Verschiedenwertigkeit der stratigraphischen Glieder zurückzuführen. Die Schwierigkeit der Altersbestimmung der einzelnen Silurschichten auf Gottland beruht merkwürdigerweise nicht auf der Armut, sondern auf der Überfülle von Versteinerungen, aus denen Leitfossilien für einzelne Stufen herauszufinden, nicht leicht ist. Ausserdem kommt der Fazieswechsel als ein besonders erschwerender Umstand noch hinzu.

Da die fossilen Algen eine unerwartet grosse Verbreitung in den Gottländer Gesteinen haben, so werden sie in Zukunft sicherlich eine ebenso grosse Bedeutung für die Stratigraphie erlangen wie die fossilen Tiere, aber auch bei ihnen ist, und wegen ihrer Bodenständigkeit vielleicht in noch höherem Masse, die Unterscheidung örtlichen Nebeneinanders und zeitlicher Aufeinanderfolge sehr schwierig. In den nachfolgenden Zusammenstellungen habe ich deshalb zunächst nach diesen beiden Richtungen hin die mir bekannten Tatsachen zu gruppieren versucht. Nur häufige und weit verbreitete For'nen 7-131019. S.G.U. Ser.Ca, N:o 10. Rothpletz, Obersilur. Kalkalgen etc. Gottlands. 
können hierbei Dienste leisten, und deshalb beschränke ich mich auf die Sphaerocodien, Rhabdoporellen, Hedströmia, Solenopora und ziehe ausserdem nur noch Spongiustroma in diese Betrachtung ein. Für die geographische Verbreitung halte ich mich an die Fundortsangaben, welche den Gesteinsproben und Dünnschliffen von den schwedischen Geologen beigegeben sind. Doch ist dabei zu beachten, dass diese Fundorte nicht gleichmässig über ganz Gottland verteilt sind und somit das geographische Bild nicht einmal als annähernd genau angesehen werden darf. Das ersieht man am besten daraus, dass allein durch die letzte in diesem Jahre erfolgte Sendung von Dünnschliffen das Bild der geographischen Verbreitung der Rhabdoporellen sich ganz verändert hat. Noch schwieriger ist es mir gefallen, die vertikale Verbreitung innerhalb der aufeinanderliegenden Schichten festzustellen, zunächst deshalb, weil die Etiquetten über diese Aufeinanderfolge sich zumeist ausschweigen. Fast nur in der Umgebung von Visby liegen genauere nach Metern gemessene Höhenangaben vor. In anderen Füllen ist zwar entweder das liegende oder das hangende Glied noch erwähnt, in den meisten aber fehlen diese Angaben ganz, weil eben darüber an Ort und Stelle sich nichts feststellen liess. Angaben wie mit Whitfieldia tumida, Spirifera exporrecta, Pentamerus conchidium sind zwar sehr wertvoll, aber keine entscheidenden Hilfsmittel für die Altersbestimmung, weil ja auch für diese die vertikale Verbreitung nicht einwandfrei feststeht.

\section{Horizontale Verbreitung.}

1) Sphaerocodium gotlandicum ist durch ganz Gottland von der Nord- bis zur Südspitze verbreitet.

2) Sphaerocodium Munthei ist seltener, kommt aber auch in Nord- und Südgottland vor.

3) Solenopora gotlandica ist auf der Insel Fårö, in Nord- und Südgottland nachgewiesen, jedoch im südlichsten Gottland fehlend.

4) Solenopora compacta fehlt ebenfalls im südlichsten Gottland und kommt nur selten mit Solenopora gotlandica zusammen vor.

5) Hedströmia halimedoidea ist sehr verbreitet, aber bis jetzt weder ganz im Süden noch ganz im Norden Gottlands nachgewiesen.

6) Rhabdoporella fehlt im Norden, die Hauptverbreitung liegt in Südgottland, reicht dort jedoch nicht bis zur Südspitze herab.

7) Spongiostroma ist über ganz Gottland von Nord bis Süd verbreitet.

Man sieht daraus, dass die Verbreitung dieser sieben Formen nach dem heutigen Stand unserer Kenntnisse eine sehr grosse, wenn auch nicht ganz gleichmässige ist. In dieser Beziehung genügen sie den Ansprüchen, welche man an stratigraphische Leitfossilien stellt.

\section{Vertikale Verbreitung.}

Ich habe mich bei dem Versuche, die vertikale Verbreitung der beschriebenen Fossilien auf Gottland festzustellen, darauf beschränkt, das dortige Silur in zwei Abteilungen zu bringen, die ich als untere und obere Stufe des Gottländer Silurs bezeichnet habe. Es soll damit weder auf das Gotlandien der modernen Silureinteilung, noch auf das Lower- 
und Upper-Gotlandian Hedströn's (1910) Bezug genommen werden, denn von ersterem kommen bei meiner Untersuehung nur die mittleren und oberen Schichten in Betracht, und Hedström's Einteilung bezieht sieh nur auf Nordgottland und auch da stimmt sie nicht völlig mit meinen zwei Stufen überein. Hensтröm nimnt als Grenze teils das Pterygotuslager an, mit welehem er das Lower-Gotlandian schliesst, während er das UpperCrotlandian mit dem Spongiostromenkonglomerat beginnen lässt, teils benutzt er als Grenze jene schwaehe, aber doch reeht auffällige Diskordanzfäehe, die in einigen Kalkbrüchen im Norden von Visby aufgeschlossen ist.

Als Ausgangspunkt für meine Gliederung des Gottländer Silurs in eine untere und cine obere Stufe nahm ieh die Tatsaehe, dass Sphaerocodium gotlandicum zwar im ganzen Gottländer Silur mit Ausnahme der obersten Ascoceras-Bänke verbreitet ist und, wo es mit Spongiostroma zusammen vorkommt, sogar in ein symbiotisches Verhältnis mit diesem getreten ist, dass aber Spongiostroma in tieferen Lagen, soweit meine Untersuchungen reichen, gänzlieh fehlt. Es muss also eine Grenzfäehe im Gottländer Silur geben, unter welcher Spongiostroma nieht vorkommt und sie muss sich um so bestimmter naehweisen lassen, je mehr sich die mikroskopiseh untersuehten Fundplätze verdichten. Diese Grenzfläche hat ausserdem den Vorzug, sich aueh in Südgottland feststellen zu lasse1ı, so dass mit ihr eine einheitliehe Zweigliederung über die ganze Insel zu erreiehen ist. Damit ist nun freilieh die Aufgabe einer stratigraphischen Zweigliederung noch lange nieht gelöst, denn es muss zuvor bewiesen werden, dass die statistiseh verhältnismässig leieht und sicher festzulegende räumliehe Grenzfläehe zugleieh eine zeitliehe sei. Denn nur in diesem Falle kommt ihr ein stratigraphiseher Wert zu.

In biologischer Beziehung war das Auftreten der Spongiostromen im Silurmeer ohne Zweifel von grosser Bedeutung und wenn ảies Folge einer allgemeinen und raschen Einwanderung war, dann kann dieser Zeitpunkt sehr gut als Beginn für eine neue geologisehe Periode benutzt werden. Wenm hingegen die Einwanderung nicht überall auf einmal, sondern zunächst an einzelnen dem Leben der Spongiostromen besonders günstigen Stellen erfolgte, und die Spongiostromen von dort aus erst später auch andere Mecresteile besiedelten, nachdem sich für sie günstige Verhältnisse auch da herausgebildet hatten, dann würde die von uns festgelegte Grenzfläehe nur noeh einen faziellen Wert haben und Ablagerungen ohne Spongiostromen könnten zeitlich solchen mit Spongiostromen entsprechen. Die endgültige Entscheidung darüber, welche dieser zwei Mögliehkeiten der Wirkliehkeit entsprieht, muss ich den schwedisehen Aufnahmsgeologen überlassen und ich will im nachfolgenden nur zwei Gründe eingehender besprechen, welche mir für die erste Mögliehkeit zu sprechen scheinen. Erstens kommen die Spongiostromen sowohl in Mergeln wie in reinen Kalksteinen vor und sind in dieser Hinsieht an keine bestimmte Gesteinsfazies gebunden. Im Quarzsandstein fehlen sie allerdings ganz, aber soviel wir zur Zeit wissen, gibt es solche Sandsteine nur in tieferen Lagen des Gottländer Silurs. Wo hingegen in diesen tieferen Lagen die Sandsteine fehlen und nur Mergel und Kalkstcine entwickelt sind, da fehlen die Spongiostromen gleiehwohl gänzlich trotz der für sie günstigen Fazies. Zweitens sind mit den Spongiostromen teils gleiehzeitig, teils kurz vorher noeh andere Formen ins Gottländer Silurmeer eingewandert, während gleiehzeitig manehe ältere Formen verschwinden. Man gewinnt aus diesen zweierlei Tatsachen den Eindruek, als ob tatsächlich eine biolo- 
gische Wandlung, wenn auch nicht auf einen Schlag, doch innerhalb eines verhältnismässig kurzen Zeitraumes im Silurmeere eingetreten sei und dass jene Grenzfäche diesen Zeitpunkt ungeführ angibt.

\section{Lage der Spongiostroma-Grenzfläche.}

Bei Visby im Profil von Vattenfallet reicht Spongiostroma bis 29,9 $\mathrm{m}$ herab und liegt auch im dortigen Pterygotuslager. Sie kommt dort zusammen mit Solenopora gotlandica und Hedströmia halimedoidea vor, letztere geht jedoch bis $28 \mathrm{~m}$ herab und Solenopora gotlandica sogar bis $18,7 \mathrm{~m}$, also tief in die Stufe III des Lower-Gotlandian Henström's.

Bei Galgberget sind die Kalkbänke unmittelbar unter der erwähnten Diskordanzfläche erfüllt mit Spongiostroma, Solenopora gotlandica und Hedströmia halimedoidea. Ich lege deshalb die Grenze zwischen der unteren und der oberen Stufe des Gottländer Silurs hier etwas tiefer, nämlich unter die Diskordanzfläche und unter das eigentliche Pterygotuslager. Aus dem Umstande, dass im Profil von Vattenfallet die Solenopona gotlandica zuerst, darauf Hedströmia und zuletzt erst Spongiostroma sich einstellt, schliesse ich, dass die Einwanderung dieser drei für die obere Stufe charakteristischen Formen nicht ganz gleichzeitig erfolgt ist.

In Südgottland ist es nicht so leicht, eine Aufeinanderfolge der Einwanderung festzustellen. Nach Muntue haben wir dort folgende Glieder zu unterscheiden:

8. Ascoceras-Kalkstein.

7. Megalomus- und Trimerella-Kalkstein.

6. Ilionia- und Spongiostroma-Kalkstein.

5. Oberes Sphaerocodiumlager und Oolith.

4. Sandstein und Ton.

3. Unteres Sphaerocodiumlager.

2. Dayiaplatten.

1. Mergelschiefer mit Kalkbündern.

Korallenriffe treten als besondere Fazies in den verschiedensten Stufen auf und erschweren im einzelnen die Horizontierung der Schichten.

Ich habe gefunden, dass Spongiostroma erst in oberen Sphaerocodiumlager Muntme's auftritt, niemals in $1-4$, die Oolithe hingegen sind nicht etwa auf 5 beschränkt, sondern kommen von $3 \mathrm{ab}$ vor und sind wie die Korallenriffe als eine besondere Fazies innerhalb der verschiedenen Stufen anzutreffen. Auch Solenopora gotlandica und Hedströmia halimedoidea habe ich nur in 5-7 gefunden.

Die Grenze zwischen meiner unteren und oberen Stufe des Gottländer Silurs liegt demnach zwischen der unteren und oberen Sphaerocodienbank und zwar über Stufe 4, wobei ich es jedoch dahingestellt sein lassen muss, inwieweit noch manche der hangenden Oolithe von Munite's Stufe 5 in dessen Stufe $3 \mathrm{zu}$ rechnen sind.

Die Stufe 4 Munthe's ist nicht palaeontologisch, sondern nur petrographisch bestimmt und die Vermutung liegt nahe, es könnten die Quar\%glimmersandsteine Südgottlands vielleicht nicht alle gleichalterige Ablagerungen sein. Ihre Verbreitung ist auf zwei Gebiete beschränkt: erstens auf die Südspitze der Insel nordwärts bis Ronehamn und 
zweitens auf die weitere Umgebung Klintes am Westufer des südlichen Gottlands. Während im Norden ihres Verbreitungsgebietes die Spongiostromen sich sofort in Hangenden der Sandsteine einstellen, fehlen sie im Süden bei Hoburgen ganz, obwohl dort noch beinahe 35 in mächtige Kalksteine über dem Sandstein liegen.

Merkwürdigerweise fehlen in diesen oberen z. T. als Korallenriffe entwickelten Kalksteinen die Spongiostromen und, wie wir später sehen werden, auch die sonst sie begleitenden Kalkalgen, und die Fauna, soweit sie Muntue selbst beschreibt, zeigt mehrere Formen, die anderwärts für die tieferen Horizonte als charakteristisch gelten. Gleichwohl identifiziert Munche diese oberen Kalksteine mit seinem Ilioniakalkstein, setzt aber hinzu: ves ist evident, dass ein grosser Unterschied zwischen der Fauna der eigentlichen Ilioniakalksteine und deren Äquivalent im Hoburgendistrikt besteht».

Ich halte dic Möglichkeit für keineswegs ausgeschlossen, dass die Hoburger Kalksteine alle oder doch zum grössten Teil noch in die untere Stufe fallen, dass die SandsteinEinschwemmung hier früher aufhörte als weiter im Norden, und statt dessen sich Oolithe und Sphaerocodienkalke bildeten, auf denen nachher Korallenriffe und Crinoideenrasen wuchsen, während weiter in Norden der Meeresboden noch immer sandig blieb. In diesem Falle entspräche die Stufe 4 Muntue's nur einer besonderen Fazies sciner Stufen 3 und 5. Auf jeden Fall aber liegt bei Hoburgen die gesuchte Spongiostromengrenzfläche über dem Riff.

Während bei Visby die Solenopora gotlandica schon ein wenig früher als Spongiostroma erscheint, lässt sich in Südgottland nur die Gleichzeitigkeit beider Formen feststellen, jedenfalls liegt hier diese Kalkalge über der Spongiostromagrenzfläche. Das gilt auch für Hedströmia. halimedoidea und wir können ganz allgemein sagen, dass überall in ganz Gottland Spongiostroma, Solenopora gotlandica und Hedströmia halimedoidea annähernd gleichzeitig und meist auch zusammen im gleichen Lager auftreten. Sie sind ein neues Floren- und Faunenelement, das den tieferen Schichten noch fehlt.

Anders liegt dies mit den Rhabdoporellen, die ich in keinem Schliffe mit den Spongiostromen zusammen angetroffen habe. Dahingegen sind sie meist mit kleinen Fragmenten von Sphaerocodien oder auch mit Knollen dieser Pflanze vergesellschaftet, so dass man vermuten darf, dass die Spongiostromengrenzfläche allerorten über den Rhabdoporellen-führenden Gesteinen liegt. Im Profil von Vattenfallet bei Visby liegt ihr höchster Horizont bei 22,75 $\mathrm{m}$. Unsicher bin ich in Bezug auf die stratigraphische Stellung des Kalksteines von Sjonhem (52), der nach MunTuE's Karte schon in der oberen Stufe liegen müsste, ebenso wie der Kalkstein von Puser bei Fröjel (82). Der Schliff selbst gibt keine stratigraphischen Anhaltspunkte.

Wir können somit die stratigraphischen Ergebnisse durch nachfolgende Tabelle übersichtlich zur Darstellung bringen.

\section{Untere}

Sphaerocodium

Solenopora compacta

Rhapdoporella
Obere Stufe des Gottländer Silurs

Sphaerocodium

Solenopora compacta

Spongiostroma 


\section{- Solenopora gotlandica ${ }^{1}$ \\ - Hedströmia halimedoidea.}

Dieser Tabelle lässt sich dann noch eine zweite beifügen, die nach dem gegenwärtigen Stand der Forschung die Verbreitung aller der von mir in dieser Arbeit beschriebenen Formen innerhalb der zwei Stufen angibt, ohne dass damit den in der vorausgehenden Tabelle fehlenden Arten eine für die stratigraphische Einteilung beweisgebende Kraft zugeschrieben werden soll.

Untere Stufe

Sphaerocodium gotlandicum

》 Munthei

Rhabdoporella pachyderma

$\gg \quad$ Stolleyi

Solenopora compacta

Hedströmia bifilosa

Oolithe
Obere Stufe

Sphaerocodium gotlandicum Munthei

Spongiostroma Holmi

$\gg \quad$ balticum

Solenopora compacta

gotlandica

filiformis

Hedströmia halimedoidea

Oolithe

Man gewinnt so den Eindruck, dass mit dem Auftreten der Spongiostromen im Silurmeere Gottlands keine durchgreifende Änderung im Bestande der Kalkalgen verknüpft war, sondern dass die Sphaerocodienarten und die Oolithe ungehindert, z. T. sogar durch eine Art von Symbiose von den Spongiostromen unterstützt, sich weiter entwickelten. Die Rhabdoporella pachyderma und $R$. Stolleyi und Hedströmia bifilosa verschwinden hingegen ungefähr in dem Momente, da die Spongiostromen zusammen mit einer neuen Algenflora einwanderten. $\mathrm{Zu}$ der schon vorhandenen Solenopora compacta kamen nun noch zwei weitere Arten, von denen Sol. gotlandica zuerst auftrat und sich alsbald eine herrschende Stellung eroberte, aber auch die Hedströmia halimedoidea entwickelte sich reichlich auf Kosten ihrer älteren Schwester.

1 Bei Visby schon in den obersten Lagen der unteren Stufe. 


\section{Tafelerklärung.}

\section{Tafel 1.}

Fig. 1 Solenopora gotlandica RotHP. von Allehage (19), westsüdwestlich von Slottet, K. Vesterhejde, Bl. Visby. Tangentialschnitt mit Sporangien. $\times 13$.

Fig. 2 Dasselbe von ebenda. Vertikalschnitt mit Sporangien. $\times 13$.

Fig. 3 Dasselbe von Vattenfallet bei Visby (14) aus 20,3 $\mathrm{m}$ Höhe, mit Bohrgängen am oberen Rand des Stockes. $\times 13$.

Fig. 4 Dasselbe von Korpklint (21), K. Vesterhejde, aus Riffkalk. Auf einem Bryozoenstock (b) liegt das Hypothall, das sich auf der unteren Hälfte des Schliffes ausbreitet und in der oberen Hälfte in Perithall übergeht. $\times 12$.

Fig. 5 Solenopora compacta BILL. von Allehage (19), westsüdwestlich von Slottet, K. Vesterhejde, Vertikalschuitt. $\times 13$.

Fig. 6 Dasselbe von ebenda. Tangentialschnitt. $\times 43$.

\section{Tafel 2.}

Fig. 1 Solenopora spongioides DrB. von Peikull bei Sak im Estland. Links unten Hypothall, das nach rechts oben in Perithall übergeht. $\times 12$.

Fig. 2 Dasselbe von ebenda. Hypothall. $\times 47$.

Fig. $3 \gg \gg \otimes$ Perithall. $\times 47$.

Fig. 4 Solenopora filiformis NıcH. vom K. Hejde, 700 in südlich von d. Kirche (68), Bl. Roma, aus einem Kalkstein mit Pentamerus conchidium, Hedströmia halimedoidea, Spongiostroma Holmi und Sphaerocodium gotlandicum. $\times 13$.

Fig. 5 Hedströmia bifilosa nov. gen. et spec. von einem Acker, nordwestlich von Dibjers backe im K. Hörsne (26), Bl. Visby, aus der unt. Stufe. Vertikalschnitt. $\times 13$.

Fig. 6 Dasselbe von ebenda. Tangentialschliff. $\times 13$.

\section{'Tafel 3.}

Fig. 1 Hedströmia halimedoidea nov. gen. et spec. von Järnvägsklinten bei Visby (15), oberstes Plateau, gerade vor Manhemsrauken, Kalksteinplatte bedeckt mit Hedströmia-Ästen. $\times 1,4$. Photographiert bei auffallendem Licht.

Fig. 2--5 Einzelne Äste und Zweige voll ebenda. $\times 12$.

2-3 Vertikal-, 4 Horizontalschnitt, 5 schräger Schnitt.

Fig. 6 Dasselbe von Vattenfallet bei Visby (14). Tangentialschnitt. $\times 12$. 


\section{'T'af'el 4.}

Fig. 1 Sphaerocodium gotlandicum vom Meeresstrand nördlich von Kapellsuddens fiskeläge in K. När (113), Blatt Roma. Untere Stufe. $\times 60$. Zeigt das feinste Zellgeflecht dieser Art.

Fig. 2 Dasselbe, südlich von Bondarfve im K. Burs (108), Blatt Roma, aus dem Rifflkalk über der Dayiabank. Untere Stufe. $\times 45$. Zeigt einige der grossen Schlauchzellen am oberen Rande des normalen Endzellengewebes. $(0-0$.

Fig. 3 Sphaerocodium Munthei nor. spec. von Lau backar im K. Lau (118), Bl. Roma. Ein Vertikalschliff durch das Grundgeflecht. $\times 45$.

Fig. 4 Dasselbe von Hörsne kanal (25), Bl. Visby. Ein Tangentialschliff mit melreren Endzellen. $\times 45$.

Fïg. 5 Dasselbe ron Galgberget bei Visby (12), am Gehänge südlich vom Galgen, $11,5 \mathrm{~m}$ unter dem Plateaurand. Vertikalschliff mit Grundgewebe und Endzellen. $\times 45$.

Fig. 6 Dasselbe von Hörsne kanal (25). Tangentialschliff mit den fächerförmig geteilten Endzellen. $\times 45$.

\section{Tafel 5.}

Fig. 1 Rhabdoporella Stolleyi nov. spec. aus einem Bruchstück von Romingeriakalk, gefunden am Strand von Visby (12 a). $\times 45$. Zeigt einen Quer- und cinen Längsschnitt.

Fig. 2 Dasselbe von ebenda, ein Querschnitt. $\times 140$.

Fig. 3 Siphoneenkalk mit Rhabdoporella Stolleyi und R. pachyderma nov. spec. vom Kanal nordwestlich von Anningåra im Kí. Hafdhem (101 a), Blatt Roma. × 14 .

Fig. 4 Dasselbe, 500 Meter nordwestlich von Bosarfve im K. Sproge (91), Bl. Roma. In der unteren Hälfte ist der Querschnitt eines Palechiniden-Stachels sichtbar. $\times 50$.

Fig. 5 Dasselbe von Skinnarfve im K. Levede (93), B3l. Roma. $\times 50$.

Fig. 6 Dasselbe, 1,6 km. südwestlich der Kirche von Levede $(92) . \quad \times 50$.

\section{Tafel 6.}

Fig. 1 Oolithe aus dem Sphaerocodiumbeutel vom K. Grötlingbo, Bl. Hamra, südwestlich der Lotsstation (135). $\times 12$.

Fig. 2 Oolithüberzug über einer Schale, südöstlich von Gerete im K. Rone (106), Bl. Roma. $\times 14$.

Fig. 3 u. 4 Oolithe aus Oolithischem oberhalb d. Dayiaschicht, S0 von Alfva Kirche (100 a), Bl. Roma. $\times 12$.

Fig. 5 Sphacrocodiumbeutel mit eingeschlossenen Oolithen, Fundort wie bei Fig. $1 . \quad \times 1,7$.

Fig. 6 Dasselbe. $\times 12$. Teil der Sphaerocodienlülle mit angrenzenden Oolithen.

Fig. 7 Oolith aus oolithischem Kalkstein von Domerarfve im K. Öja $(140$ a), Bl. Hamra. $\times 43$.

\section{Tafel \%.}

Fig. 1 Vermiporella sp. vou Korpklint, uördlich von Visby. $\times 50$.

Fig. 2 Vermiporella (?), K. Klinte, S von Klintehamn (60), Bl. Roma. $\times 50$.

Fig. 3 Sphaerocodium gotlandicum in Symbiose mit Spongiostroma Holmi von Vikarfve im K. Viklau (55), Bl. Roma, aus Ostrakodenkalkstein. $\times 13$. Drei Zonen von Sphaerocodien liegen zwischen SpongiostromenCoenost ohne scharfe Abgrenzung. (1-3.)

Fig. 4 Silurischer Kalkstein mit rezentem Mycelgeflecht, das sich von der Oberfläche in das Gestein eingebohrt hat. Man erkennt leicht die grösseren, ziemlich geradlinigen Bohrgänge. Dazwischen liegen zu zarten Büschelı gruppiert ganz feine Röhrchen, die auf dem Bilde wie kurze schwarze Striche erscheinen. $\times 50$.

Fig. 5 Bohrgang eines Tieres in einem Sphaerocodium-Knollen von K. När, Bl. Roma. $\times 14$.

Fig. 6 Algenbohrgänge in einem Schalenfragment aus einem Kalkstein vom Lau kanal, K. Lau (118a), Bl. Roma. $\times 140$. 
Tafel. 8.

Fig. 1 Phyllocariden-Längssclnitt mit Schale, Abdomen und einem Gliederfuss am vierten Abdominalsegment, von Närsholm im K. När (115), Bl. Roma. $\times 60$.

Fig. 2 Schalenquerschnitt aus demselben Dünnschliff. $\times 60$.

Fig. 3 Artemienkot aus dem Bodenabsatz des Great Salt Lake (Utah, U. S.). $\times 13$.

Fig. 4 Crustaceenkot aus dem Leperditiaschiefer von Allehage, südsüdöstlich vom Schloss, K. Vesterhejde, Bl. Visby (19). $\times 13$.

Fig. 5 Crustaceenkot aus Oolithkalk südöstlich von Gerete im K. Rone, Bl. Roma (106). (Aus demselben Schliff wie Fig. 2, Taf. 6.) $\times 13$. Neben den in einer Reihe angeordneten 20 Kotballen liegt eine grössere Schale mit dünmem Oolithüberzug. Andere liegen weiter oben.

Fig. 6 Crustaceenkot vom K. Ganthem, Bl. Roma (50). $\times 46$.

\section{Tafel 9.}

Fig. 1 Zwei Palechiniden-Stacheln im Kalkstein von einem Brumen östlich von Hemmor im K. När, Bl. Roma. $\times 140$.

Fig. 2 Dasselbe, rom Kanal südöstliclı Snäckarfve im K. Stenkumla, Bl. Roma (40), aus mergeligem Kalkstein mit Leperditia baltica (pectinata). $\times 130$.

Fig. 3 Romingeria candelabrum nov. spec. vom Strand bei Visby $(12$ a). $\times 2$. Schliff.

Fig. 4 Dasselbe in natürlicher Grösse.

Fig. 5 Echinodermenrest mit der charakteristischen porösen Struktur, nicht zu verwechseln mit RhabdoporellenRölren. Von Vattenfallet bei Visby $(18,7 \mathrm{~m}$ Höhe). $\times 42$.

Fig. 6 Nodosaria (Dentalina), Gehäuse, $350 \mathrm{~m}$ südlich von Klinte Kirche, Bl: Roma $(64) . \times 50$.

\section{Tafel 10.}

Karte von Gottland. Massstab 1:300 000. Die roten Punkte bezeichnen die in dieser Arbeit erwähnten Fundorte. 
UNIVERSITY OF ILLINOIS LIBRAARY

MAY 71921

$\operatorname{coc} 2 \cos$ 

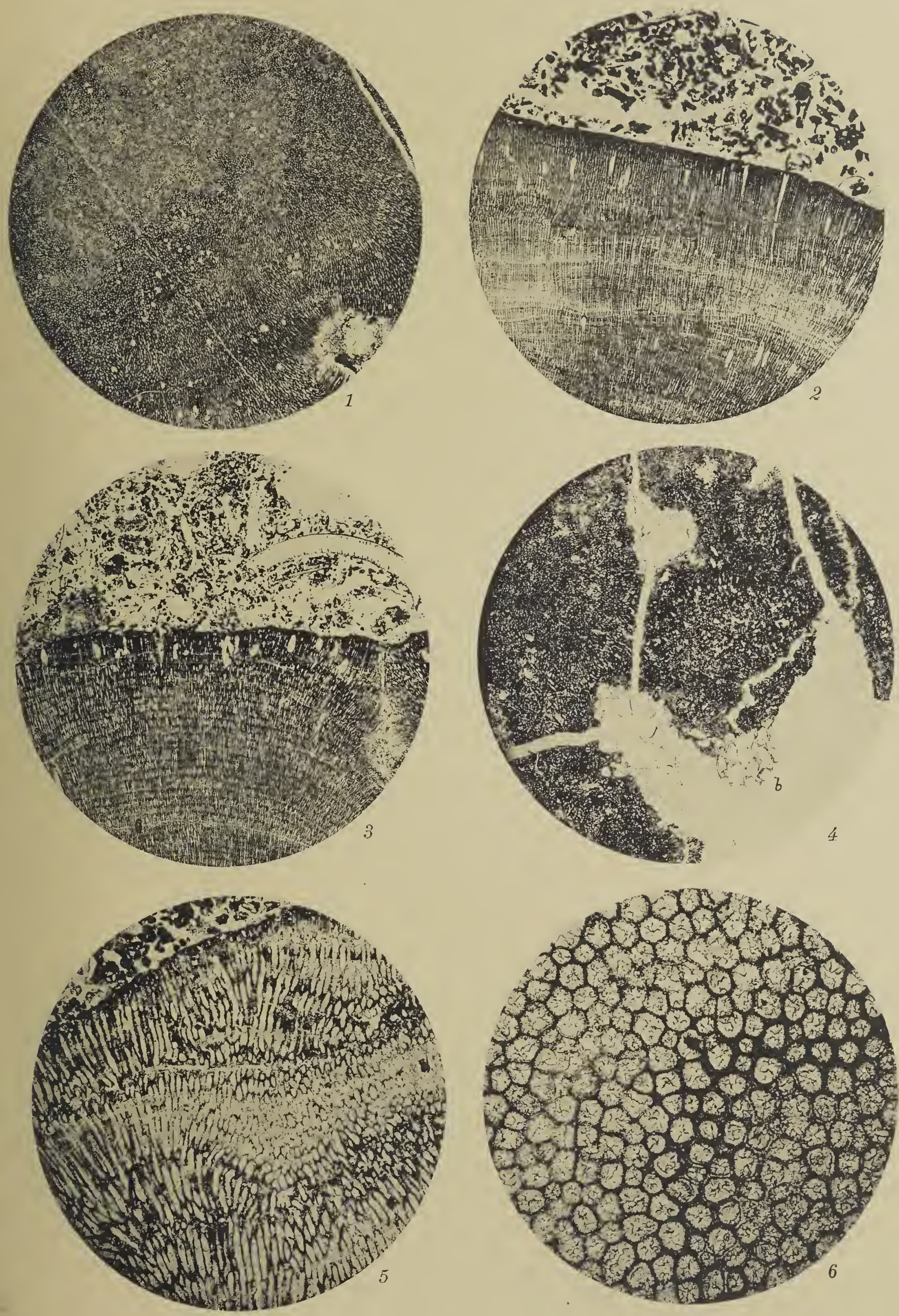


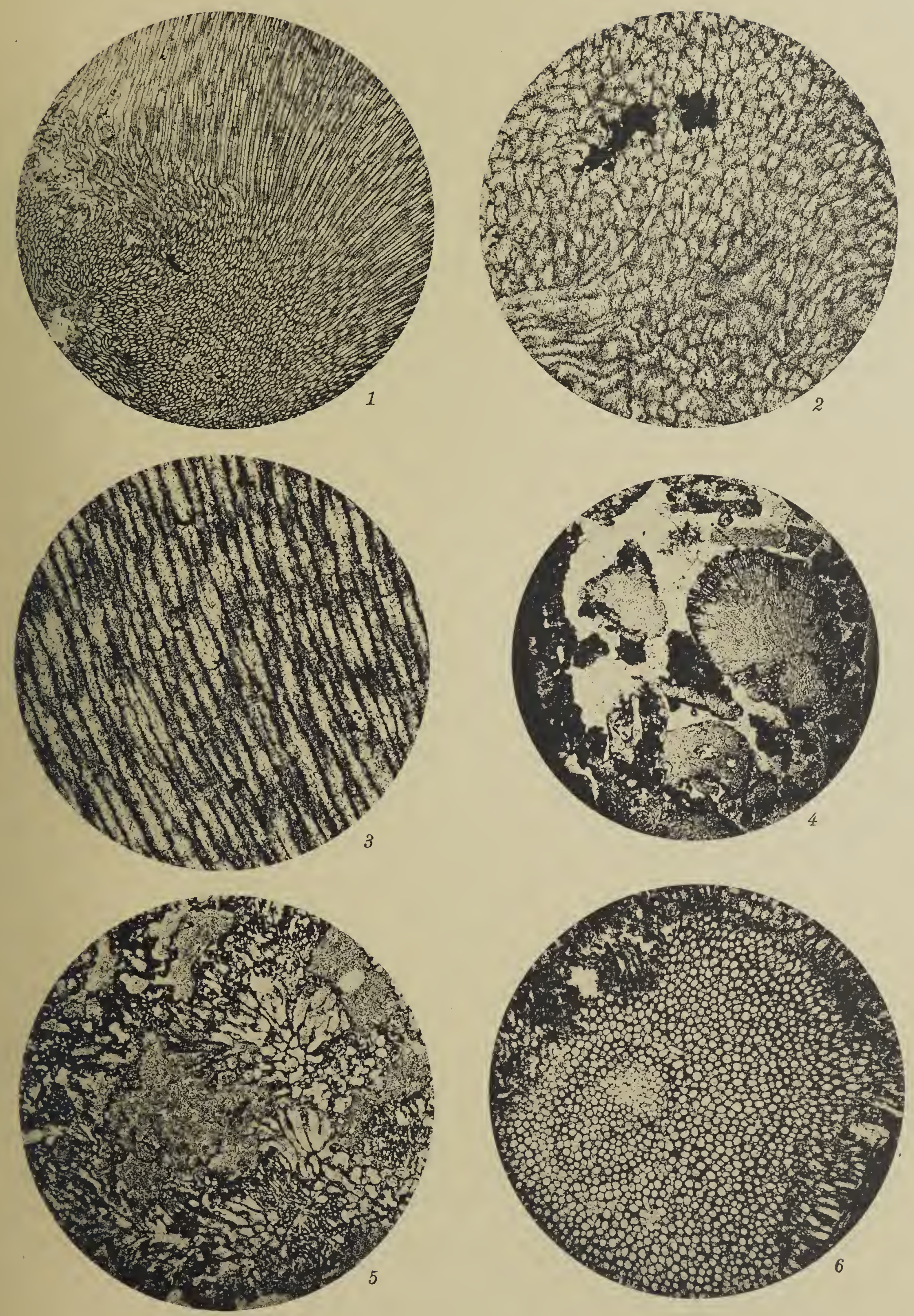


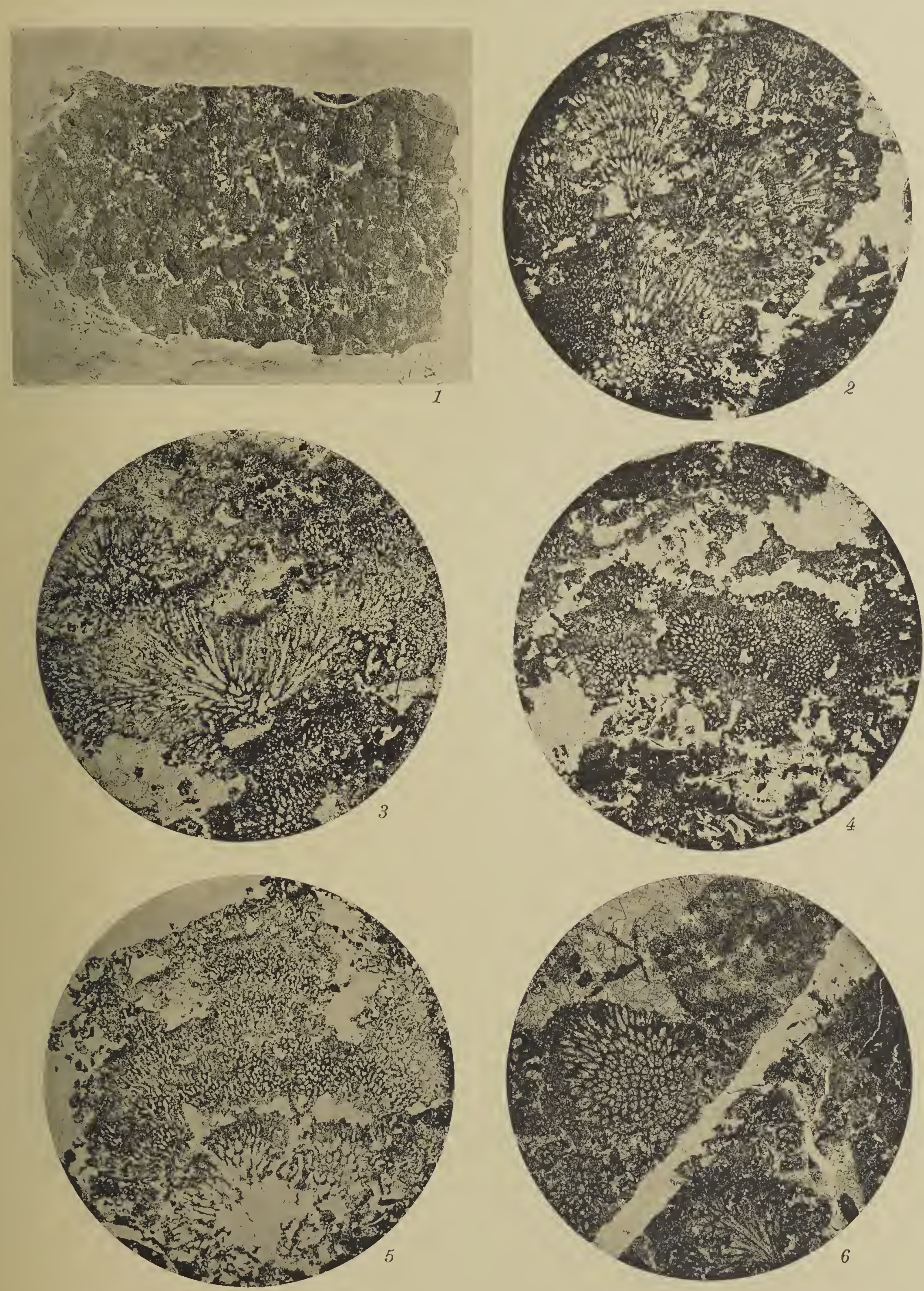



(3) 

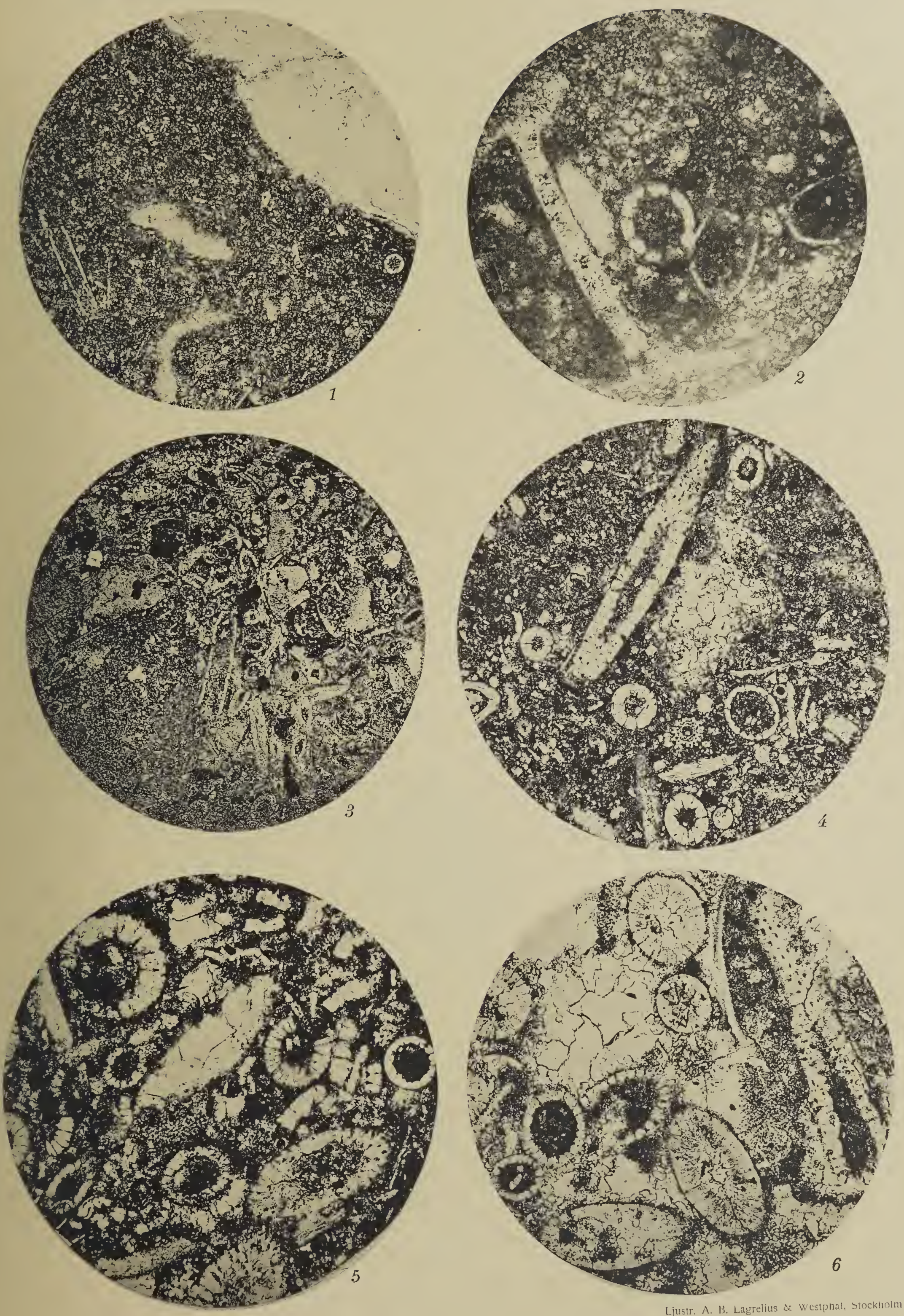


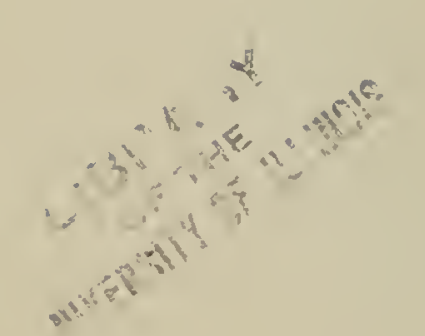



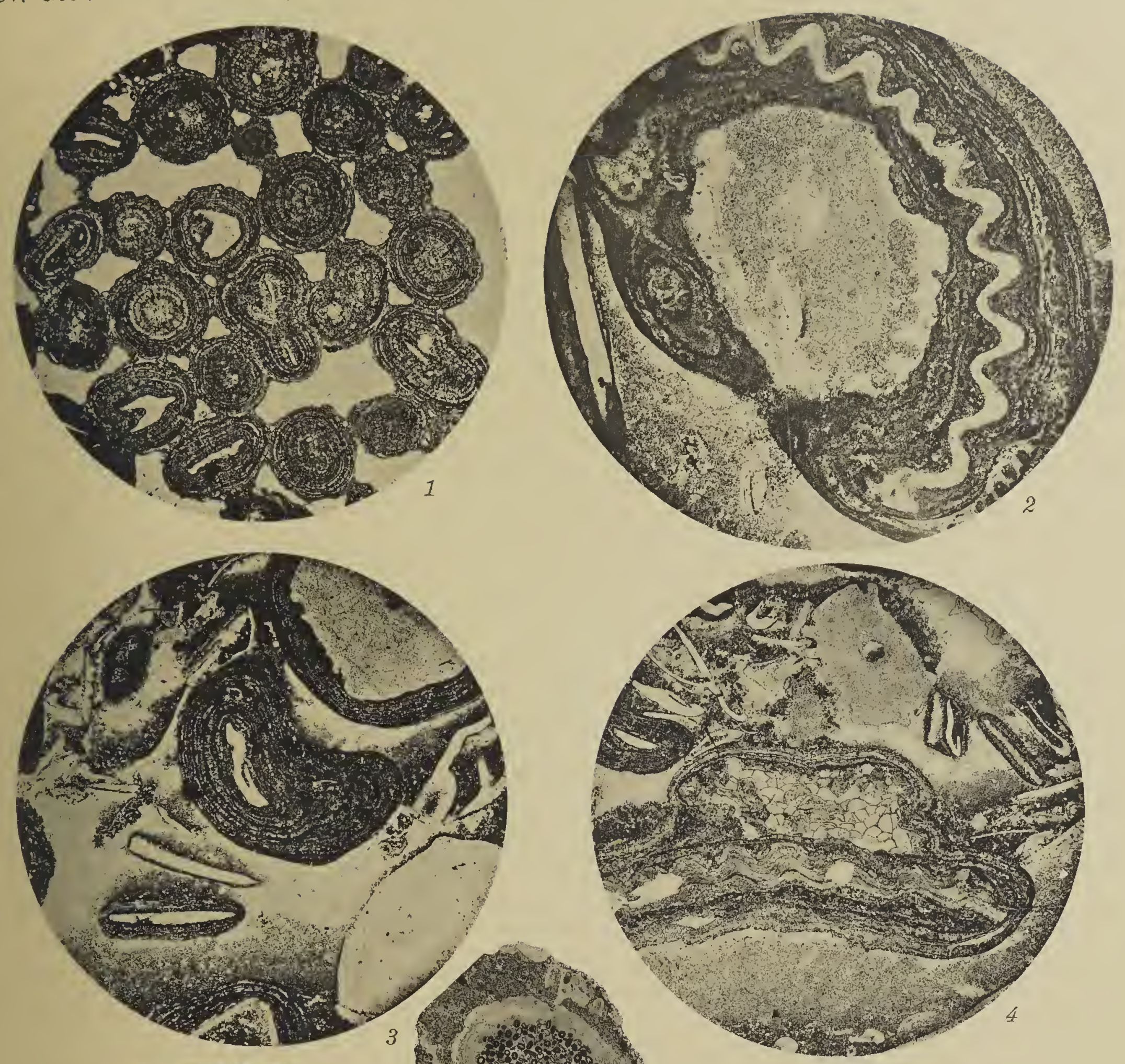

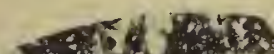

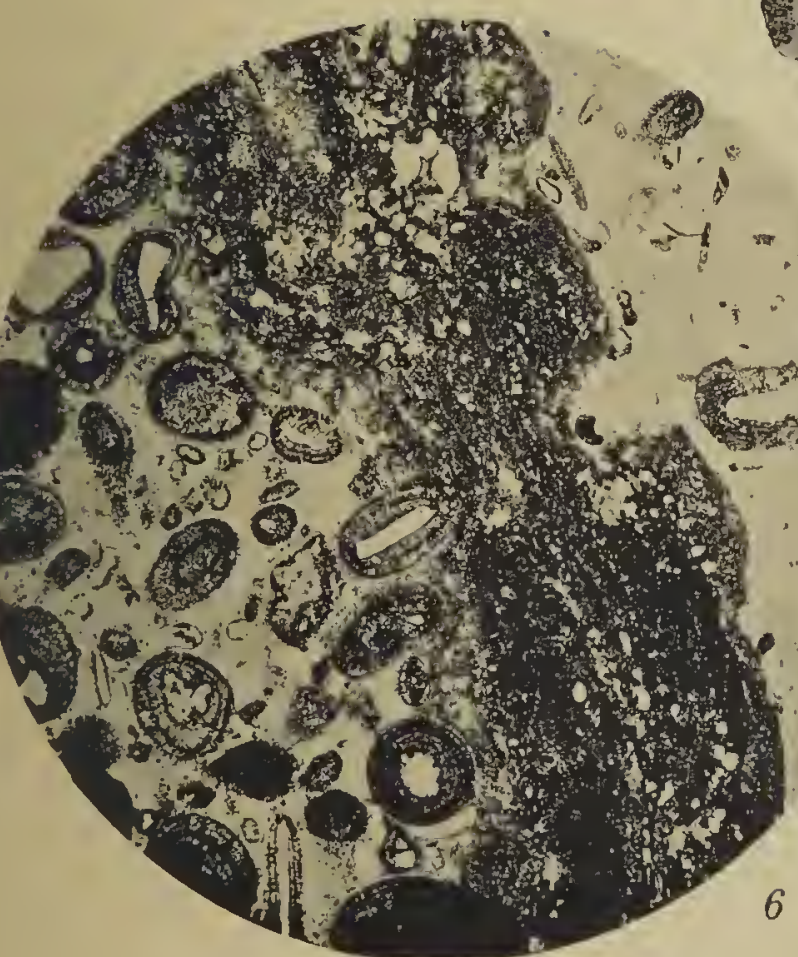

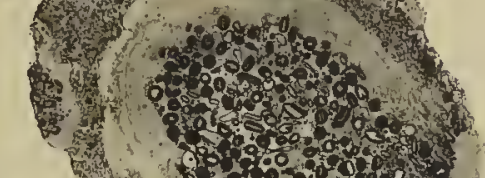

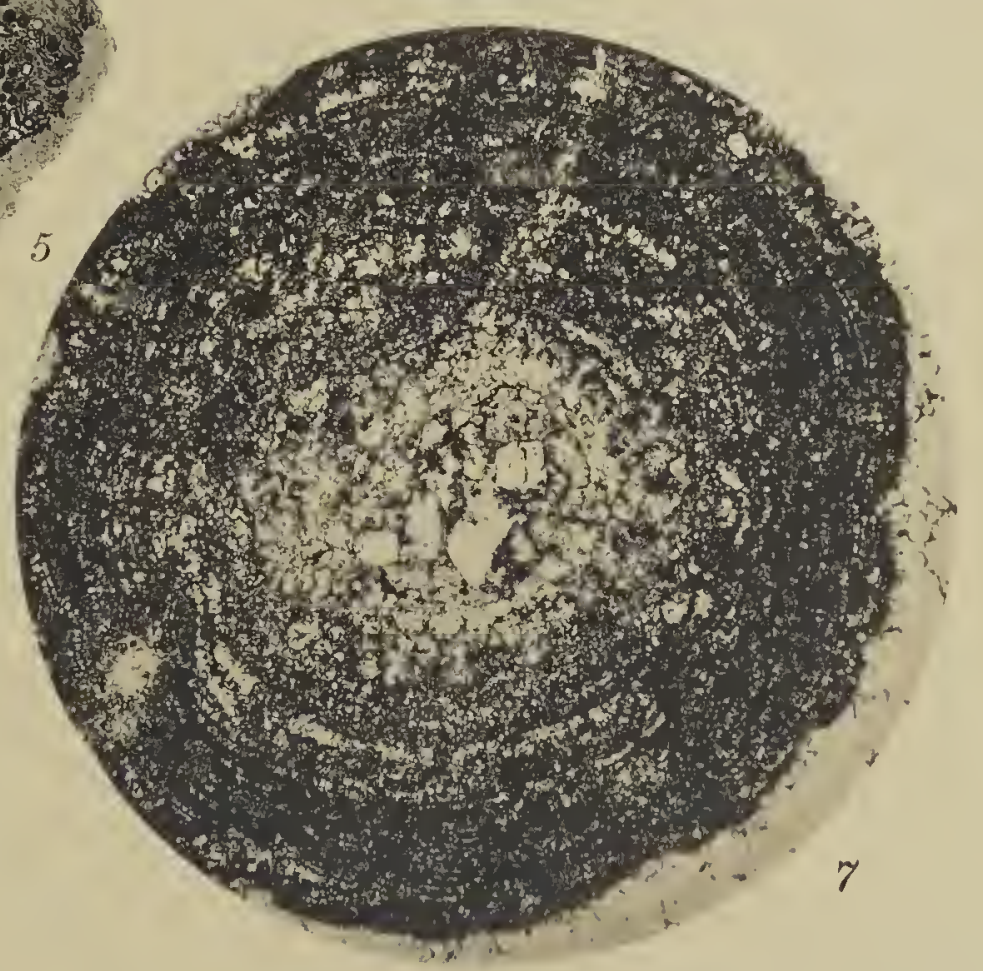


s. 

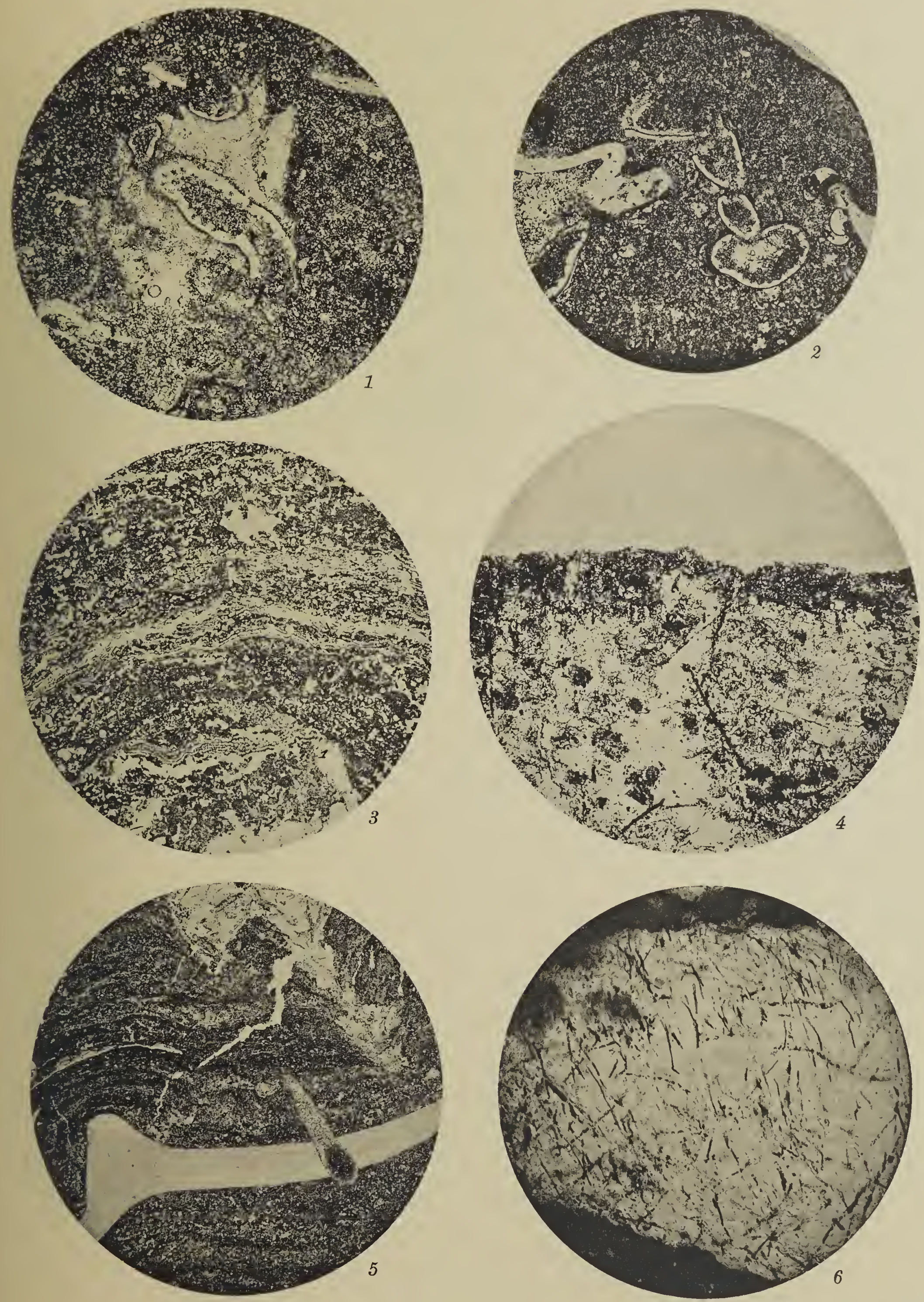
sin 

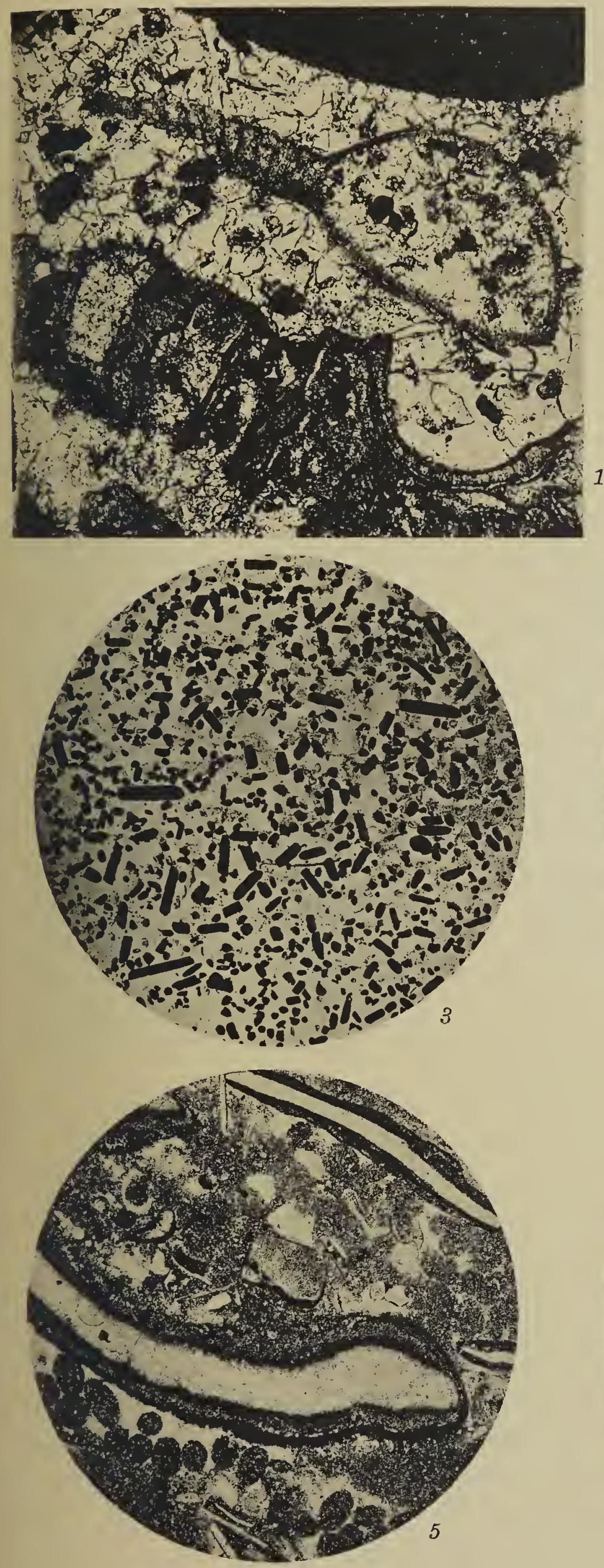
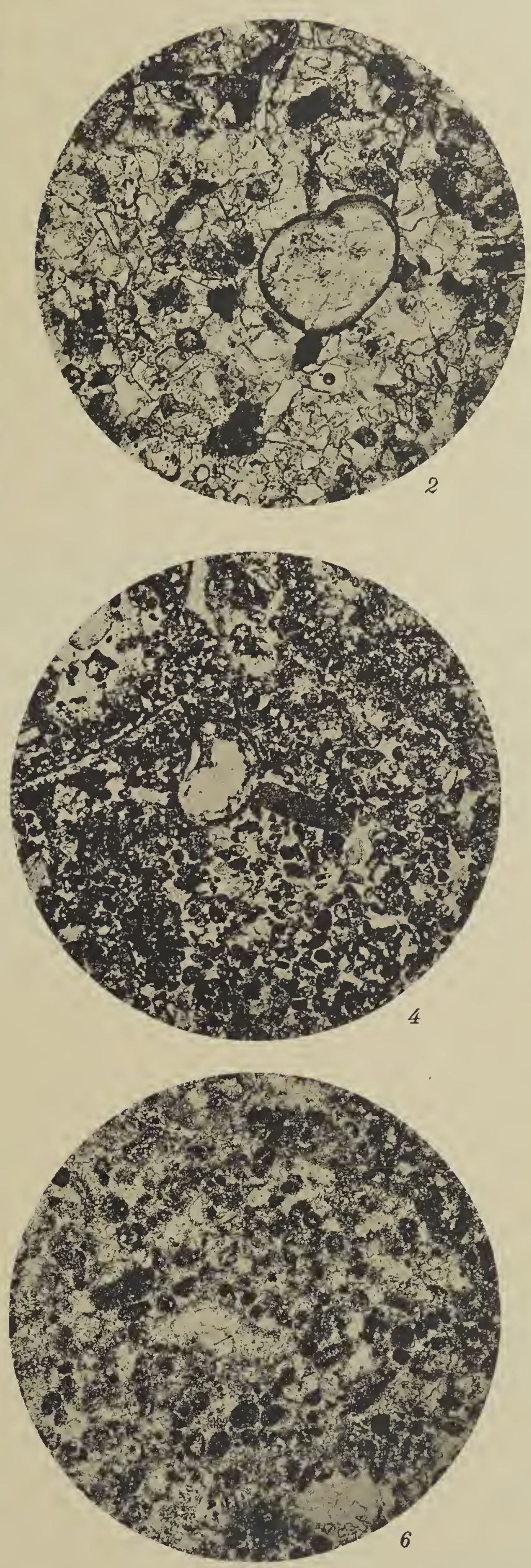

grelius \& Westphal Stock 




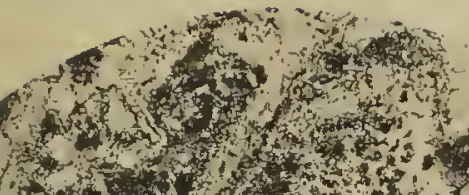

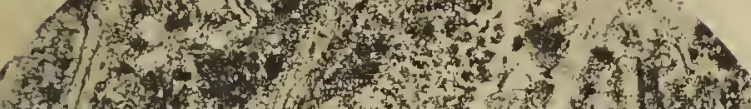

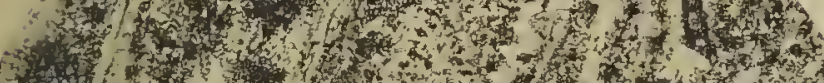

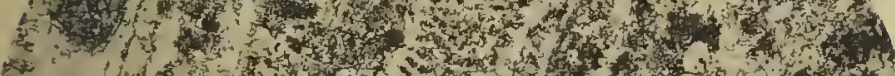

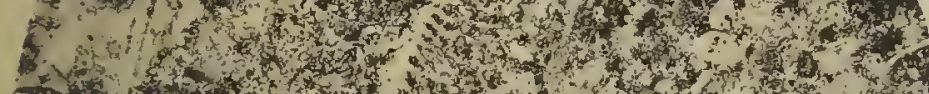

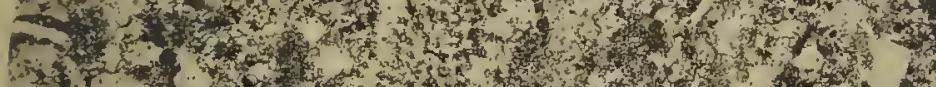

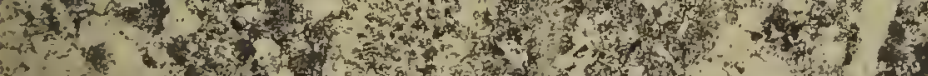

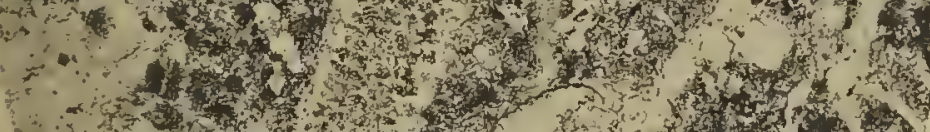
mon

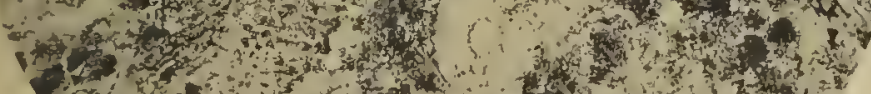
H. 30 . motom and

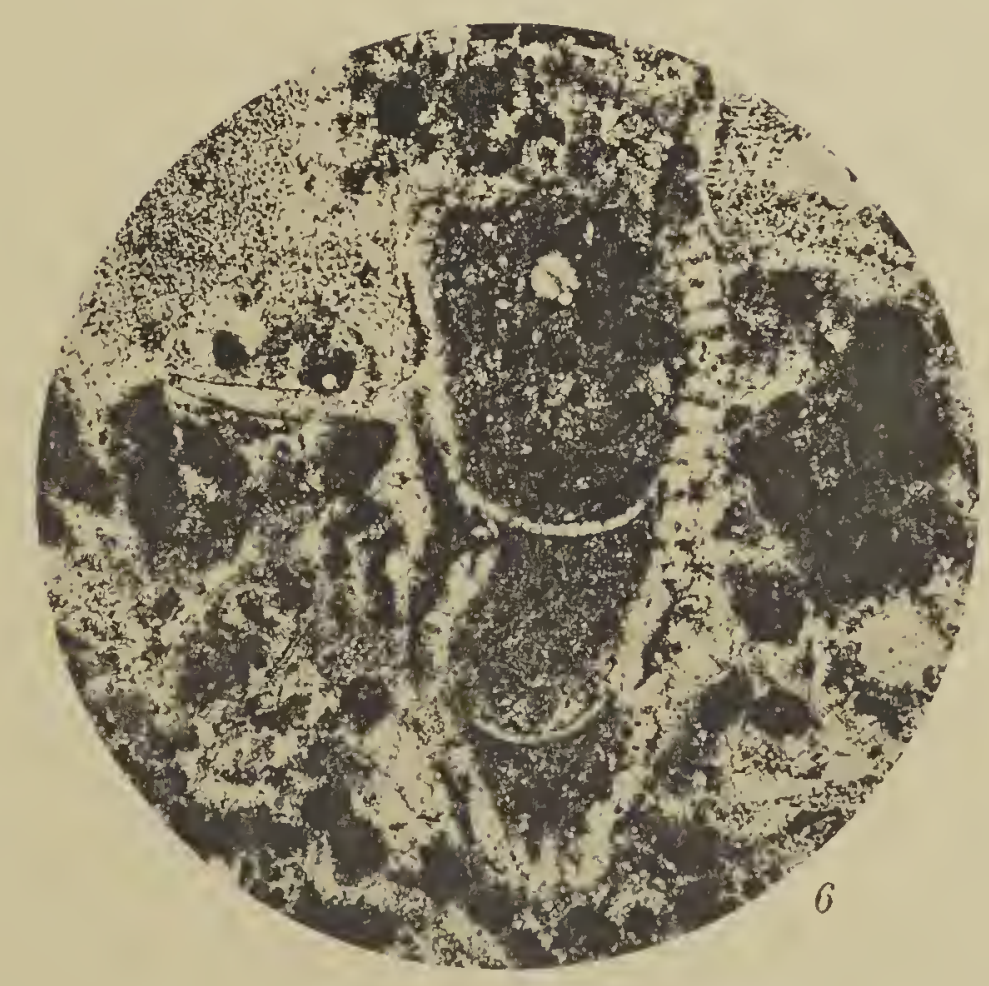





\section{L $155^{\circ} A$}

OF THE

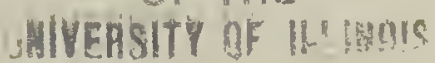

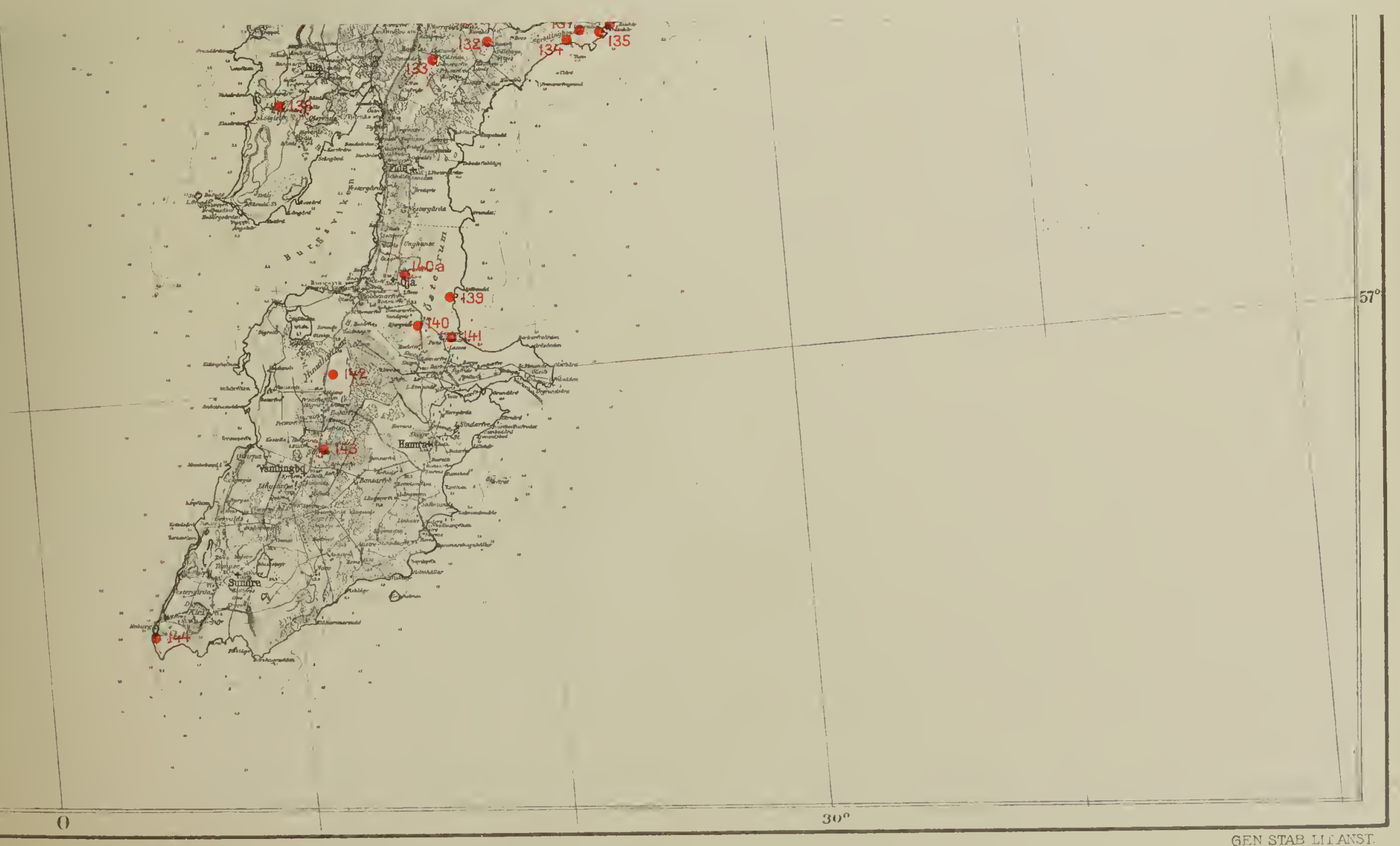




\section{GOTTLAND}

Massstab 1:300000

- 45 Findorte für Kralkalgen etc.

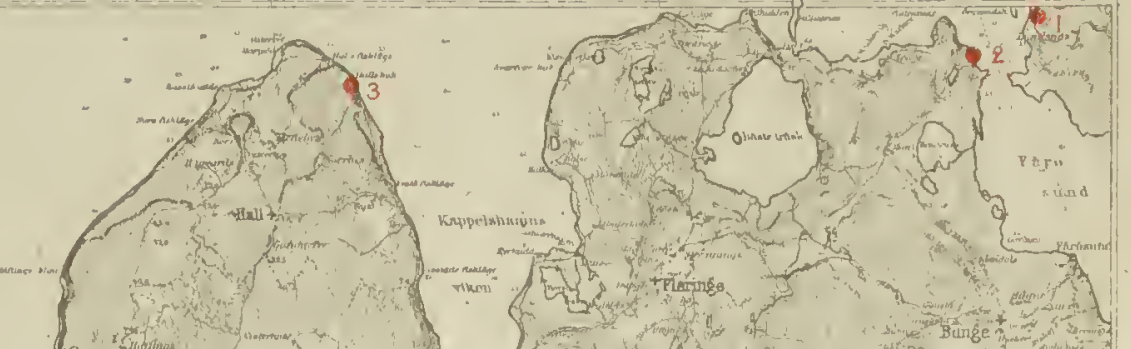
$3 \mathrm{~S}^{2} \mathrm{z}$

Af

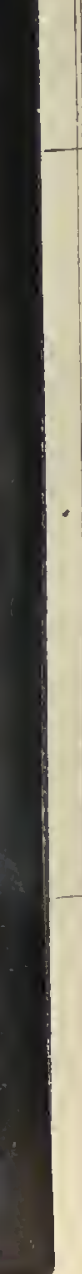







\section{,}





\section{UNIVERSITY OF ILLINOIS-URBANA}

0.554.85SW3SSER.CA COO1

GGU SERIES CA. RESEARCH PAPERS UPPSALA

9-14 1913-16

|||||||||||||||||||||||||||||||||||||||||||||||||||||

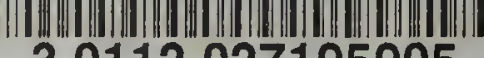

30112027195905 